\title{
WestVirginiaUniversity
}

THE RESEARCH REPOSITORY @ WVU

Graduate Theses, Dissertations, and Problem Reports

2015

\section{Three Essays in Health Economics}

Patrick Manzi

Follow this and additional works at: https://researchrepository.wvu.edu/etd

\section{Recommended Citation}

Manzi, Patrick, "Three Essays in Health Economics" (2015). Graduate Theses, Dissertations, and Problem Reports. 6160.

https://researchrepository.wvu.edu/etd/6160

This Dissertation is protected by copyright and/or related rights. It has been brought to you by the The Research Repository @ WVU with permission from the rights-holder(s). You are free to use this Dissertation in any way that is permitted by the copyright and related rights legislation that applies to your use. For other uses you must obtain permission from the rights-holder(s) directly, unless additional rights are indicated by a Creative Commons license in the record and/ or on the work itself. This Dissertation has been accepted for inclusion in WVU Graduate Theses, Dissertations, and Problem Reports collection by an authorized administrator of The Research Repository @ WVU.

For more information, please contact researchrepository@mail.wvu.edu. 


\title{
"Three Essays in Health Economics"
}

\author{
Patrick Manzi \\ Dissertation submitted to the College of Business and Economics at West Virginia University \\ In partial fulfillment of the requirements for the degree of \\ Doctor of Philosophy in Economics
}

\author{
John Deskins, Ph.D., Chair \\ Tami Gurley-Calvez, Ph.D. \\ Brian Cushing, Ph.D. \\ Amanda Ross, Ph.D. \\ Joshua Hall, Ph.D.
}

Department of Economics

Morgantown, West Virginia

2015

Keywords: Economics, Health, Policy, Nutrition Assistance, Smoking, Cigarettes, Insurance, WIC, Regression Discontinuity, Preventive Care

Copyright 2015: Patrick Manzi 


\title{
ABSTRACT
}

\section{"Three Essays in Health Economics"}

\author{
Patrick Manzi
}

I examine three issues in health economics. I first consider the effect of smoking bans on weight gain and find that while smoking bans do not lead to weight gain among the whole population, they may lead to slight increases in weight gain among current smokers. In the second essay I examine differences in maternal and infant health outcomes among mothers enrolled in the WIC program using a regression discontinuity approach. Results indicate that WIC participation decreases the likelihood of premature births, reduces the likelihood of breastfeeding and leads to decreases in maternal weight gain during pregnancy. Finally I examine how insurance coverage contributes to an individual's decision to utilize several preventive care services. I find that in all cases individuals with insurance coverage are more likely to utilize all preventive care services examined and also that visiting a doctor's office in the previous year is a significant driver in the uptake of preventive care services. 


\section{Contents}

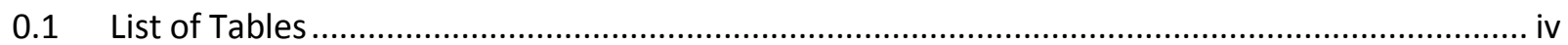

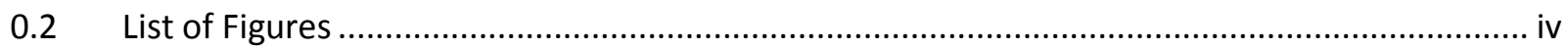

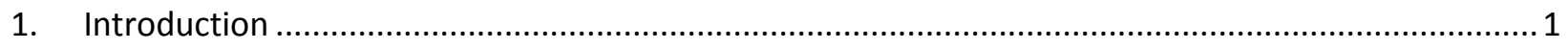

2. “Do Smoking Bans Lead to Higher Rates of Obesity?" ................................................................ 7

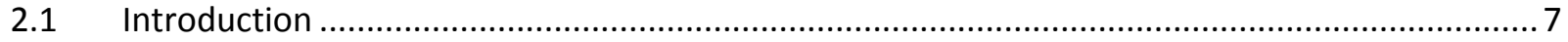

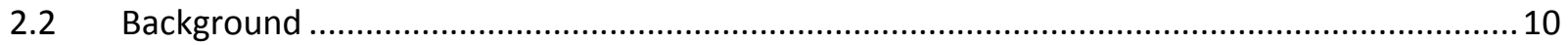

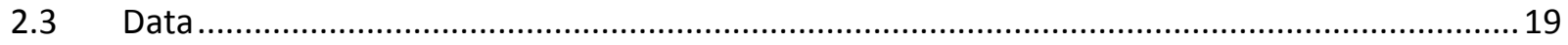

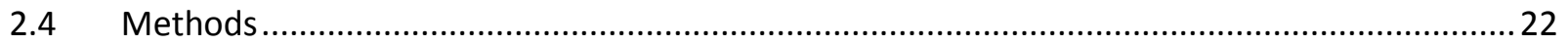

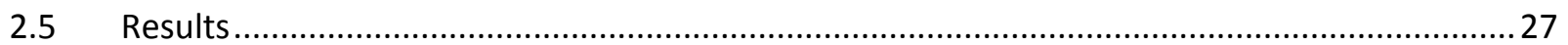

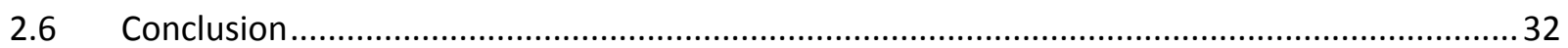

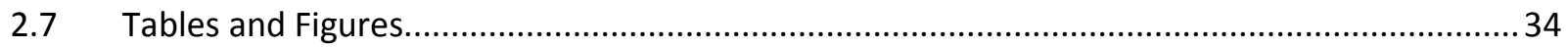

3. "How does WIC Affect Health Outcomes? A Fuzzy Regression Discontinuity Approach." with Tami

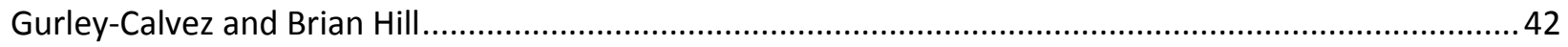

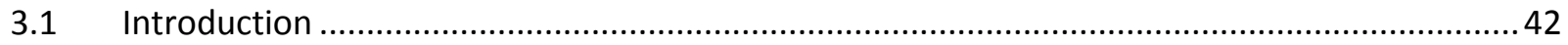

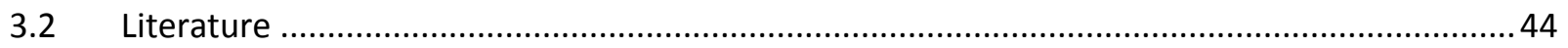

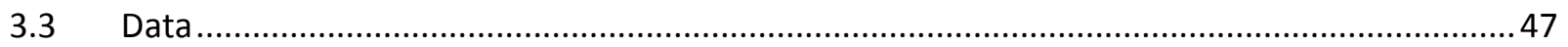

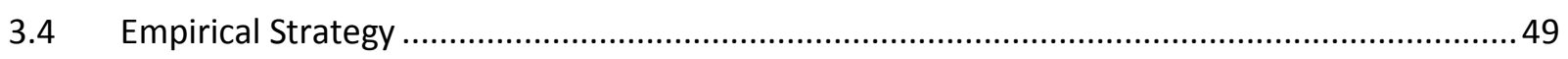

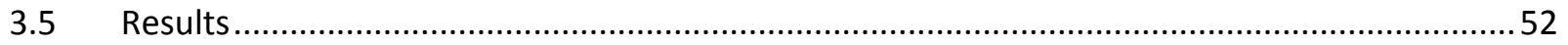

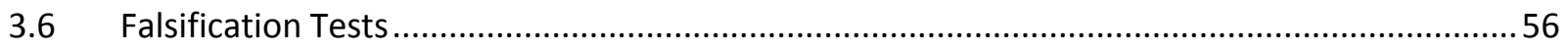

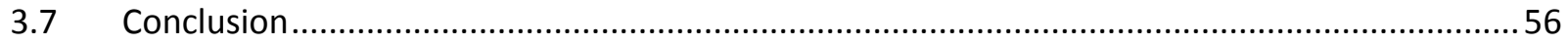

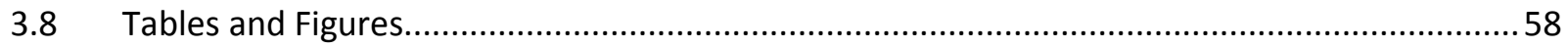

4. “How Does Insurance Contribute to an Individual's Decision to Use Preventive Care?" ..................67

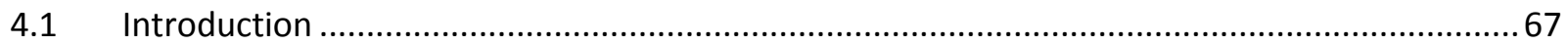

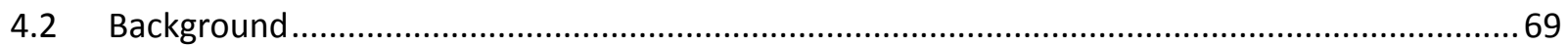

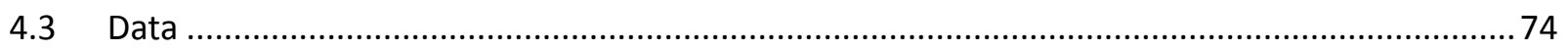

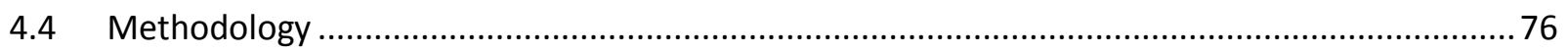

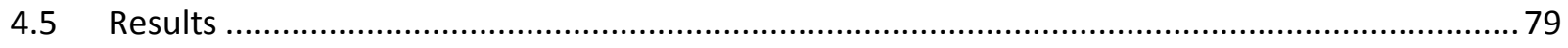

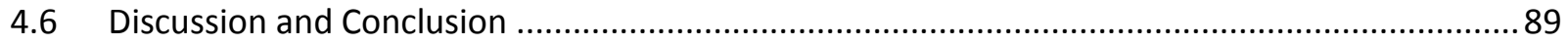

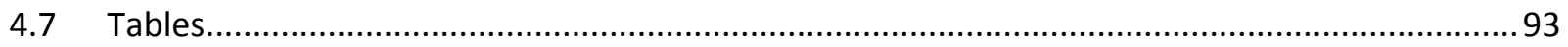

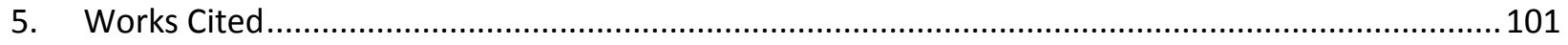




\section{$0.1 \quad$ List of Tables}

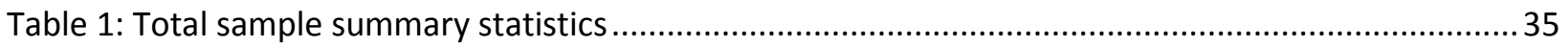

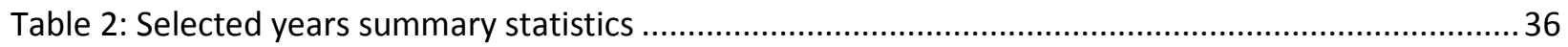

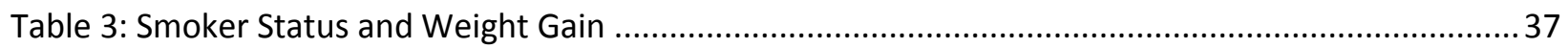

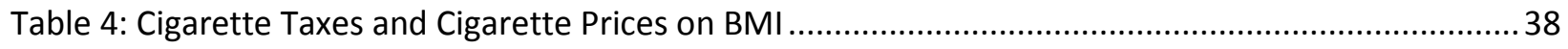

Table 5: Impact of Smoking Bans on the Probability That One is a Smoker: Results from Logit Regressions

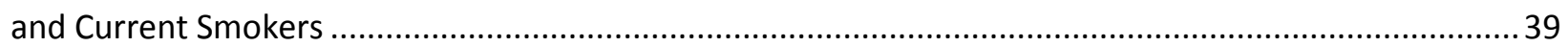

Table 6: Falsification Tests: Impact of Smoking Bans on Never Smokers ................................................ 40

Table 7: Impact of smoking bans on BMI: Results from OLS Regressions ............................................. 40

Table 8: Impact of Smoking Bans on BMI. Limit Sample to Current Smokers ......................................... 41

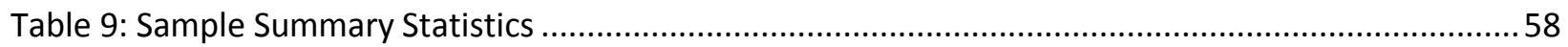

Table 10: Restricted Sample Summary Statistics ................................................................................. 59

Table 11: Fuzzy regression discontinuity estimates of the impact of WIC participation on premature

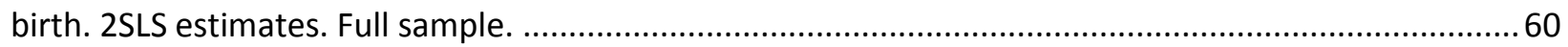

Table 12: Fuzzy regression discontinuity estimates of the impact of WIC participation on the likelihood of

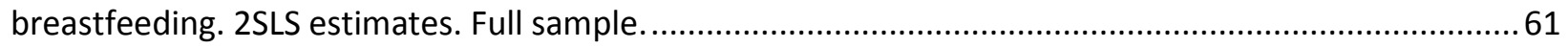

Table 13: Fuzzy regression discontinuity estimates of the impact of WIC participation on the maternal weight gain during pregnancy. 2SLS estimates. Full sample. ..............................................................62

Table 14: Fuzzy regression discontinuity estimates. 2 Stage estimates. Full sample ............................... 63

Table 15: Fuzzy regression discontinuity marginal effects. 2 Stage estimates. Full sample......................64

Table 16: Fuzzy regression discontinuity estimates of the impact of WIC participation on the likelihood of a mother having a ruptured membrane during pregnancy. 2SLS estimates. Full sample.........................65

Table 17: Fuzzy regression discontinuity estimates of the impact of WIC participation on the likelihood of

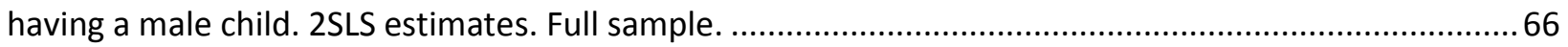

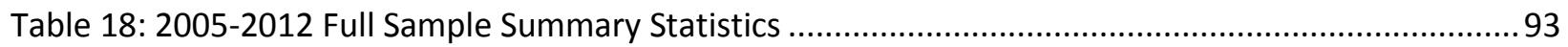

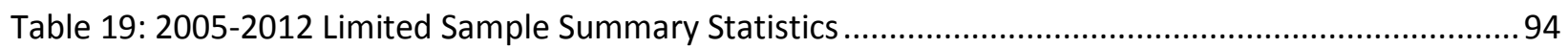

Table 21: Utilization of Prostate Checks by Income Level among Males 2005-2012 ..............................96

Table 22: Utilization of Select Preventive Care Services by Income Level among Females 2005-2012:

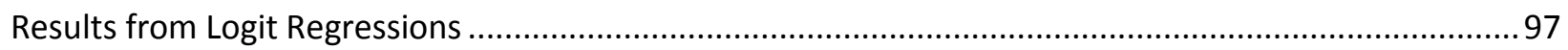

Table 23: 1996-2000 Sample Summary Statistics ................................................................................ 98

Table 24: Utilization of Select Preventive Care Services by Type of Health Care Coverage among Males and Females 1996-2000: Marginal Effects of Logit Regressions Presented ............................................ 99

Table 25: Utilization of Select Preventive Care Services by Type of Health Care Coverage among Females 1996-2000: Marginal Effects of Logit Regressions Presented 100

\subsection{List of Figures}

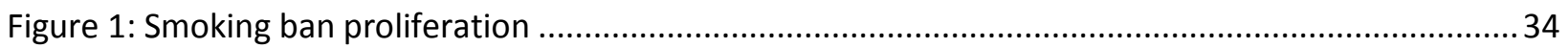

Figure 2: WIC Participation at the Income Cutoff............................................................................... 58 


\section{Introduction}

This dissertation contains three essays, each of which addresses some question related to the economics of health policy. The first examines the effectiveness and potential unintended consequences of smoking bans; the second examines maternal and birth outcomes among low-income mothers who qualify for WIC benefits and among those whose income makes them just ineligible for the program; the third essay analyzes the usage of preventive care services among the insured and uninsured and among different income groups.

In the first essay, presented in Chapter II, I examine a potential contributor to the unprecedented rise in obesity rates in the United States over the past several decades. Concurrently and following a trend since the 1970s, the United States has continued to see a decline in cigarette smoking rates. The rise in obesity has been attributed to various causes such as increased sugar intake and a more sedentary lifestyle that is a consequence of the modern work environment. As with obesity, the decline in smoking can be attributed to many causes. Beginning with a study published in 1954 by the Office of the Surgeon General, individuals have been presented with a multitude of studies since showing the many ways in which tobacco consumption can lead to adverse health outcomes. Armed with this information on the detrimental effects of tobacco consumption, legislators have levied high and everincreasing excise taxes on the purchase of tobacco. Legislators have also sought to reduce tobacco consumption by banning the consumption of cigarettes in many public places in most states across the U.S. 
Upon cessation from cigarette smoking, many individuals noticed a gain in their body weight. In fact, several studies referenced in Chapter II find that upon cessation individuals may experience a weight gain of 5 to 10 pounds. It is unclear whether this weight gain is permanent, as some studies indicated that the weight gained as a result of cigarette cessation is transitory and may slow down after several months.

Building on the idea of the relationship between cigarette cessation and weight gain as well as legislation enacted to encourage individuals to quit smoking, this paper asks the question, "Do Smoking Bans Lead to Higher Rates of Obesity?" In chapter II of this dissertation I examine the relationship between smoking bans and weight gain. I begin with a simple analysis to examine whether a link exists between smoking cessation and weight gain. Then I perform a second analysis to examine the effects of increasing cigarette taxes and cigarette prices on smoking cessation. These two steps are fundamentally preliminary analyses to examine how the findings of the previous literature compare to those gleaned from my dataset. I then move to my primary contribution to the literature: I use a fixed effects approach to first examine whether smoking bans have their desired effect of reducing smoking. Next, I again implement a fixed effects approach and examine the effects of smoking ban legislation on weight gain and obesity.

The analysis in Chapter II is able to confirm the previous finding in the literature that there is indeed a link between smoking cessation and weight gain. I also find that smoking bans tend to have the desired effect of reducing smoking. However, when I address the question of whether smoking bans have the unintended consequence of increasing weight gain and obesity among my full sample, I am unable to find compelling evidence to support this hypothesis. 
When I examine the effect of smoking bans on weight gain among smokers, I find that bans in private and government establishments and restaurants could possibly lead to slight weight gains among those who are current smokers.

In chapter III I examine how participation in the Women, Infants and Children Program (WIC) affects select maternal and infant health outcomes. Previous research by Chatterji et al. (2002) has found that WIC negatively affects the probability of breastfeeding. Bitler and Currie (2005), Filgio, Hammersmith and Roth (2009) and Hoynes, Page and Stevens (2011) all find that WIC participation leads to a decreased likelihood of having a low birth weight child. The general consensus of the previous literature is that in WIC participation appears to improve health outcomes for mothers and their children. However, these findings have been questioned in recent studies that assert that most WIC studies fail to appropriately address that problem of selection bias into the program.

In an attempt to address this bias, we utilize data from the CDC's Pregnancy Risk Assessment Monitoring System (PRAMS) and implement a fuzzy regression discontinuity design to examine the effects of WIC participation on maternal and infant health outcomes. Mothers, and in some cases fathers or other caretakers, are eligible for WIC enrollment in their income falls at or below an income cut-off. This cut-off varies based on the number of people who are dependent on that income. Our regression discontinuity strategy allows us to examine the birth outcomes of mothers who are very close to the income cut-off on each side of that income threshold. In other words, we examine the outcomes of mothers whose income is just high enough to disqualify them from participating in WIC and mothers whose income is just low enough to qualify for WIC participation. 
We examine six infant and maternal health outcomes in our analysis: the probability of low birth weight, the probability of premature birth, birth weight, whether or not a mother has ever breast fed, duration of breast feeding and maternal weight gain during pregnancy. We find significant results in a number of specifications for three main outcomes: decreased probability of premature birth, decreased likelihood of breast feeding and decreased maternal weight gain during pregnancy. Results indicate that WIC participation decreases the likelihood of premature births, reduces the likelihood of breastfeeding and leads to decreases in maternal weight gain during pregnancy.

In Chapter IV I examine the usage of preventive care services among different groups of people. Specifically I examine how insurance coverage contributes to an individual's decision to utilize a variety of preventive care services. One of the goals of the recently passed Affordable Care Act (ACA) is to increase the usage of preventive care services. Maciosek et al. (2010) state that increased use of preventive care services could prevent the loss of more than 2 million quality-adjusted life years ${ }^{1}$ and could result in savings of several billion dollars.

Previous research has found that whites are more likely to have insurance coverage than blacks and Hispanics (Ahluwalia et al., 2009). Other studies have found that the working poor are less likely to receive certain preventive care services and women are more likely than men to receive preventive care services. Tian et al. (2010) show that in Taiwan, usage of preventive care services in the present leads to fewer inpatient hospital visits in the future.

\footnotetext{
${ }^{1}$ A quality-adjusted life year (QALY) is a measure of disease burden which includes both the quality and the quantity of life lived. It is used in assessing the value of money of a medical intervention. The QALY is based on the number of years of life that would be added by the intervention.
} 
Finally, Decker et al. (2012) show that individuals who had insurance coverage before becoming eligible for Medicare at age 65 use their Medicare coverage differently than those who were without coverage before age 65. During the first few years of Medicare enrollment those without previous coverage continued to use the Medicare system differently than those with previous coverage, mainly by using fewer of the services offered.

Chapter IV uses data from the CDC's Behavioral Risk Factor Surveillance System (BRFSS) over two time periods, $1996-2000$ and $2005-2012$, to analyze the usage of specific preventive care services. Data from 1996-2000 contain information on six types of coverage held by individuals and eight preventive care services. After controlling for several demographic characteristics such as age, race, employment status, and income and education levels, I find that relative to those who purchase their own private insurance plans, those with insurance through their employer or spouse's employer and those with coverage through the military are more likely to receive preventive care. Having a check-up with a doctor in the previous year also seems to increase the usage of preventive care services in all cases. A simple conversation with a doctor could be a significant driver the results found in this paper.

In the years 2001-2012 the data only contain information on whether an individual has some form of insurance coverage. In this phase of the analysis I create five income categories for individual and examine their usage of nine preventive care services. I control for the same demographic characteristics as well as whether or not an individual has visited a doctor within the past year. Individuals with insurance coverage are much more likely to use preventive care services relative to those without coverage. Results also point to a high income bias in the 
utilization of nearly all preventive care services in the BRFSS data set. This implies that as income increases, individuals are more likely to use preventive care services. 


\section{2. “Do Smoking Bans Lead to Higher Rates of Obesity?"}

\subsection{Introduction}

Two notable trends have been occurring in the United States over the past several decades: The country has experienced an unprecedented rise in the share of its population that is obese $(B M I \geq 30)$ while it has simultaneously seen a significant decline in cigarette smoking. In 1990, 10 states had an obesity rate of less than 10 percent and no states had rates of obesity greater than or equal to 15 percent. By 2000, no state had an obesity rate of less than 10 percent, 23 states had prevalence between 20-24 percent, and no state had prevalence greater than or equal to 25 percent. In sharp contrast, by 2012 no state had an obesity rate of less than 20 percent. Nine states and the District of Columbia had prevalence between 20-25 percent. Thirteen states had prevalence equal to or greater than 30 percent. In 2008 the estimated annual medical cost of obesity was $\$ 147$ billion. Annual medical costs for people who are obese are estimated to be $\$ 1,429$ higher than those of normal weight ${ }^{2}$.

In 1954 the Office of the Surgeon General released the first report on the effects of smoking on health. In the more than 60 years since, a multitude of studies have been published consistently demonstrating the detrimental effects of smoking on health. From 2000 to 2011, total per capita cigarette consumption declined from 2,076 in 2000 to 1,232 in 2011 , a $40.7 \%$ decrease. From 2000-2004 cigarette smoking was estimated to be responsible for $\$ 193$ billion in annual health-related economic losses in the United States ${ }^{3}$.

\footnotetext{
${ }^{2}$ http://www.cdc.gov/obesity/data/adult.html

3 http://www.cdc.gov/tobacco/data statistics/fact sheets/economics/econ facts/\#costs
} 
Some have suggested that these trends are related. Some evidence indicates that smoking cessation can lead to weight gain. A 1990 report from the U.S. surgeon general states that the fear of post-cessation weight gain may discourage many smokers from trying to quit and the fear or occurrence of actual weight gain may drive the relapse of many who have already quit. Roughly half of those mentioned in the report agreed with the statement that, "smoking helps control weight". However the mean weight gain of those who did gain weight after cessation was only 5 pounds (U.S. Department of Health and Human Services, 1990). Cann et al., (1996) find weight gain is often a deterrent for many people who would like to quit smoking, especially women. Finklestein et al. (2003) postulate that if it is true that these two phenomena are related, then the welfare gains from reduced smoking may be offset by the costs from increased obesity. Rashad and Grossman (2004) estimate that declines in smoking account for almost 20 percent of the growth in obesity over the past several decades.

Many states have also enacted legislation to restrict smoking in certain areas, mainly in indoor work spaces, bars, and restaurants. In 1995 California was the first state to enact a statewide smoking ban. Throughout the 2000s many states enacted smoking bans of their own. As of June 2013, 28 states have enacted statewide bans on smoking in all public places, including bars and restaurants. Several states leave the decision up to local municipalities or exempt a variety of places from their smoking bans. The effects of these bans is important to consider as it may cause changes in people behavior.

We seek to examine a potential unintended consequence of smoking ban legislation. If it is true that smoking cessation often leads to higher levels of weight gain and obesity and that smoking bans reduce cigarette smoking prevalence, then smoking ban legislation could 
unintentionally lead to higher levels of weight gain and obesity. This paper uses data from the CDC Behavioral Risk Factor Surveillance System (BRFSS) and the CDC State Tobacco Activities Tracking and Evaluation System (STATE) over the period 1995-2012 to estimate the effects of smoking ban legislation on obesity.

Previous research has examined the causal link between cigarette taxes and prices and obesity. Chou et al. (2004) show that higher cigarette prices reduce smoking rates and are linked with higher rates of obesity. Gruber and Frakes (2006) perform an analysis similar to Chou et al. (2004), however, in contrast to Chou et al., Gruber and Frakes find reduced smoking actually leads to lower body weights. However Gruber and Frakes' results imply very large effects of smoking on body weight and thus they are unable to confirm that reduced smoking is a major contributor to rising obesity in the U.S.

We begin by performing studies similar to the report from the U.S. Department of Health and Human Services (1990) to examine how results from our data compare to the previous literature. We first examine the effects of smoking cessation on weight gain. We continue our comparative analysis by examining the effects of cigarette price and cigarette taxation on weight gain using methods similar to Chou et al. (2004) and Gruber and Frakes (2006). Results from our comparative analysis section confirm findings of the previous literature confirming that smoking cessation and cigarette prices are positively related to weight gain and cigarette taxes are negatively related to weight gain. We then examine the effects of four types of smoking ban legislation on the probability that one is a smoker, using methods similar to Black (2010), as well as an instrumental variables approach. We confirm Black's finding that the presence of smoking bans lowers the probability that one is a smoker. We conclude by 
examining the effects of smoking ban legislation and present our unique contribution to the literature by providing an update to Chou et al.'s (2004) paper. We implement OLS, Logit, and Two-Stage Least Squares regression models and find no compelling evidence that smoking ban legislation has a significant effect on levels of weight gain and obesity in the U.S. However, when we limit the sample to those who identify as current smokers we are able to identify a positive and economically significant relationship between smoking bans and BMI.

\subsection{Background}

\section{Smoking on Weight Gain}

Several researches have examined the effect of smoking on weight. Caan et al. (1996) show that post-cessation weight gain is transient, slowing down after 6 months once energy intake returns to baseline levels. Similar to U.S. Department of Health and Human Services (1990), they also find that weight gain may cause relapse. In their study women gained, on average 9.9 pounds over a 1-year period. Froom et al. (1999) in a study of occupationally active men in Israel show that weight gain before this equilibrium may be present for several years. Mizoue et al. (1998) examine workers and found that heavy smokers experience large weight gains and weigh more than never smokers in the few years after smoking cessation, they thereafter lose weight to the never smoker level. Further, they find that light and moderate smokers gain weight, but only up to the never smoker level. Pinkowish (1999) finds that individuals who quit smoking typically gain weight. John et al. (2005) find that the number of cigarettes smoked per day was positively related to being overweight upon cessation and more so to obesity among former smoking men, but not women. 
Even the perception that quitting smoking will lead to weight gain is enough to prevent cessation. Concerns of weight gain are deterrents to many who would like to quit smoking. These concerns could also cause a former smoker to relapse by using smoking as a control mechanism for weight gain (Caan et al., 1996). From the 1986 Adult Use of Tobacco Survey current smokers who had returned to smoking were asked why they returned to smoking. Twenty-seven percent reported that actual weight gain was an important factor for their return to smoking and 22 percent said that possibility of gaining weight was reason enough for their relapse (U.S. Department of Health and Human Services, 1990).

\section{Smoking Bans and Obesity}

Farrelly et al. (1999) use data from the Current Population Study - Tobacco Use Supplements data from 1992 and 1993 to examine self-reported workplace smoking bans. When a workplace made the change from no ban to a complete ban smoking prevalence fell by 5.7 percentage and average daily consumption dropped by 14 percent. If the workplace still allowed smoking in certain areas, such as break rooms or common areas the effects of the bans were halved. Smoking prevalence was lowered by only 2.6 percent and average daily consumption fell by 8 percent. Partial work place bans had no effect on smoking prevalence, but did reduce average daily consumption by roughly 3 percent.

Evans et al. (1999) investigate whether workplace smoking bans reduce smoking prevalence and smoking intensity among workers. They estimate that workplace bans reduce smoking prevalence by at least 5 percent and average daily consumption by 10 percent. Furthermore, their study found that the effects of the bans increased the longer the workweek and the more restrictive the ban. 
Czart (2001) examines the effect of cigarette prices, clean indoor air laws and campuslevel smoking policies on the smoking behaviors of college students using a dichotomous indicator of daily smoking participation in the past 30 days with OLS, Probit and Logit model specifications. The article provides evidence to support the argument that higher cigarette prices discourage both smoking participation and the level of smoking among young adults. Smokers living in areas with comprehensive state and local restrictions appear to smoke less. However, smoking restrictions on college campuses tend to only be effective at curbing smoking when then are actively enforced.

Fichtenberg and Glantz (2002) poured over 26 studies that examined private worksites which had enacted smoking restrictions. They state that smoke-free workplaces not only protect non-smokers from passive smoking, but also have the effect of encouraging smokers to quit or reduce their consumption. Their principle findings were that totally smoke-free workplaces are associated with reductions in smoking prevalence of 3.8 percent fewer cigarettes smoked per day per continuing smoker. Reduced consumption of 1.3 cigarettes per day per employee comes about through the combination of the effects of reduce prevalence and lower consumption per smoker. They estimate that if all workplaces were to become smoke free, consumption per capita in the entire population would drop by 4.5 percent in the United States and 7.6 percent in the United Kingdom.

Levy and Friend (2003) review the research on the effects of smoking bans on smoking rates and compare the results to other studies examining workplace bans. In total, they reviewed 18 studies. They find similar results to Fichtenburg and Glantz (2002), specifically that 
extensive smoking bans are associated with lower smoking prevalence and cigarette consumption. They find that the presence of smoking bans reduced smoking prevalence by 5 to 20 percent. However, it should be noted that all but one of the studies they examined reviewed legislation that was enacted prior to 1994. As can be seen below in Figure 1 total smoking bans were very rare in 1994 and previous years.

Goel and Nelson (2006) perform a survey of the literature focusing on government efforts to curb the use of undesirable goods, notably tobacco products. Their paper examined 5 international studies as well as 5 studies in the United States which looked at smoking control measures using data from the 1970 s to the 1990 s. They concluded that in most cases smoking restrictions were effective in reducing smoking.

Kenkel and Wu (2008) delve into the impact of restaurant smoking bans on demand for smoking and restaurant food. They work with data from the Simmons National Community Survey (NCS) and the Consumer Expenditure Survey (CES). The NCS contains information on respondents restaurant-going while the CES is used to measure household expenditures on food away from home. They also implement data on smoking bans in restaurants from a database constructed by the American Nonsmokers' Rights foundation (ANRF). The database contains detailed information on states and municipalities with 100 percent smoke free restaurants laws and the dates when the laws became effective. They create a ban variable that captures the percentage of the population that is affected by the smoking ban. They note that within survey wave variation in restaurant bans may be potentially endogenous. The unobserved differences are captured by the error terms in their models. In order to account for 
differences across states they include a direct measure of state anti-smoking sentiment from the Tobacco Use Supplements of the Current Population Survey. The results of their Tobit model specification show that smoking bans increase food expenditures by nonsmokers slightly and has no significant effect on smokers' expenditures food expenditures. They also find insignificant effects of smoking bans on daily cigarette consumption, smoking cessation attempts, or successful cessation among smokers.

Black (2010) examines the effects of complete smoking bans in bars, restaurants and workplaces on smoking prevalence and intensity. Black implements data from the Tobacco Use Supplements of the Current Population Survey from 1995 - 2007. Black uses a probit specification to examine the effects of smoking ban implementation on smoking status. Black examines smoking in workplaces, bars and restaurants individually. His results suggest that complete smoking bans have little effect on smoking prevalence and have a mixed effect on smoking intensity. Black's findings could be strengthened by reexamining his question with more recent smoking ban data. Since 2007 many more states have implemented smoking bans in bars, restaurants and workplaces and the increased variation in smoking bans could lead to stronger results for his paper.

Liu et al. (2010) use self-reported workplace smoking bans as an instrumental variable for smoking to examine the relationship between smoking and body weight in a two-stage least squares estimation. They utilize data from the BRFSS for the years 1996-2006. They find that current smokers have were have BMI levels ranging from 1.8 - 3.6 indexes lower and were 9.4 18.5 percentage points lower in likelihood of obesity. Their results imply that while tobacco 
control policies are effective at reducing smoking, they may have an unintended consequence of increasing obesity.

Anger et al. (2011) investigate the short-term effects of public smoking bans on individual smoking behavior in Germany. State level smoking bans were introduced in the country in 2007 and 2008. They exploit the time variation in the implementation of smoking bans to identify the effects that the bans had on individual's smoking propensity and intensity using data from the German Socio-Economic Panel Study. The results show that in the shortterm, smoke free policies did not change the population's average smoking behavior; both smoking intensity and overall cigarette consumption were relatively unaffected. However, individuals who went out to restaurants and bars more often and were more affected by the bans, did adjust their smoking behavior. They found that these individuals had a lower propensity to smoke, had a reduced likelihood to smoke regularly and lowered their daily consumption of cigarettes following the implementation of smoking bans. Their findings indicate that smoking bans can be an effective tobacco control policy at least for certain subgroups of the population and can provide important health benefits beyond reducing nonsmokers exposure to second-hand smoke.

\section{Cigarette Costs and Weight Gain}

We are currently aware of several papers that have attempted to provide a causal link between smoking and obesity. Two of the papers utilize the same BRFSS data, although with slightly different time periods. Chou et al. (2004) attempt to gain an understanding of the factors associated with the stability in obesity between the early 1960 s and the late 1970 s and the rapid increase since that time. They utilize repeated cross-sectional BRFSS data from 1984- 
1999. They augment the BRFSS data with data pertaining to the per capita number of fast food and full service restaurants, the prices of meals at each type of restaurant, the price of and amount of food consumed at home, the prices of cigarettes and alcohol and the presence of clean indoor air laws. They also control for individual-level measures of age, race, household income, years of formal schooling completed, and marital status. They employ state fixed effects, a quadratic time trend, and use a reduced form model to calculate an elasticity, 0.025, of BMI with respect to changes in cigarette prices.

The largest contribution to increasing trends in weight outcomes was the increase in the per capita number of restaurants, accounting for 61 percent of the actual growth in BMI and 65 percent of the rise in the percentage of the obese. They find that increases in the real price of cigarettes ranks second, with a contribution roughly one-third as large as that due to restaurants. The three real food prices the authors considered also fell during their sample period, which also led to higher levels of weight gain. However, it is the combined force of the fall in all three prices that most affected changes in weight. Assessed alone, the change in each price was modest and had little explanatory power. Chou et al. also found that the rising prevalence of clean indoor air laws led to slight increases in BMI and the percentage of the population that is obese. They note the magnitude of the effect was very similar to the reduction in fast food restaurant prices. However, it is important to note that Chou et al.'s time frame was from 1984-1999. As this paper demonstrated in Figure 1, there were very few states which had implemented clean indoor air laws by 1999. The lack of variation in clean indoor air laws could have affected their results. 
Gruber and Frakes (2006) begin by noting that there is a strong negative correlation over time between smoking rates and obesity. They also note that some suggest that the decline in smoking leads to increased levels of obesity and weight gain. They re-examine the work of Chou et al. (2004) by implementing BRFSS data from 1984-2002 and cigarette tax, rather than cigarette price data. They believe that the cigarette prices, used in Chou et al. (2004) may be potentially endogenous. They rely on variation within states based on local cigarette taxes for their analysis.

Gruber and Frakes find evidence of a negative relationship between cigarette taxes and BMI. Their finding implies that the reduced smoking due to higher taxes decreases, rather than increases, weight. However, they note that these effect they estimate is very small. For example, according to their results a $\$ 1$ increase in cigarette taxes would lower BMI by 0.15 , or less than one percent of the sample mean. The same $\$ 1$ increase would lower the odds of being obese by 0.015 percent, also roughly 1 percent of the sample mean.

Gruber and Frakes note that there is the potential for reverse causality when using cigarette taxes (or prices) as a regressor. It could be that taxes (or prices) are reacting to the underlying trends in smoking and body weight. In order to address this concern they include state-specific time trend variables for each year of the data in their study. The interactions of each state dummy variable with a time trend will pick up generally increasing or decreasing body weight trends in each state that might be correlated with cigarette tax (or price) policy.

Baum (2009) sought to update the literature by re-examining the conflicting findings regarding the relationship between cigarette costs and weight gain of Chou et al (2004) and 
Gruber and Frakes (2006). He does so by controlling more carefully for time-variant statespecific factors that might be correlated with state cigarette taxes and prices and utilizing the National Longitudinal Survey of Youth (NLSY79) panel data. He replicates the findings of Chou et al. and Gruber and Frakes and then attempts to identify the effects of cigarette costs on a subsample who are likely to be affected by cigarette costs and compares the results to a comparison group that is unlikely to be affected by cigarette costs. The results of his study show that cigarette costs significantly increase BMI and the prevalence of overweight and obese people. He also finds that the increases in weight gain are more concentrated among younger and low-income individuals. He also notes that lagged cigarette costs have stronger positive effects on weight gain measures than the effects of contemporaneously measured cigarette costs. He concludes that the conflicting findings in the literature are due to correlation between state cigarette costs and state-specific time trends.

Courtemanche (2009) examines cigarette prices and taxes and their effect on weight gain and obesity. His study utilizes data from the NSLY and BRFSS data sets. He shows that including lags of prices/taxes causes the different methodologies in the literature to produce the same result. Namely, that higher cigarette costs are associated with reductions in BMI and obesity in the long run.

We extend this literature by applying a methodology similar to Gruber and Frakes (2006) and Chou et al. (2004) and updating Chou et al.'s (2004) early work with smoking bans. We utilize the same cigarette tax and price data as well as BRFSS data and augment the data with information on state-level smoking bans to examine the effects of smoking ban policy on levels 
of weight gain. All of these studies lead us to believe that there will be effects on smoking prevalence and consumption upon enactment of a smoking ban.

\subsection{Data}

Our primary data source is the Behavioral Risk Factor Surveillance System (BRFSS). The BRFSS is a nationally representative telephone survey of persons aged 18 or older in the United States and has been conducted by state health departments with the help of the Centers for Disease Control (CDC). The BRFSS collects data on several individual-level behavioral health risk factors associated with the leading causes of premature mortality and morbidity among adults, chronic health conditions, and use of preventative services. Fifteen states took part in the initial study in 1984 and by 1994, all 50 states and the District of Columbia became involved. Currently the BRFSS conducts more than 400,000 adult surveys annually. Each year the survey includes more respondents. Our sample consists of cross-sections from years 1995-2012 and contains roughly 3.1 million observations.

Of particular interest to this study is the system's information on self-reported smoking status, demographic characteristics, and height and weight measures. Self-reported height and weight allow for our calculation of the Body Mass Index (BMI) of each respondent ${ }^{4}$. We create dummy variables indicating whether each respondent is a current smoker, a former smoker, or has never smoked. We exclude respondents who are older than age 65 in order to minimize the impact of more general health factors associated with older people and help focus our analysis on our behavioral factors of interest. We also exclude respondents below age 25 in order to

\footnotetext{
${ }^{4}$ We exclude those with a BMI in between 15 and 45 to cut off outliers at the tail ends of the distribution of our sample.
} 
eliminate those who may have smoked sporadically during their college years. We also control for whether or not a person has had any form of light exercise during the past 30 days ${ }^{5}$. We also include data on whether respondents are currently employed, their income level, education level, marital status, and race.

We match our data with smoking ban data from the CDC's State Tobacco Activities Tracking and Evaluation System (STATE) and cigarette excise tax and price data from The Tax Burden on Tobacco (Orzechowski and Walker, 2011). The STATE system is an interactive application that displays and houses current and historical state-level data on tobacco use, prevention, and control. From the STATE system we extract data on state level smoking bans, cigarette taxes, and cigarette price. Data on state-level smoking bans are reported quarterly and we use the data from the $4^{\text {th }}$ quarter of each year to construct four specific dummy variables denoting whether states impose smoking bans in bars, restaurants, private businesses, and government offices. A smoking ban in a bar or restaurant prohibits smoking in any bar or restaurant establishment in the state, while if a private worksite ban is enacted, smoking is banned in all other private worksites. A government smoking ban prohibits smoking inside all government facilities within that particular state. As shown in Figure 1 we begin with data from 1995 and our sample period runs through 2012, the most recent year for which the BRFSS is available. We do not account for local level smoking bans within states.

We utilize data from The Tax Burden on Tobacco which contains data on cigarette taxation, sales, and price data dating back to as early as 1921. Cigarette tax data vary by year

\footnotetext{
${ }^{5}$ The BRFSS asks respondents whether or not they have participated in any physical activities or exercises such as running, calisthenics, golf, gardening, or walking for exercise, other than their regular job, during the past month.
} 
and state. Cigarette price data is the average price of a 20 -count pack of cigarettes in each state for each year.

As reported in Table 1, our sample consists of roughly 3.1 million observations spanning from 1995-2012. The average BMI level in our sample is 27.20 which implies that the average participant in our sample is overweight. Among those who are overweight, 26 percent meet the CDC's classification for obesity. Roughly 80 percent of participants in our sample are white, 8 percent are black, 6 percent are Hispanic, and 4 percent are Asian or a Pacific Islander. Around 42 percent of participants in the sample are male and the average age of participants is 46 years old. Seventy-two percent of participants are employed, 22 percent are not in the labor force, and 5 percent are unemployed. Approximately 77 percent of the sample exercised in the past month. Finally, 22 percent of individuals in our sample reported that they are current smokers, 25 percent report that they are former smokers, and 53 percent report having never smoked.

It is interesting to observe how our key variables change from 1995 to 2012. For instance, the average BMI level in 1998 was 25.80 and by 2012 it had risen to 27.79 . The average participant in our sample meets the CDC's classification for being overweight in 1995 and 2012. More shocking is the increase in the prevalence of obesity (BMI $\geq 30)$. In 1995, 19 percent of our sample was obese and by 2012 this share has increased to 30 percent. We can also see the trend of falling smoking by examining the percentage of our sample that are smokers over our sample period. Twenty-six percent of our sample are smokers in 1995 and by 2012 only 20 percent of our sample continue to smoke. Real cigarette taxes have nearly tripled 
over the sample period rising from $\$ 0.47$ in 1995 to $\$ 1.49$ in 2012 . The real price of a pack of cigarettes has nearly doubled starting at $\$ 1.97$ in 1995 and increasing to $\$ 4.48$ by $2012^{6}$.

Also noteworthy are the changes in state-level clean indoor air laws, or smoking bans. Shown in Figure 1, in 1995 there was no state that had a state-level smoking ban in bars or private establishments. Also in 1995 only 2.6 percent of states had enacted smoking bans in restaurants and 20 percent of states had bans in government offices. By 2012 smoking bans have become much more prevalent. In 2012, 59 and 68 percent of states have enacted indoor smoking bans in bars and restaurants respectively. Bans in government and private workplaces have spread to 75 and 70 percent of states respectively.

\subsection{Methods}

We believe that smoking bans may affect an individual's weight through different channels. For instance, a smoking ban in a workplace may reduce the opportunities that an individual has to smoke. As a result, there may be a substitution effect in which an individuals has a small snack instead of going out of the office for a cigarette. A smoking ban in a restaurant may encourage smokers to instead stay at home and cook for themselves which could lead to an effect on their weight. Conversely a smoking ban in a restaurant may also increase the amount of food an individual consumes at a restaurant. Instead of having a cigarette after a meal, an individual might stay for dessert rather than going outside for a cigarette. Restaurant bans might also increase the number of nonsmokers who eat out at restaurants since they would no longer be bothered by cigarette smoke while eating. This effect

\footnotetext{
${ }^{6}$ Cigarette prices and taxes are adjusted for inflation to 2013 dollars.
} 
could increase levels of weight gain for nonsmokers as well. Bar bans may lead to an increased effect on weight gain also. Individuals may instead

The primary focus of our analysis attempts to estimate the effect of smoking bans on different measures of body weight. However, before we present our primary analysis, we estimate a series of preliminary models to gauge how our data and methodology compare to results found in previous studies. First, since our basic premise rests on the idea that a smoking ban could affect a person's smoker status, which in turn affects BMI, we begin with a simple model to test whether variation in smoking status is related to BMI. This model has been estimated in the previous literature; we simply reconsider this model to test whether results using our data differ from those in the previous literature. We then move on to estimate the effect of cigarette taxes and prices on $\mathrm{BMI}$ and the probability that one is a smoker, primarily to compare to Chou et al. (2004) and Gruber and Frakes (2006). We then move on to our particular contribution by examining first how smoking bans affect the probability that one is a current smoker, and then we reach our final analysis in which we examine the effect of smoking bans on BMI. The way in which our analysis proceeds is summarized as follows:

Effects of smoking status on BMI

$$
B M I_{i j t}=\beta_{0}+\beta_{1} S M O K E R_{i j t}+\beta_{2} X_{i j t}+\tau_{j}+\gamma_{t}+\theta_{t}+\varepsilon_{i j t}
$$

The effects of cigarette taxation and cigarette price on $B M I$

$$
B M I_{i j t}=\beta_{0}+\beta_{1} Z_{j t}+\beta_{2} X_{i j t}+\tau_{j}+\gamma_{t}+\theta_{t}+\varepsilon_{i j t}
$$

The effects smoking bans on the probability that one is a smoker

$$
P(\text { Smoker })_{i j t}=\beta_{0}+\beta_{1} B A N_{j t}+\beta_{2} X_{i j t}+\beta_{3} Z_{j t}+\tau_{j}+\gamma_{t}+\theta_{t}+\varepsilon_{i j t}
$$


The effects smoking bans on BMI

$$
B M I_{i j t}=\beta_{0}+\beta_{1} B A N_{j t}+\beta_{2} X_{i j t}+\beta_{3} Z_{j t}+\tau_{j}+\gamma_{t}+\theta_{t}+\varepsilon_{i j t}
$$

where $i$ indexes individuals, $j$ indexes the states, $t$ indexes the years, BMI represents the body mass index or a dummy variable indicating whether an individual is obese.

SMOKER is a dummy variable representing a person's smoker status. Smoker status is divided into three categories: smoker, former smoker, and never smoker. We further condense our definition of smoker status by combining the smoker and former smoker categories into a fourth category that we call ever smoker. $B A N$ represents four specific dummy variables denoting the four types of state-level smoking bans: restaurant bans, private establishment bans, government facility bans, and bar bans. We estimate regression models for each of the four types of smoking ban individually.

We control for demographic characteristics and we include year and state fixed effects; overall our set of control variables largely mirrors the approach used in Gruber and Frakes (2006). $X$ is a matrix of individual specific characteristics: gender, age, marital status, employment, education, race, and income. $Z$ is a matrix of state specific characteristics including: cigarette taxes, the average after tax price of a pack of cigarettes for each year in our sample, and the annual unemployment rate in each state. Finally, $\tau_{j}, \theta_{t}$ and $\gamma_{t}$ represent year, month and state fixed effects.

In equation 1, we estimate an individual's BMI using a basic fixed effects regression specification with state-clustered standard errors. ${ }^{7}$ In equation 2 we estimate the effect of

\footnotetext{
${ }^{7}$ OLS regressions were run using the STATA command "regress, cluster (state) robust" and are available upon request.
} 
cigarette prices and cigarette taxes on BMI. In equation 3 we estimate the effect of smoking bans on an individual's smoker status using a fixed effects logit model with state-clustered standard errors. Finally, in equation 4 we estimate the effects of smoking bans on BMI again using a fixed effects OLS specification with state-clustered standard errors.

The familiar problem of endogeneity could potentially bias our coefficient estimates. In particular, it is possible that the decision to implement a smoking ban may not be a strictly exogenous decision. Rather, the decision to impose such a ban may be correlated with some other factor that is excluded from our model that is also correlated with obesity. For instance, some cultural element that applies to states may be related to obesity in the state as well as to whether a state imposes a smoking ban.

Our first approach to overcoming this potential bias is by including state fixed effects in our model. If the unobserved factor that is related to obesity as well as to the adoption of smoking bans is relatively time-invariant across states, then state fixed effects should capture that factor. Some have suggested that in certain situations such an approach can be effective in overcoming omitted variable bias in this context. Besley and Case (1994) examine the incidence of endogenous policies. In their paper, they explore the use of different methods for estimating policy incidence in the face of potential policy endogeneity by examining worker's compensation benefits data. In cases where a researcher is lacking a valid instrument, they suggest a fixed effects specification. The authors conclude, "More generally, cross-state fixed effect estimation and difference-indifference estimation can be interpreted as instrumental variable estimation (Besley and Case, 1994, p. 23)." 
Similar to the methodology used in Baum (2009), we also perform some falsification tests by examining the effect of smoking bans on individuals who have never smoked. In any regression where we examine the effects of a policy on smokers, we also run the same regressions on never smokers. That is, in cases where the variable "smoker" or "ever smoker" is the dependent variable, we run the same regressions with "never smoker" as the dependent variable. Policies intended to solely affect smokers should have no effect on individuals who do not smoke.

Even though a fixed effects specification should be appropriate, we also estimate a two stage least squares $^{8}(2 \mathrm{SLS})$ model with year fixed effects in an attempt to address the omission of variable relating to the smoking culture of a state using tobacco production in 1975 as our instrument. We believe that this figure on historic tobacco production may appropriately serve to explain sentiment toward tobacco-related laws, including smoking bans, but may be strictly exogenous to the model otherwise. Using the same instrument, we also estimate IV Probit ${ }^{9}$ models with year fixed effects in attempt to estimate the effects of smoking bans on the probability that one is a smoker as well as the probability that one is obese ${ }^{10}$.

\footnotetext{
${ }^{8}$ 2SLS regressions are run using the STATA command "ivreg". First stage regressions are not reported but are available upon request.

${ }^{9}$ IV Probit models are run using the STATA command "IV Probit". Results are not reported but are available upon request.

${ }^{10}$ Due to questionable results, we have decided not to report the results of our instrumental variables specification. These results are available upon request.
} 


\section{$2.5 \quad$ Results}

Now we turn to our results. We begin with results from models in which we estimate $\mathrm{BMI}$ and the probability of being obese as a function of smoker status, which is summarized as follows:

Effects of smoking status on BMI

$$
B M I_{i j t}=\alpha+\beta_{1} S M O K E R_{i j t}+\beta_{2} X_{i j t}+\tau_{j}+\gamma_{t}+\varepsilon_{i j t}
$$

Our results are shown in Table 3 and provide evidence in favor of the hypothesis that current smokers will have a lower BMI and lower probability of being obese and former smokers will have a higher BMI and higher probability of being obese both relative to those who have never smoked. Using a standard fixed effects OLS model with state-clustered standard errors, we estimate that being a current smoker reduces BMI by a coefficient of -1.251 whereas BMI is estimated to be 0.250 higher for former smokers, both in comparison to someone who has never smoked. These coefficients imply that BMI is one-fourth of a standard deviation lower for current smokers relative to never smokers. BMI is 0.1 of a standard deviation higher BMI for former smokers compared to those who have never smoked. Both of these results are significant at the 1 percent level.

The results from Table 3 are similar to those found by U.S. Surgeon General (1990), Caan et al. (1996), Mizoue et al (1998), and Pinkowish (1999) who also found significant differences in weight across smoking status. Specifically, relative to those who have never smoked, we find that former smokers have higher levels of BMI and probabilities of being obese. Also, relative to never smokers, current smokers have lower levels of BMI and lower probabilities of being 
obese. Overall, our data and methodology do not produce results that differ substantially from the existing literature regarding the relationship between smoking status and obesity.

The effects of cigarette taxation and cigarette price on $B M I$

$$
B M I_{i j t}=\alpha+\beta_{1} Z_{j t}+\beta_{2} X_{i j t}+\tau_{j}+\gamma_{t}+\varepsilon_{i j t}
$$

In this section we analyze the effects of cigarette taxation and cigarette price on BMI. We control for demographic characteristics and state, month and year fixed effects. Based on the results from Chou et al. (2004), we expect that cigarette prices will have a positive effect on BMI. Also, based on the results from Gruber and Frakes (2006), we expect that cigarette taxes will have a negative effect on BMI. Results from these models are presented in Table $4 .{ }^{11}$

Our results fail to identify a statistically significant relationship between cigarette taxes and BMI. Using OLS models we estimate a coefficient of -0.036 for cigarette taxes and -0.017 for cigarette prices. Our control variables take their expected signs. For instance we estimate a positive relationship between age and BMI. This result makes sense as we believe that in general as individual's age, they are more likely to weigh more.

Our results on the effects of cigarette price on BMI are contrary to those found by Chou et al. (2004). They find a positive effect of cigarette prices on BMI and the probability that one is obese and we fail to find a statistically significant relationship. Like Gruber and Frakes (2006) we find a negative relationship between cigarette taxes and BMI, again however our results are statistically insignificant.

\footnotetext{
${ }^{11}$ In this section we examine cigarette price and tax independently. In the following sections we include them in regressions together as control variables.
} 
The effects smoking bans on the probability that one is a smoker

$$
P(\text { Smoker })_{i j t}=\alpha+\beta_{1} B A N_{j t}+\beta_{2} X_{i j t}+\beta_{3} Z_{j t}+\tau_{j}+\gamma_{t}+\varepsilon_{i j t}
$$

In this section we examine the effects of smoking bans on the probability that one is a smoker. We analyze four different types of smoking bans in our analysis: private establishment bans, bar bans, government office bans, and restaurant bans. Based on results from Evans et al. (1996) who found that workplace smoking bans reduce smoking prevalence and average daily cigarette consumption, we believe that smoking bans will reduce the likelihood that one is a smoker. Using a Logit specification with state-clustered standard errors we examine each of the four types of bans individually and also all four at the same time. Also, we examine the effect of the effect of smoking bans on smoker status for current, former and never smokers. In our sample 22 percent of individuals are current smokers.

Shown below in Table 5 are our results from this section of our analysis. We estimate marginal effects of $-0.004,-0.003,0.001$, and -0.003 for bar, private, government and restaurant bans respectively. Only the bar ban result is significant at the 5 percent level. This implies that if a bar ban is in place, an individual is 0.4 of a percentage point less likely to be a smoker relative to the sample mean of 22 percent. Since all of the other ban variables have such small, insignificant effects, we conclude that they have no effect on the likelihood that an individual is a smoker. ${ }^{12}$

\footnotetext{
12 We also estimate models with all four bans included in the regression at the same time and the results do not differ dramatically from estimating each ban individually. If a bar, private or government ban is in place, we find that individuals are $0.4,0.4$ and 0.2 percentage points less likely to be smokers relative to the sample mean. If a government ban is in place we find that individuals are 0.3 percentage points more likely to be smoker. These results are available upon request.
} 
We also perform regressions to examine the effect of smoking bans on individuals who have never smoked as a falsification test. These results are presented in Table 6 . We estimate a range of marginal effects of $-0.004-0.004$ for the four smoking bans when examined individually. None of these results are significant. This results reinforces strengthens our finding of a negative relationship between the implementation of a bar ban the likelihood that one is a smoker presented in Table 5.

Results are mixed when examining the effects of smoking bans on the probability that one is a smoker. In certain specifications smoking bans reduce the likelihood that one is a smoker, while in others, however, it should be noted that in all cases the magnitudes of the coefficients were very small. ${ }^{13}$

The effects smoking bans on BMI

$$
B M I_{i j t}=\alpha+\beta_{1} B A N_{j t}+\beta_{2} X_{i j t}+\beta_{3} Z_{j t}+\tau_{j}+\gamma_{t}+\varepsilon_{i j t}
$$

In this section we arrive at our unique contribution to the literature. We analyze the effects of smoking bans on BMI. We examine each ban individually using an OLS specification with fixed effects. Since smoking bans lower smoking prevalence and smoking cessation leads to higher levels of BMI, our primary hypothesis is that increasing the prevalence of smoking bans will lead to higher levels of BMI. Results for regressions on BMI are presented in Table 7 and Table 8.

\footnotetext{
${ }^{13}$ Finally in this section we attempt an instrumental variables analysis using an IV Probit model. We use 1975 statelevel tobacco production as an instrument to represent state cultural attitudes towards tobacco. Our instrument is significant at the 1 percent level in the first stage and we find significant coefficients for all bans in the second stage. We estimate marginal effects of $0.090,-0.079,-0.15$, and -0.16 for bans in bars, private establishments, government workplaces and restaurants respectively. However, these results are so large that we question them and have decided to omit them from discussion. These results are available upon request.
} 
Presented in Table 7 are results estimating the impact of smoking bans on BMI for our entire sample. In regressions with our fixed effects OLS model we estimate coefficients for bar, private, government, and restaurant bans of $-0.043,0.010,0.013$, and -0.006 respectively. None of these coefficients are significant leading us to believe that there is no effect on of smoking bans when we examine the whole sample ${ }^{14}$.

In Table 8 we restrict the sample to those who identify as current smokers. In regressions where the sample is limited to current smokers we estimate a positive relationship between smoking bans and BMI. We estimate coefficients of $0.065,0.052$, and 0.075 for private, government and restaurant bans respectively. These results for these three bans are significant at the 5 percent level. We estimate a coefficient of 0.021 for bar bans, however, this result is statistically insignificant. These results show that smoking bans seem to have an effect on the weight of those most likely to be affected by them, current smokers. However, there seems to be no effect on body weight on never and former smokers due to the implementation of a smoking ban.

Our control variables are robust to different specifications and do not change sign or magnitude when we run regressions on different bans. We find that as a person ages they are likely to have a higher level of BMI, although the effect is very small. Men are more likely to have higher BMI's, roughly 1/6 of a standard deviation higher than women. Those with higher incomes and a higher education level have lower BMI levels. Those who are unemployed and

\footnotetext{
${ }^{14}$ We also run regressions with all four bans in the model simultaneously. In our OLS specification we estimate coefficients of $-0.109,0.041,0.017$ and 0.042 for bar, private, government and restaurant bans respectively. These results are not discussed here, but are available upon request.
} 
those not in the labor force have lower BMI levels relative to those in the labor force. However, the effects are very small. Single and divorced individuals have lower BMI levels relative to married couples. Blacks have $1 / 3$ of a standard deviation higher BMI levels relative to whites. Hispanics have higher BMI levels relative to whites. The majority of our results are significant at the 99 percent level. ${ }^{15}$

\subsection{Conclusion}

In this paper we attempt to examine the effect of clean indoor air legislation on an individual's BMI. In an exploratory analysis, with our data we are able to produce similar results to the previous literature. In particular, our data and model indicate that smoking cessation leads to higher levels of weight gain, just as with U.S. Surgeon General (1990), Caan et al. (1996), Mizoue et al (1998), and Pinkowish (1999). In our analysis of cigarette prices our results differ from those of Chou et al. (2004). Chou et al. find a positive relationship between cigarette prices and BMI while we find that cigarette prices have little to no effect. We find similar results to Gruber and Frakes (2006) we analyze the effects of cigarette taxes on BMI, namely we find a negative relationship between cigarette taxes and $\mathrm{BMI}$ and the probability that one is obese. We also find that the implementation of smoking bans lowers the probability that one is a smoker in cases where a bar ban has been enacted, however, this result is very small. When we apply these data to the new question of how smoking bans relate to weight gain, our results are

\footnotetext{
${ }^{15}$ To conclude our analysis of the potential unintended consequences of smoking ban legislation, we also estimate the effects of smoking bans on BMI and the probability that an individual is obese using a Two-State Least Squares and IV-Probit model specification using state-level tobacco production in 1975 as an instrument for state tobacco culture. We have decided not to present these results here, however, they are available upon request.
} 
unable to confirm that the hypothesis that smoking bans could have the perverse effect of increasing weight gain or obesity. We do find a positive and statistically significant relationship between smoking bans and weight gain when we limit the sample to those who identify as current smokers, however, the statistical significance of this result disappears when we examine the effect of smoking bans on the entire sample.

In the future we would like to pursue this topic further. Future analyses would seek to implement better controls for unobserved heterogeneity across states. Also future work could perhaps be strengthened by modifying our smoking ban variables. Implementing data on smoking bans at the local or county level would be a great start. 


\subsection{Tables and Figures}

Figure 1: Smoking ban proliferation

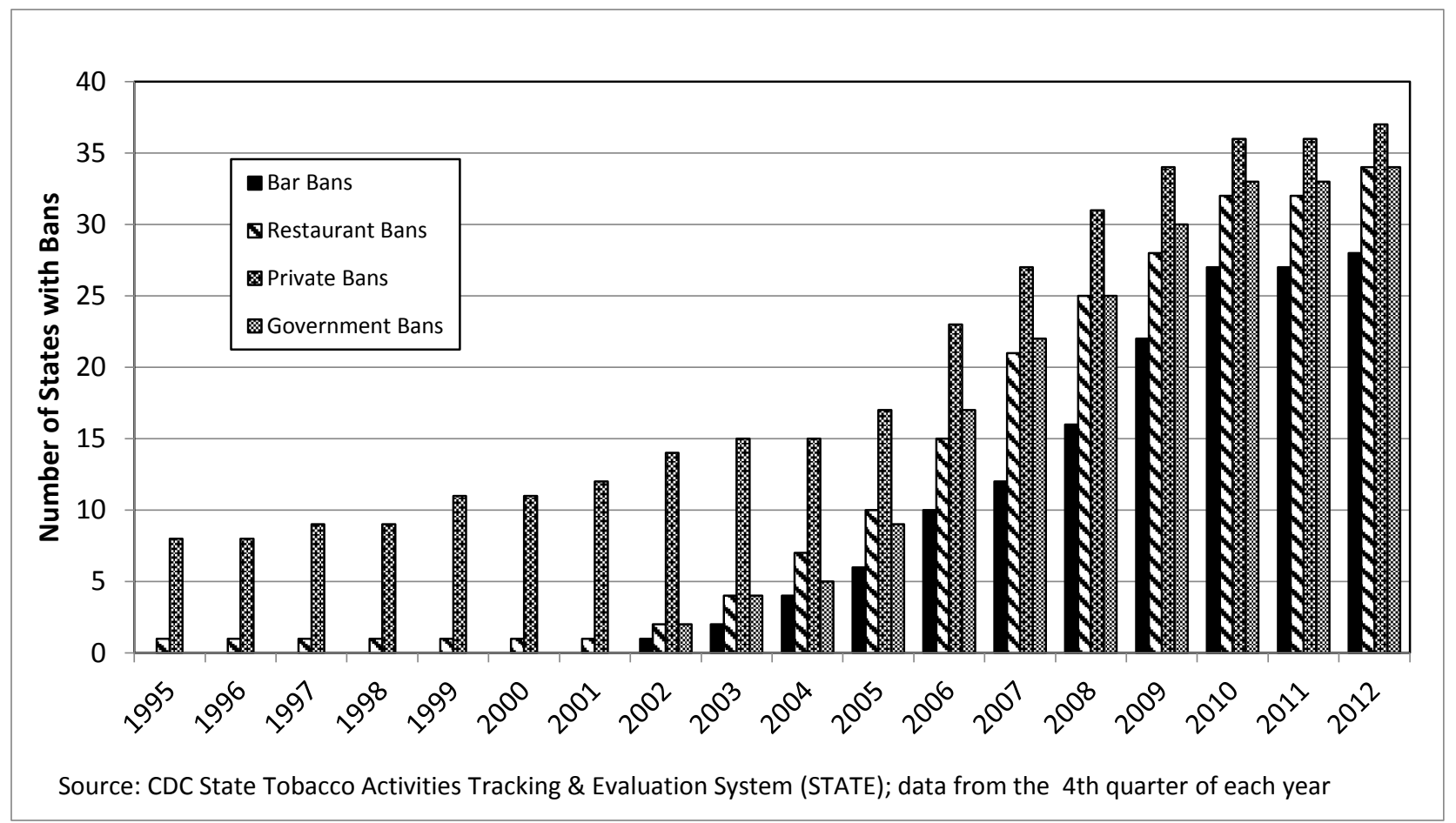


Table 1: Total sample summary statistics

\begin{tabular}{|c|c|}
\hline $\mathrm{BMI}$ & $27.20(0.003)$ \\
\hline Obese & $0.26(0.0003)$ \\
\hline Age & $46.35(0.007)$ \\
\hline Exercise Past Month & $0.77(0.0002)$ \\
\hline Single & $0.13(0.0002)$ \\
\hline Married & $0.62(0.0003)$ \\
\hline Divorced & $0.16(0.0002)$ \\
\hline Widowed & $0.039(0.0001)$ \\
\hline Separated & $0.028(0.0001)$ \\
\hline Unmarried Couple & $0.027(0.0001)$ \\
\hline Less than High School & $0.020(0.00008)$ \\
\hline Some High School & $0.050(0.0001)$ \\
\hline High School Grad & $0.27(0.0003)$ \\
\hline Some College & $0.28(0.0001)$ \\
\hline College Grad & $0.38(0.0003)$ \\
\hline White & $0.80(0.0002)$ \\
\hline Black & $0.083(0.0002)$ \\
\hline Hispanic & $0.063(0.0001)$ \\
\hline Asian/Pacific Islander & $0.039(0.0001)$ \\
\hline Other Race & $0.074(0.0001)$ \\
\hline Male & $0.42(0.0003)$ \\
\hline Employed & $0.72(0.0003)$ \\
\hline Unemployed & $0.054(0.0001)$ \\
\hline Not in Labor Force & $0.22(0.0002)$ \\
\hline Income & $5.85(0.0012)$ \\
\hline Bar Ban & $0.27(0.0003)$ \\
\hline Restaurant Ban & $0.35(0.0003)$ \\
\hline Government Ban & $0.50(0.0003)$ \\
\hline Private Ban & $0.36(0.0003)$ \\
\hline Cigarette Tax & $1.10(0.0005)$ \\
\hline Raw Cigarette Price & $3.49(0.0005)$ \\
\hline Unemployment Rate & $5.92(0.001)$ \\
\hline Smoker & $0.22(0.0002)$ \\
\hline Former Smoker & $0.25(0.0003)$ \\
\hline Never Smoker & $0.53(0.0003)$ \\
\hline Sample Size & $3,066,984$ \\
\hline
\end{tabular}


Table 2: Selected years summary statistics

\begin{tabular}{|c|c|c|}
\hline & 1995 & 2012 \\
\hline BMI & $25.80(0.02)$ & $27.79(0.01)$ \\
\hline Obese & $0.16(0.001)$ & $0.30(0.0009)$ \\
\hline Age & $42.06(0.04)$ & $48.50(0.03)$ \\
\hline Exercise Past Month & $0.73(0.003)$ & $0.79(0.001)$ \\
\hline Single & $0.14(0.001)$ & $0.14(0.0007)$ \\
\hline Married & $0.63(0.002)$ & $0.60(0.001)$ \\
\hline Divorced & $0.16(0.001)$ & $0.016(0.0007)$ \\
\hline Widowed & $0.034(0.0005)$ & $0.041(0.0003)$ \\
\hline Separated & $0.030(0.0005)$ & $0.027(0.0003)$ \\
\hline Unmarried Couple & $0.022(0.0005)$ & $0.031(0.0003)$ \\
\hline Less than High School & $0.034(0.0005)$ & $0.016(0.003)$ \\
\hline Some High School & $0.061(0.0008)$ & $0.046(0.004)$ \\
\hline High School Grad & $0.32(0.002)$ & $0.26(0.0009)$ \\
\hline Some College & $0.28(0.001)$ & $0.28(0.0009)$ \\
\hline College Grad & $0.31(0.002)$ & $0.40(0.001)$ \\
\hline White & $0.86(0.001)$ & $0.74(0.0008)$ \\
\hline Black & $0.086(0.0009)$ & $0.091(0.0006)$ \\
\hline Hispanic & 0.055 (0.0007) & $0.066(0.0005)$ \\
\hline Asian/Pacific Islander & $0.014(0.0005)$ & $0.046(0.0004)$ \\
\hline Other Race & $0.034(0.0004)$ & $0.086(0.0006)$ \\
\hline Male & $0.45(0.002)$ & $0.44(0.001)$ \\
\hline Employed & $0.77(0.001)$ & 0.68 (0.0009) \\
\hline Unemployed & $0.039(0.0006)$ & $0.068(0.0005)$ \\
\hline Not in Labor Force & $0.19(0.001)$ & $0.25(0.0008)$ \\
\hline Income & $5.45(0.006)$ & $5.97(0.004)$ \\
\hline Bar Ban & 0 & $0.59(0.0009)$ \\
\hline Restaurant Ban & $0.026(0.0005)$ & $0.68(0.0009)$ \\
\hline Government Ban & $0.20(0.001)$ & $0.75(0.0008)$ \\
\hline Private Ban & 0 & $0.70(0.0009)$ \\
\hline Cigarette Tax & $0.47(0.0008)$ & $1.49(0.002)$ \\
\hline Raw Cigarette Price & $1.97(0.0003)$ & $4.48(0.0007)$ \\
\hline Unemployment Rate & $5.12(0.003)$ & $7.30(0.003)$ \\
\hline Smoker & $0.26(0.001)$ & $0.20(0.0008)$ \\
\hline Former Smoker & $0.23(0.001)$ & $0.26(0.0008)$ \\
\hline Never Smoker & $0.50(0.002)$ & $0.54(0.001)$ \\
\hline Sample Size & 71,748 & 252,165 \\
\hline
\end{tabular}


Table 3: Smoker Status and Weight Gain

\begin{tabular}{lc}
\hline & Results from OLS Regressions \\
\hline Smoker & Dependent Variable: BMI \\
Former Smoker & $-1.251(0.047)^{* *}$ \\
\hline Exercise Past Month & $0.250(0.017)^{* *}$ \\
Age & $-1.150(0.024)^{* *}$ \\
Gender (Male=1) & $0.035(0.001)^{* *}$ \\
Income & $1.169(0.037)^{* *}$ \\
Less than High School & $-0.154(0.007)^{* *}$ \\
Some High School & $1.052(0.062)^{* *}$ \\
High School Grad & $1.184(0.042)^{* *}$ \\
Some College & $1.025(0.037)^{* *}$ \\
Unemployed & $1.035(0.027)^{* *}$ \\
Not in Labor Force & $0.025(0.022)$ \\
Single & $-0.104(0.023)^{* *}$ \\
Divorced & $0.141(0.029)^{* *}$ \\
Widowed & $-0.243(0.023)^{* *}$ \\
Unmarried Couple & $-0.010(0.025)$ \\
Black & $-0.089(0.029)^{* *}$ \\
Hispanic & $1.726(0.065)^{* *}$ \\
Asian/Pacific Islander & $-0.184(0.156)$ \\
Other Race & $-0.412(0.195)^{*}$ \\
\hline
\end{tabular}

Note: Standard errors in parentheses. ${ }^{* *}$ results are significant at the $1 \%$ level and * are significant at the $5 \%$ level. State, month and year fixed effects employed in all regressions. All regressions use state-clustered standard errors. Only those age 25-65 included in regressions. 
Table 4: Cigarette Taxes and Cigarette Prices on BMI

\begin{tabular}{lcc}
\hline & \multicolumn{2}{c}{ Results from OLS Regressions } \\
\hline Cigarette Taxes & BMI (Cig Taxes) & BMI (Cig Prices) \\
Raw Cigarette Prices & $-0.036(0.025)$ & - \\
\hline Exercise Past Month & $-1.056(0.024)^{* *}$ & $-1.056(0.024)^{* *}$ \\
Age & $0.040(0.001)^{* *}$ & $0.040(0.001)^{* *}$ \\
Gender (Male=1) & $1.146(0.039)^{* *}$ & $1.146(0.039)^{* *}$ \\
Income & $-0.123(0.007)^{* *}$ & $-0.123(0.007)^{* *}$ \\
Less than High School & $0.895(0.072)^{* *}$ & $0.895(0.072)^{* *}$ \\
Some High School & $0.875(0.052)^{* *}$ & $0.875(0.052)^{* *}$ \\
High School Grad & $0.854(0.041)^{* *}$ & $0.854(0.041)^{* *}$ \\
Some College & $0.920(0.029)^{* *}$ & $0.920(0.029)^{* *}$ \\
Unemployed & $-0.063(0.025)^{*}$ & $-0.063(0.025)^{*}$ \\
Not in Labor Force & $-0.101(0.022)^{* *}$ & $-0.101(0.022)^{* *}$ \\
Single & $0.082(0.029)^{* *}$ & $0.082(0.029)^{* *}$ \\
Divorced & $-0.373(0.028)^{* *}$ & $-0.373(0.028)^{* *}$ \\
Widowed & $-0.070(0.026)^{* *}$ & $-0.070(0.026)^{* *}$ \\
Unmarried Couple & $-0.230(0.031)^{* *}$ & $-0.230(0.031)^{* *}$ \\
Black & $1.799(0.065)^{* *}$ & $1.800(0.065)^{* *}$ \\
Hispanic & $-0.008(0.160)$ & $-0.009(0.160)$ \\
Asian/Pacific Islander & $-0.414(0.184)^{*}$ & $-0.414(0.184)^{*}$ \\
Other Race & $0.688(0.153)^{* *}$ & $0.688(0.153)^{* *}$ \\
\hline Note Standard errors in par & &
\end{tabular}

Note: Standard errors in parentheses. ${ }^{* *}$ results are significant at the $1 \%$ level and * are significant at the $5 \%$ level. State, month and year fixed effects employed in all regressions. All regressions use state-clustered standard errors. Only those age 25-65 included in regressions. Cigarette taxes and raw cigarette prices have been adjusted for inflation, presented here in 2013 dollars. 
Table 5: Impact of Smoking Bans on the Probability That One is a Smoker: Results from Logit Regressions

\begin{tabular}{|c|c|c|c|c|}
\hline$P($ smoker $)=0.22$ & $\mathrm{P}$ (smoker) (Bar) & P(smoker) (Priv) & $\mathrm{P}$ (smoker) (Govt) & $\mathrm{P}$ (smoker) (Rest) \\
\hline Bar Ban & $-0.004(0.002)^{*}$ & - & - & - \\
\hline Private Ban & - & $-0.003(0.002)$ & - & - \\
\hline Government Ban & - & - & $0.001(0.002)$ & - \\
\hline Restaurant Ban & - & - & - & $-0.003(0.002)$ \\
\hline Exercise Past Month & $-0.065(0.001)^{* *}$ & $-0.065(0.001)^{* *}$ & $-0.065(0.001)^{* *}$ & $-0.065(0.001)^{* *}$ \\
\hline Age & $-0.003(0.000)^{* *}$ & $-0.003(0.000)^{* *}$ & $-0.003(0.000)^{* *}$ & $-0.003(0.000)^{* *}$ \\
\hline Gender (Male=1) & $0.030(0.002)^{* *}$ & $0.030(0.002)^{* *}$ & $0.030(0.002)^{* *}$ & $0.030(0.002)^{* *}$ \\
\hline Income & $-0.021(0.000)^{* *}$ & $-0.021(0.000)^{* *}$ & $-0.021(0.000)^{* *}$ & $-0.021(0.000)^{* *}$ \\
\hline Less than High School & $0.189(0.008)^{* *}$ & $0.189(0.008)^{* *}$ & $0.189(0.008)^{* *}$ & $0.189(0.008)^{* *}$ \\
\hline Some High School & $0.313(0.007)^{* *}$ & $0.313(0.007)^{* *}$ & $0.313(0.007)^{* *}$ & $0.313(0.007)^{* *}$ \\
\hline High School Grad & $0.180(0.004)^{* *}$ & $0.180(0.004)^{* *}$ & $0.180(0.004)^{* *}$ & $0.180(0.004)^{* *}$ \\
\hline Some College & $0.138(0.002)^{* *}$ & $0.138(0.002)^{* *}$ & $0.138(0.002)^{* *}$ & $0.138(0.002)^{* *}$ \\
\hline Unemployed & $0.062(0.002)^{* *}$ & $0.062(0.002)^{* *}$ & $0.062(0.002)^{* *}$ & $0.062(0.002)^{* *}$ \\
\hline Not in Labor Force & $0.001(0.001)$ & $0.001(0.001)$ & $0.001(0.001)$ & $0.001(0.001)$ \\
\hline Single & $0.047(0.003)^{* *}$ & $0.047(0.003)^{* *}$ & $0.047(0.003)^{* *}$ & $0.047(0.003)^{* *}$ \\
\hline Divorced & $0.106(0.003)^{* *}$ & $0.106(0.003)^{* *}$ & $0.106(0.003)^{* *}$ & $0.106(0.003)^{* *}$ \\
\hline Widowed & $0.069(0.003)^{* *}$ & $0.069(0.003)^{* *}$ & $0.069(0.003)^{* *}$ & $0.069(0.003)^{* *}$ \\
\hline Unmarried Couple & $0.130(0.005)^{* *}$ & $0.130(0.005)^{* *}$ & $0.130(0.005)^{* *}$ & $0.130(0.005)^{* *}$ \\
\hline Black & $-0.061(0.006)^{* *}$ & $-0.061(0.006)^{* *}$ & $-0.061(0.006)^{* *}$ & $-0.061(0.006)^{* *}$ \\
\hline Hispanic & $-0.108(0.005)^{* *}$ & $-0.108(0.005)^{* *}$ & $-0.108(0.005)^{* *}$ & $-0.108(0.005)^{* *}$ \\
\hline Asian/Pacific Islander & $-0.008(0.011)$ & $-0.008(0.011)$ & $-0.008(0.011)$ & $-0.008(0.011)$ \\
\hline Other Race & $0.026(0.004)^{* *}$ & $0.026(0.004)^{* *}$ & $0.026(0.004)^{* *}$ & $0.026(0.004)^{* *}$ \\
\hline Cigarette Tax & $-0.006(0.001)^{* *}$ & $-0.006(0.001)^{* *}$ & $-0.006(0.001)^{* *}$ & $-0.006(0.001)^{* *}$ \\
\hline Cigarette Price & $-0.001(0.001)$ & $-0.001(0.001)$ & $-0.001(0.001)$ & $-0.001(0.001)$ \\
\hline Unemployment Rate & $-0.002(0.001)^{* *}$ & $-0.003(0.001)^{* *}$ & $-0.002(0.001)^{* *}$ & $-0.002(0.001)^{* *}$ \\
\hline
\end{tabular}

Note: Standard errors in parentheses. These marginal effects are calculated with a standard Logit model with state-clustered standard errors. ${ }^{* *}$ results are significant at the $1 \%$ level and * are significant at the $5 \%$ level. State, month and year fixed effects employed in all regressions. Only those age 25-65 are included in regressions. 
Table 6: Falsification Tests: Impact of Smoking Bans on Never Smokers

\begin{tabular}{lcccc}
\hline $\mathrm{P}($ neversmoker) $=0.53$ & $\mathrm{P}($ never) (Bar) & $\mathrm{P}$ (never) (Priv) & $\mathrm{P}$ (never) (Govt) & $\mathrm{P}$ (never) (Rest) \\
\hline Bar Ban & $0.004(0.003)$ & - & - & - \\
Private Ban & - & $0.004(0.003)$ & - & - \\
Government Ban & - & - & $-0.003(0.003)$ & - \\
Restaurant Ban & - & - & - & $0.002(0.003)$
\end{tabular}

Note: This table presents falsification tests examining the effects of smoking bans on individuals who have never smoked and individuals who have formerly smoked. Control variables are not reported here but are available upon request. Standard errors in parentheses. These marginal effects are calculated with a standard Logit model with state-clustered standard errors. ${ }^{* *}$ results are significant at the $1 \%$ level and * are significant at the $5 \%$ level. State, month and year fixed effects employed in all regressions. Only those age 25-65 are included in regressions.

Table 7: Impact of smoking bans on BMI: Results from OLS Regressions

\begin{tabular}{|c|c|c|c|c|}
\hline & BMI (Bar) & BMI (Priv) & BMI (Govt) & BMI (Rest) \\
\hline Bar Ban & $-0.043(0.030)$ & - & - & - \\
\hline Private Ban & - & $0.010(0.026)$ & - & - \\
\hline Government Ban & - & - & $0.013(0.032)$ & - \\
\hline Restaurant Ban & - & - & - & $-0.006(0.028)$ \\
\hline Exercise Past Month & $-1.056(0.024) * *$ & $-1.056(0.024) * *$ & $-1.056(0.024) * *$ & $-1.056(0.024)^{* *}$ \\
\hline Age & $0.040(0.001)^{* *}$ & $0.040(0.001)^{* *}$ & $0.040(0.001)^{* *}$ & $0.040(0.001)^{* *}$ \\
\hline Gender (Male=1) & $1.146(0.038)^{* *}$ & $1.146(0.038)^{* *}$ & $1.146(0.038)^{* *}$ & $1.146(0.038)^{* *}$ \\
\hline Income & $-0.123(0.007)^{* *}$ & $-0.123(0.007)^{* *}$ & $-0.123(0.007)^{* *}$ & $-0.123(0.007)^{* *}$ \\
\hline Less than High School & $0.895(0.072)^{* *}$ & $0.895(0.072)^{* *}$ & $0.895(0.072)^{* *}$ & $0.895(0.072)^{* *}$ \\
\hline Some High School & $0.875(0.052)^{* *}$ & $0.875(0.052)^{* *}$ & $0.875(0.052)^{* *}$ & $0.875(0.052)^{* *}$ \\
\hline High School Grad & $0.854(0.040)^{* *}$ & $0.854(0.040)^{* *}$ & $0.854(0.040)^{* *}$ & $0.854(0.040)^{* *}$ \\
\hline Some College & $0.920(0.029)^{* *}$ & $0.920(0.029)^{* *}$ & $0.920(0.029)^{* *}$ & $0.920(0.029)^{* *}$ \\
\hline Unemployed & $-0.077(0.025)^{*}$ & $-0.063(0.025)^{*}$ & $-0.063(0.025)^{*}$ & $-0.063(0.025)^{*}$ \\
\hline Not in Labor Force & $-0.101(0.022)^{* *}$ & $-0.101(0.022)^{* *}$ & $-0.101(0.022)^{* *}$ & $-0.101(0.022)^{* *}$ \\
\hline Single & $0.082(0.029)^{* *}$ & $0.082(0.029)^{* *}$ & $0.082(0.029)^{* *}$ & $0.082(0.029)^{* *}$ \\
\hline Divorced & $-0.373(0.028)^{* *}$ & $-0.373(0.028)^{* *}$ & $-0.373(0.028)^{* *}$ & $-0.373(0.028)^{* *}$ \\
\hline Widowed & $-0.070(0.026)$ & $-0.070(0.026)$ & $-0.070(0.026)$ & $-0.070(0.026)$ \\
\hline Unmarried Couple & $-0.230(0.031)^{* *}$ & $-0.230(0.031)^{* *}$ & $-0.230(0.031)^{* *}$ & $-0.230(0.031)^{* *}$ \\
\hline Black & $1.799(0.066)^{* *}$ & $1.799(0.066)^{* *}$ & $1.799(0.066)^{* *}$ & $1.799(0.066)^{* *}$ \\
\hline Hispanic & $0.009(0.180)$ & $0.008(0.180)$ & $0.008(0.180)$ & $0.008(0.180)$ \\
\hline Asian/Pacific Islander & $-0.414(0.190)^{*}$ & $-0.414(0.190)^{*}$ & $-0.414(0.190)^{*}$ & $-0.414(0.190)^{*}$ \\
\hline Other Race & $0.688(0.175)^{* *}$ & $0.688(0.175)^{* *}$ & $0.688(0.175)^{* *}$ & $0.688(0.175)^{* *}$ \\
\hline Cigarette Tax & $-0.034(0.027)$ & $-0.041(0.027)$ & $-0.040(0.027)$ & $-0.040(0.027)$ \\
\hline Cigarette Price & $-0.020(0.014)$ & $-0.027(0.014)$ & $-0.027(0.014)$ & $-0.026(0.014)$ \\
\hline Unemployment Rate & $-0.006(0.013)$ & $-0.002(0.013)$ & $-0.003(0.013)$ & $-0.004(0.013)$ \\
\hline
\end{tabular}


Table 8: Impact of Smoking Bans on BMI. Limit Sample to Current Smokers

\begin{tabular}{lcccc}
\hline Current Smoker & BMI (Bar) & BMI (Priv) & BMI (Govt) & BMI (Rest) \\
\hline Bar Ban & $0.021(0.034)$ & - & - & - \\
Private Ban & - & $0.065(0.029)^{*}$ & - & - \\
Government Ban & - & - & $0.052(0.029)^{*}$ & - \\
Restaurant Ban & - & - & - & $0.075(0.032)^{*}$ \\
\hline
\end{tabular}

Note: This sample is limited to individuals who currently smoke. Control variables are not reported here but are available upon request. Standard errors in parentheses. These marginal effects are calculated with a standard Logit model with state-clustered standard errors. ${ }^{* *}$ results are significant at the $1 \%$ level and * are significant at the $5 \%$ level. State, month and year fixed effects employed in all regressions. Only those age 25-65 are included in regressions. 


\section{3. "How does WIC Affect Health Outcomes? A Fuzzy Regression Discontinuity Approach." with Tami Gurley-Calvez and Brian Hill}

\subsection{Introduction}

Early life health outcomes are important determinants of long-term health, education, and labor market outcomes. Low birth weight has significant long-term effects on self-reported health status as well as educational and labor market outcomes (Currie and Hyson, 1999). Preterm birth has been associated with increased rates of mortality in early childhood and young adulthood and greater risk of later adult chronic medical conditions such as hypertension, heart disease, and diabetes (Crump et al., 2011; Goldenberg and Culhane, 2007). Breastfeeding in infancy may protect against poor mental well-being and obesity in childhood and there is strong evidence that prolonged and exclusive breast feeding leads to gains in children's cognitive development (Reynolds, Hennessy and Polek, 2014; Kramer et al., 2008). ${ }^{16}$

Many early health problems are often associated with infants of lower-income mothers (Kramer et al., 2000; Currie and Moretti, 2007; Larson, 2007). As seen in Table 9 below, lower income mothers (as defined as being eligible for the Special Supplemental Nutrition Program for Women, Infants, and Children (WIC) in our sample) typically have babies with lower birth weight, are more likely to have pre-mature births, are less likely to breastfeed, and are more likely to be obese pre-pregnancy.

Researchers have associated these birth outcomes with food sufficiency and nutrition (e.g. Fowles, 2004; Abu-Saad and Fraser, 2010). Given what we know about the importance of

\footnotetext{
${ }^{16}$ Several papers in medical journals exist on this topic with similar findings. See Bernard et al. (2013), Quigley et al. (2009), or Holme, MacArthur and Lancashire (2010) for more information.
} 
early life health and its relationship to income, policy makers have sought out ways to provide income support, but in a way that also promotes health. One program that serves lower income families is the Special Supplemental Nutrition Program for Women, Infants, and Children (WIC), which is designed to support low-income woman and children who are at risk of adverse nutrition outcomes.

Generally, program participants are eligible for education programs and nutrition credits to be spent on a list of very specific nutritional foods. Specifically, WIC is designed to provide food supplements to low-income (those with income below $185 \%$ of the federal poverty line (FPL)) pregnant and lactating women, infants, and children under the age of five. Eligible food items include juice, milk, cereal, cheese, eggs, fruits and vegetables, whole wheat bread, fish, legumes, infant formula and cereal, and baby food. ${ }^{17}$ In addition to the restrictions on types of foods that may be purchased, there are generally limits on the maximum monthly purchase within a category. Bitler, Currie, and Scholz (2003) estimate that 73.2 percent of eligible households receive WIC benefits. Total enrollment in the WIC program was about 9 million in 2011..$^{18}$

The WIC program also has the potential to alter total food spending as well as the nutritional composition of purchases for eligible households. In addition, the WIC program might also provide stronger "signals" about nutrition for new and expecting mothers and their children as the program targets a few specific food items. Cole and Fox (2008b) find that WIC participants had diets with higher nutrition density but similar Healthy Eating Index scores

\footnotetext{
${ }^{17}$ See http://www.fns.usda.gov/wic/ for more specific details on how participants receive WIC funds and what food purchases are allowed across states.

${ }^{18}$ U.S. Department of Agriculture. "WIC Program and Participation Rates" accessed November 5, 2012: http://www.fns.usda.gov/pd/wisummary.htm.
} 
when compared to income eligible non-participants. Program participation might affect our near-birth maternal and infant health outcomes of interest.

A common issue in program evaluation is the difficulty in identifying causal relationships between program participation and outcomes. The goal of this research is to utilize a fuzzy regression discontinuity $(\mathrm{RD})$ approach to estimate a causal relationship between WIC participation and a variety of infant and maternal outcomes. Using this strategy we believe we will be identifying the causal effects of WIC participation by examining mothers with similar characteristics and income levels who only differ in their assistance program participation. Results indicate that WIC participation decreases the likelihood of premature birth, reduces the likelihood of breast feeding and decreases maternal weight gain during pregnancy. These results are robust to alternative fuzzy $\mathrm{RD}$ specifications and falsification tests. We fail to reject the null of no effect of WIC on birth weight and probability of low birth weight.

\subsection{Literature}

As described in Fox, Hamilton, and Lin (2004), much of the early work on WIC participation found a positive impact on a broad array of birth outcomes, including birth weight. In order to infer causality from program evaluation studies, it is important to recognize that non-random selection into the program creates standard selection bias problems. ${ }^{19}$ Recent studies have set out to address the selection bias problem using instrumental variable methods. Studies using these techniques have produced less consistent findings with respect to the effectiveness of WIC. Brien and Swann (2001) and Chatterji, et al. (2002) use state variation in WIC rules and individual-specific fixed effects as instrumental variables for WIC participation in

\footnotetext{
${ }^{19}$ For an example of the criticism of some of WIC literature because of selection bias problems, see Besharov and Germanis (2001).
} 
an attempt to address the selection bias problem. Brien and Swann (2001) find that the positive impact of WIC on birth weight is sensitive to the race of the mother. Chatterji, et al. (2002) find that WIC negatively affects the probability of breastfeeding. In general, studies which use instrumental variables report results that are not as consistent as the earlier studies and suffer from limitations caused by weak instruments.

As described in Bitler and Currie (2005), reliance on state-level WIC regulation variations may be poor instruments. In an attempt to resolve this issue, some recent studies utilize narrowly defined sets of treatment and control groups to infer causality. Bitler and Currie (2005) use data from the Pregnancy Risk Assessment Monitoring System (PRAMS). They focus on a subset of women who used Medicaid to pay for deliveries as this allows them to focus on treatment and control groups with similar income levels. Bitler and Currie (2005) then examine differences in birth outcomes for WIC participants and non-participants within this Medicaid subset, and find that WIC participation leads to earlier prenatal care and lower probabilities of giving birth to low weight infants. Finally, Bitler and Currie (2005) show that OLS estimates of narrowly defined treatment and control groups lead to better estimates than IV estimates with state-level variation in programs as instruments.

Filgio, Hammersma, and Roth (2009), use Florida birth certificate data for a subset of marginally eligible and marginally ineligible individuals. They then use changes in documentation requirements as an instrument for WIC participation and find that WIC participation has no effect on mean birth weight, but it does reduce the probability of very low birth weight. Hoynes, Page and Stevens (2011) take advantage of the WIC "rollout" across counties during the 1970 s. They compare infant health in counties that have recently adopted WIC with infant health in counties that have not adopted WIC and find that WIC participation is 
associated with higher average birth weights (18 to 29 grams) and lower likelihood of very low birth weights.

Kreider, Pepper and Roy $(2012,2014)$ address the issue that survey respondents often report their WIC participation incorrectly. Using comparisons of administrative and survey data, they estimate that as many as one in three survey respondents incorrectly report their WIC participation, with some misreporting their duration of program use while others omit participation entirely. Utilizing nonparametric partial identification methodologies to account for misreporting, they find that WIC participation reduces the prevalence of child food insecurity by at least 5.5 percentage points and modestly increases the probability of normal birth weight. An important finding of their work is that if participation is accurately reported, WIC appears to improve birth outcomes, however it is difficult to put a sign on the effect of WIC when there is uncertainty with the level of program participation.

We utilize another estimation tool to identify program effects, regression discontinuity (RD). ${ }^{20}$ Because WIC is a means-tested program, it is possible to examine differences in outcomes for those who are on either side of the income eligibility threshold, assuming that the probability of enrolling in the program changes once individuals clear the program's threshold. Our proposed research addresses the possibility of misreporting as the coefficient estimates are calculated only on 'compliers' or those for whom the eligibility threshold affects WIC participation. ${ }^{21}$

\footnotetext{
${ }^{20}$ See Meyerhoefer and Yang (2011) for more discussion on empirical studies that employ regression discontinuity methods.

${ }^{21}$ Angrist, Joshua David, and Jörn Pischke. "4.4.4 Counting and Characterizing Compliers." Mostly harmless econometrics: an empiricist's companion. Princeton: Princeton University Press, 2009. p. 123-129.
} 
The approach is similar to that used by Figlio, Hamersma, and Roth (2009) who restrict their administrative data to families near the WIC eligibility threshold. However, that study is limited to new mothers with at least one school-age child eligible for the National School Lunch Program (NSLP). Schanzenbach (2009) uses RD methods to examine a nutrition-related question, the effect of participation in the National School Lunch Program (NSLP) on obesity. Comparing students just above the eligibility threshold (family income less than $185 \%$ of poverty) to those just below the eligibility threshold, Schanzenbach (2009) finds that those just below (income eligible) are more likely to be obese.

\subsection{Data}

To examine the causal effect of WIC participation on health outcomes, we utilize the Centers for Disease Control and Prevention (CDC) Pregnancy Risk Assessment Monitoring System (PRAMS) data covering the period 2004-2010.22 PRAMS data are collected with the goal of improving the health of mothers and children. Participating states utilize a standardized system for collecting data for a core questionnaire developed by the CDC. States may also ask standard questions developed by the CDC in addition to questions developed by the individual state. PRAMS data currently cover 40 states and New York City. Historical data exist for six additional states including California. In addition to data collected from the questionnaire, select data elements are available from birth certificates.

Of particular interest for our analysis, PRAMS data include information about birth outcomes, including birth weight and weeks of gestation, breast feeding, and maternal BMI and

\footnotetext{
${ }^{22}$ Although PRAMS data are available as early as 1988, we limit our analysis to years in which income information is available.
} 
weight gain. The survey also asks about household income $e^{23}$ and the number of individuals who depend on that income, which we use to calculate eligibility for WIC. Specifically, for each survey respondent we compute the maximum income level to qualify for WIC based on the number of people dependent on the reported income. We then create a ratio of WIC eligibility to reported income that increases as households move further under the maximum allowable income. We subtract one so that the ratio is zero for households that are at the eligibility threshold, less than zero for those with incomes over the threshold and greater than zero for those under the threshold. Table 9 and Table 10 provide summary statistics. Table 9 presents an overview from our entire sample of the health outcomes we examine in this paper. Mothers who are eligible for WIC have slightly higher probabilities of having a premature and low birth weight child than mothers who are not eligible for WIC. Children born to WIC eligible mothers tend to have lower birth weights than mothers who are ineligible. WIC eligible mothers are less likely to breast feed their child and if they do breast feed, they breastfeed for a shorter duration than WIC eligible mothers. Finally WIC eligible mothers tend to have higher pre-pregnancy BMI levels than ineligible mothers, however they tend to gain less weight during pregnancy.

In Table 10 we present summary statistics of WIC eligible and WIC ineligible mothers near the income eligibility cutoff for enrollment in the WIC program. As described below, it is important that there are no discontinuities in covariates among individuals who are on either side of the eligibility cutoff. As seen in the table, mothers on either side of the income eligibility cut off have very similar characteristics. The majority of mothers fall into the age group 20-34. Roughly 72 percent of WIC eligible and WIC ineligible mothers are between the ages of 20-34.

\footnotetext{
${ }^{23}$ Income available beginning in 2004 and is reported in up to 18 categorical ranges. We utilize the upper income threshold of the range to calculate eligibility and assign a missing value to the eligibility variable if the income cutoff.
} 
Mothers age 35 and up make up roughly 26 percent of our sample and roughly 1 percent of our sample are teen mothers among WIC eligible and WIC ineligible mothers. Non-Hispanic white mothers make up the majority of our sample at roughly 76 percent and Non-Hispanic blacks make up 6 percent of the sample among both eligibility categories. Six percent of WIC ineligible mothers are Hispanic and 5 percent of WIC eligible mothers are Hispanic. Mothers from other races make up 12 percent of WIC ineligible mothers and 14 percent of WIC eligible mothers. In our sample, education levels near the income cutoff are similar among WIC eligible and WIC ineligible mothers. Roughly 62 percent of mothers in our restricted sample have a college degree, 22 percent have taken some college courses, 13 percent have a high school diploma and roughly 2 percent did not finish high school.

In terms of covariates, we only reject the null of no differences between the two groups for the Hispanic and other race categories. For outcome measures, we reject the null that the values are the same for premature birth, probability of low birth weight, and ever breastfeeding. WIC eligible mothers are less likely to have a premature birth and low birth weight baby and are more likely to ever breastfeed.

\subsection{Empirical Strategy}

As described above, non-random selection into the program creates standard selection bias problems as it is likely that unobservable characteristics might affect both WIC participation and birth outcomes. In this research, we exploit the WIC eligibility threshold to identify the potential effects of the program on birth-related outcomes by using regression discontinuity (RD) methods. As described in Angrist and Pischke (2009), fuzzy RD methods are appropriate for identification when WIC eligibility is a discontinuous function of income. 
For a sharp RD design to be appropriate, participation in the program (treatment) is deterministically determined by the fact that the income ratio (assignment variable) is above or below the eligibility threshold. As described in Lee and Lemieux (2010), it is important that individuals are not manipulating the income ratio in order to fall on the "correct" side of the eligibility threshold. As seen in Table 10, there are a similar number of mothers that fall in the bins on either side of the cutoff and their observable characteristics are similar, which is taken as evidence that mothers are not manipulating their income to be "just eligible." Because participation in WIC is not 100 percent at the threshold, a fuzzy RD method is used. As described in Angrist and Pischke (2009), the fuzzy RD method is appropriate when the treatment status is probabilistically determined as a discontinuous function of the income ratio. That is, there is a change in the probability of WIC participation at the eligibility threshold, but it does not change from 0 to 1 . Figure 2 shows WIC participation as a function of the assignment variable. As illustrated in the figure, there is a jump in participation at the cutoff point, but the probability of WIC participation remains less than 1.

A final requirement for the appropriateness of $\mathrm{RD}$ is that there are no discontinuities in the covariates at the cutoff point. Table 10 presents the results of testing for differences in covariates on either side of the cutoff. There are no statistically significant differences in covariates except for the race categories Hispanic and other race. In all other areas, mothers on either side of the cutoff appear to be very similar.

As described in Angrist and Pischke (2009), fuzzy RD design utilizes a two-stage procedure to estimate the causal impact of a treatment that is equivalent to an instrumental variables strategy. In the first stage, actual participation is regressed on the income ratio and on an indicator variable for whether the mother is eligible for WIC participation based on the 
eligibility threshold. These estimates then provide a predicted participation level. The second stage of the model regresses outcomes on the predicted participation from the first stage, controlling for the income ratio. Equation (1) represents the first-stage estimation equation in this analysis

$$
\text { Participation }_{i}=\alpha_{1}+\alpha_{2} f\left(\text { IncomeRatio }_{i}\right)+\alpha_{3} \text { Eligible }_{i}+\varepsilon_{i}
$$

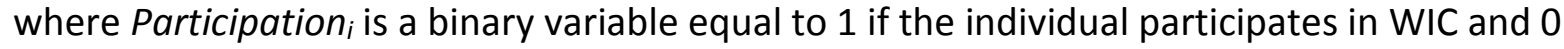
otherwise and Eligible $i$ is an indicator variable equal to 1 if the household is eligible for WIC participation. IncomeRatio $i$ is represented as a polynomial function to account for potential nonlinearities in the relationship between participation and income ratio. We estimate regressions with income ratios in first, second and third degree polynomial forms.

To estimate the causal relationship of participation on outcomes, the second stage is then estimated as described by equation (2) below:

$$
\text { Outcome }_{i}=\beta_{1}+\beta_{2} \text { Particıpatıon }_{+} \beta_{3} g\left(\text { IncomeRatio }_{i}\right)+\mu_{i}
$$

where Outcome , $_{i}$ is the outcome of choice and Part $\widehat{l c l p a t}$ ton is the estimated WIC participation from the first stage estimation. As described in Lee and Lemieux (2010), we estimate equations (1) and (2) with baseline covariates included.

We estimate equations on a limited sample as robustness checks of our results. We limit the sample to those with income ratios ranging from +3 to $-3,+1.5$ to -1.5 , and +0.5 to -0.5 . We ultimately use the second polynomial form for these robustness regressions ${ }^{24}$.

\footnotetext{
${ }^{24}$ We perform chose the polynomial form by using an AIC test for the correct polynomial form. We selected the second polynomial form as it returned a lower score in the AIC test than the first polynomial form.
} 


\subsection{Results}

We examine six infant and maternal health outcomes in our analysis: the probability of low birth weight, the probability of premature birth, birth weight, whether or not a mother has ever breast fed, duration of breast feeding and maternal weight gain during pregnancy. We find significant results in a number of specifications for three main outcomes: decreased probability of premature birth, decreased likelihood of breast feeding and decreased maternal weight gain during pregnancy. Our results for these three outcomes are presented in Table 11, Table 12 and Table 13. A full set of results for all outcomes are included in Table 14 along with marginal effects for select regressions in Table 15. We also examine two maternal and birth outcomes which we believe will not be affected by WIC as falsification tests, ruptured membrane during pregnancy and child gender. Results from these models are included in Table 16 and Table 17.

We present our results on the probability of premature birth in Table 11. Panel A in Table 11 includes the two-stage estimates on our variable of interest, WIC participation, as seen in equation (2) above. From the first stage of the model, Panel B includes the coefficient estimate on our WIC eligibility variable as seen in equation (1) above. To test the robustness of the results to the polynomial form, we estimate the model using first, second, and third degree polynomials. Each column in Table 11 indicates whether models were estimated with control variables, interaction terms between the eligibility dummy variable and the polynomial of income ratio, what polynomial was used on the income ratio, and whether the model was estimated using the full sample or a sample of individuals closer to the cutoff point.

As reported in Table 11, we find a negative and significant relationship between WIC participation the probability of giving birth to a premature child that holds across five of the six specifications. The results discussed here are from our second specification. We estimate a 
coefficient of -0.117 , which when we translate to a marginal effect, represents a 1.8 percentage point lower probability of having a low birth weight child among WIC participants. Our control variables have the expected sign in most cases. As mothers age, they have an increased probability of having a premature child. Our results show an increase ranging from 0.1 to 1.7 percentage points relative to the sample mean. Relative to white mothers, black mothers are 4.3 percentage points more likely to have a premature child and Hispanic mothers are 0.2 percentage points less likely to have a premature child. We also find a negative relationship between a mothers' years of schooling and the probability of having a premature birth. Mothers who have previously had a low birth weight child are 4.0 percentage points more likely to have a premature birth and mothers who have had a previous premature birth are 10.2 percentage points more likely to have a premature birth.

We find a negative and significant relationship between WIC participation and whether or not a mother has ever breast fed in all six specifications presented in Table 12. As seen in column (2) in Table 12, we estimate a coefficient of -0.522 for the second specification of our regressions. When we translate our results to marginal effects, we find that mothers who participate in WIC are 13.9 percent less likely to breast feed their child. This finding is similar to the results of Chatterji et al (2002). This could be due to the vouchers provided to WIC mothers for the purchase of infant formula. We find that as mothers age, they are less likely to breast feed their child. We find that relative to whites, black mothers are 0.3 percentage points less likely to breast feed and Hispanic mothers are 14.9 percentage points more likely to breast feed their child. Mothers with more years of schooling are more likely to have breast fed their child. Relative to a mother with less than a high school diploma, a mother with a college degree is 14.8 percentage points more likely to have breast fed her child. We find that single mothers are 
6.2 percentage points less likely to have breast fed their child relative to married mothers perhaps due to the time costs associated with breast feeding.

We find that mothers who participate in WIC have lower levels of maternal weight gain during pregnancy relative to non-participants. According to results presented in Table 13, we estimate a coefficient of -0.834 for the second specification of our regressions, suggesting that mothers participating in WIC gain about 1 less pound during pregnancy. This result could be a good or bad outcome. According to the Mayo clinic, the amount of weight a mother should gain during pregnancy depends on her pre-pregnancy $\mathrm{BMI}^{25}$. However since our data show that lower income mothers are more likely to be overweight or obese before pregnancy, we believe that this is a good outcome of participation in WIC. Our findings show that as mothers age, they tend to gain less weight during pregnancy. Relative to white mothers, black, Hispanic and mothers of other races tend to gain less weight during pregnancy. If a mother has had previous children, we find that she gains less weight than a mother with no previous children. Mothers with more years of schooling gain more weight during pregnancy. We also find that single mothers tend to gain more weight than married mothers.

We present results for all six health outcomes that we examine in Table 14 and Table 15. These tables show the results of regressions run with all control variables and interaction terms across our whole sample. These results also use a second degree polynomial form for the income ratio ${ }^{26}$. Below we discuss the results for our three remaining outcomes which did not have significant coefficients.

\footnotetext{
${ }^{25}$ http://www.mayoclinic.org/healthy-lifestyle/pregnancy-week-by-week/in-depth/pregnancy-weight-gain/art20044360

${ }^{26}$ We perform chose the polynomial form by using an AIC test for the correct polynomial form. We selected the second polynomial form as it returned a lower score in the AIC test than the first polynomial form.
} 
Among mothers who have breast fed their child, we find that WIC participation leads mothers to breast feed for a shorter period of time, however this result is not significant. Again, this could be the result of mothers receiving vouchers for infant formula as a result of their WIC participation. We find that as mothers age, they tend to breast feed their child for longer periods of time. Relative to whites, blacks breast feed their children for slightly less time, Hispanics breast feed for significantly less time and those of other races breast feed their children longer. Single mothers tend to breast feed their children for less time.

We estimate a coefficient of -0.024 for our probability of having a low birth weight child outcome. This result translates to a 0.3 percentage point decrease relative to the sample mean. This indicates the mothers who participate in WIC are less likely to have a low birth weight child, however it must be noted that this result is very small and statistically insignificant. This result is similar to findings by Bitler and Currie (2005), Figlio, Hammersma and Roth (2009) and Hoynes, Page and Stevens (2011). We find that as mothers age they face a higher probability of having a low birth weight child. We also find that relative to whites, blacks are more likely to have a low birth weight child. As mothers education levels increase they are less likely to have a low birth weight child. We also find that mothers who are not married, have had a previous low birth weight child or a premature child are more likely to have a low birth weight baby.

When we examine the effect of WIC participation on infant birth weight, we estimate very large but statistically insignificant coefficients. Shown in Table 14, we estimate a coefficient of -19.359 , but with little precision. A large negative result for this outcome contrasts with the previous results of Hoynes, Page and Stevens (2011) who find that WIC participation can lead to increases in birth weight of 18 to 29 grams. 


\subsection{Falsification Tests}

We also estimate regressions for birth outcomes that we believe will not be affected by WIC participation as falsification tests. We examine two outcomes, the likelihood that a mother had a ruptured membrane ${ }^{27}$ leading up to birth and the likelihood that a mother gave birth to a male child. In both cases, we posit that the outcomes are determined independent of maternal diet and the outcomes should not be related to WIC participation. We estimate regressions in three different specifications for each outcome, first, second, and third polynomials using our full sample and full set of controls. Results for these falsification tests are presented in Table 16 and Table 17.

As anticipated, we fail to reject the null of no effect in all of our falsification tests. These results mitigate concerns that our earlier results are based on spurious correlation. In addition, these results, as well as those presented earlier are not sensitive to how we specify the local linear regressions.

\subsection{Conclusion}

In this paper, we examine the effects of WIC participation on maternal and infant health outcomes by implementing a fuzzy regression discontinuity design with the CDC's PRAMS dataset. Results indicate that WIC participation decreases the likelihood of premature births, reduces the likelihood of breast feeding, and decreases maternal weight gain during pregnancy. These results are robust to alternative fuzzy regression discontinuity specifications and falsification tests mitigate the concern of spurious correlation. Early research on WIC failed to

\footnotetext{
${ }^{27}$ According to the University of Maryland Medical Center, "The membranes that hold amniotic fluid (the water surrounding the baby) usually break at the end of the first stage of labor. However, in about $10 \%$ of pregnancies after 37 weeks, the membranes will break before labor. This is referred to as premature rupture of membranes (PROM). That's difference from preterm premature rupture of membranes (PPROM), which is when the membranes rupture before 37 weeks."
} 
appropriately address the problem of selection bias into the program. In an attempt to address the problem of selection into WIC, a number of recent studies have used different techniques in an attempt to identify the program effects. Our paper provides additional evidence on WIC impacts by identifying the program effects through the fuzzy RD method.

The positive impacts of WIC on several important health outcomes are important because of our understanding that early life health outcomes are important determinants of long-term health, education, and labor market outcomes. The reductions in premature births that are caused by WIC participation potentially reduce the risk of future chronic medical conditions such as hypertension, heart disease, and diabetes (Crump et al., 2011; Goldenberg and Culhane, 2007). The nutritional assistance from WIC participation has been shown here to reduce the weight gain of mothers. To the extent that lower income mothers are overweight or obese, the reduction in weight gain during pregnancy is of benefit to the mother's and infant's health outcome. The literature has found that breastfeeding in infancy may protect against poor mental well-being and obesity in childhood, and results here find that WIC participation reduces the likelihood of ever breastfeeding. This is likely because mothers are able to purchase infant formula through the program.

Given our understanding on the importance of early life health and its relationship to income, policy makers have sought out ways to provide income support, but in a way that also promotes health. Results here indicate that WIC participation leads to a number of positive health outcomes for mothers and infants, but challenges remain because WIC alters incentives for breastfeeding. 


\subsection{Tables and Figures}

Figure 2: WIC Participation at the Income Cutoff

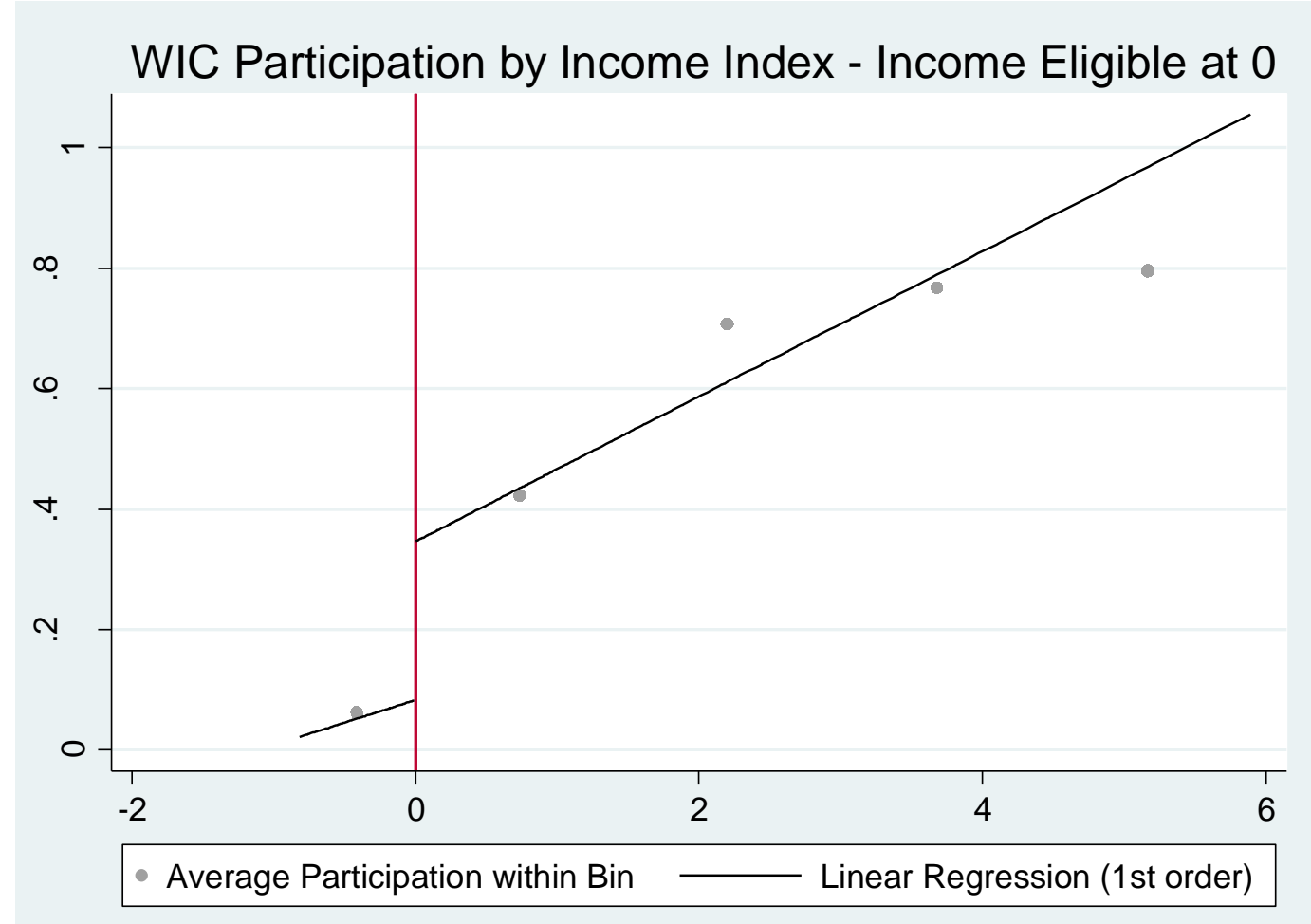

Table 9: Sample Summary Statistics

\begin{tabular}{lcc}
\hline & WIC Ineligible & WIC Eligible \\
\hline Probability of Low Birth Weight & $0.057(0.002)$ & $0.071(0.0004)$ \\
Probability of Premature Birth & $0.086(0.003)$ & $0.089(0.001)$ \\
Ever Breast Fed & $0.808(0.005)$ & $0.750(0.003)$ \\
Birth Weight & $3367(6.528)$ & $3298(2.871)$ \\
Maternal Weight Gain & $31.686(0.154)$ & $20.392(0.092)$ \\
Breastfeeding Duration & $63.01(0.457)$ & $59.17(0.234)$ \\
Maternal Pre-Pregnancy BMI & $24.55(0.067)$ & $26.26(0.041)$ \\
\hline \multicolumn{2}{l}{ Note: Standard Errors in Parentheses }
\end{tabular}


Table 10: Restricted Sample Summary Statistics

\begin{tabular}{lcc}
\hline & WIC Ineligible & WIC Eligible \\
\hline Teen Mom & $0.010(0.001)$ & $0.009(0.001)$ \\
Mom Age 20-34 & $0.723(0.005)$ & $0.726(0.005)$ \\
Mom Age 35+ & $0.267(0.005)$ & $0.265(0.005)$ \\
Non-Hispanic White & $0.759(0.005)$ & $0.758(0.005)$ \\
Non-Hispanic Black & $0.061(0.003)$ & $0.059(0.003)$ \\
Hispanic & $0.059(0.003)^{* * *}$ & $0.046(0.003)^{* * *}$ \\
Other Race & $0.121(0.003)^{*}$ & $0.136(0.004)^{*}$ \\
Education: Less than HS & $0.017(0.001)$ & $0.015(0.001)$ \\
Education: High School & $0.133(0.003)$ & $0.128(0.004)$ \\
Education: Some College & $0.223(0.005)$ & $0.234(0.005)$ \\
Education: College Degree & $0.626(0.005)$ & $0.624(0.006)$ \\
Number of Children & $0.807(0.009)$ & $0.804(0.009)$ \\
Previous Premature Birth & $0.066(0.003)$ & $0.067(0.003)$ \\
Not Married & $0.064(0.003)$ & $0.065(0.003)$ \\
Pre-Pregnancy BMI & $24.771(0.063)$ & $24.877(0.063)$ \\
Premature Birth & $0.252(0.005)^{* *}$ & $0.232(0.005)^{* *}$ \\
Low Birth Weight & $0.293(0.005)^{* *}$ & $0.276(0.005)^{* *}$ \\
Birth Weight & $3028.212(9.515)$ & $3041.982(9.479)$ \\
Maternal Weight Gain & $30.644(0.148)$ & $30.614(0.151)$ \\
Ever Breast Fed & $0.854(0.004)^{*}$ & $0.863(0.004)^{*}$ \\
Breast Feeding Duration & $64.751(0.397)$ & $64.801(0.403)$ \\
\hline Observations & 7914 & 7674 \\
\hline No: Wens & &
\end{tabular}

Note: Means and standard errors presented. Standard Errors in Parentheses. ${ }^{* *}, * *, *$ indicate that the variable is significantly different from zero at the $1 \%, 5 \%$ and $10 \%$ level. 
Table 11: Fuzzy regression discontinuity estimates of the impact of WIC participation on premature birth. 2SLS estimates. Full sample.

\begin{tabular}{|c|c|c|c|c|c|c|}
\hline & (1) & (2) & (3) & $(4)$ & $(5)$ & $(6)$ \\
\hline \multirow[t]{2}{*}{ WIC Participation } & -0.101 & $-0.117^{*}$ & $-0.143 * * *$ & $-0.136 * * *$ & $-0.120 * *$ & $-0.205^{* * *}$ \\
\hline & $(0.090)$ & $(0.068)$ & $(0.046)$ & $(0.047)$ & $(0.056)$ & $(0.063)$ \\
\hline Marginal Effects & -0.016 & $-0.018^{*}$ & $-0.022 * *$ & $-0.021 * * *$ & $-0.019 * *$ & $-0.032 * * *$ \\
\hline Controls & No & Yes & Yes & Yes & Yes & Yes \\
\hline Interaction terms & No & Yes & Yes & Yes & Yes & Yes \\
\hline Polynomial of income ratio & First & First & Second & Third & Third & Third \\
\hline Window & Whole & Whole & Whole & Whole & $-3 /+3$ & $-1.5 /+1.5$ \\
\hline Observations & 152,242 & 152,242 & 152,242 & 152,242 & 128,994 & 104,792 \\
\hline WIC Eligible & $\begin{array}{c}0.615^{* * *} \\
(0.090)\end{array}$ & $\begin{array}{c}0.659 * * * \\
(0.042)\end{array}$ & $\begin{array}{c}0.340 * * * \\
(0.063)\end{array}$ & $\begin{array}{c}0.183^{* * *} \\
(0.070)\end{array}$ & $\begin{array}{r}0.214^{* *} \\
(0.107)\end{array}$ & $\begin{array}{c}0.183^{*} \\
(0.106)\end{array}$ \\
\hline$R$-squared & 0.0002 & 0.030 & 0.030 & 0.030 & 0.030 & 0.030 \\
\hline \multicolumn{7}{|l|}{ First-stage $F$-statistics } \\
\hline$p$ value & 0.000 & 0.000 & 0.000 & 0.008 & 0.044 & 0.084 \\
\hline
\end{tabular}

Note: This table reports fuzzy RD estimates. The dependent variable is premature birth. In all regressions we control for maternal age, race, number of previous children, education level, marital status, previous low birth weight babies, previous premature births and year fixed-effects. Standard errors (reported in parentheses) are corrected for heteroskedasticity and allow for clustering at the state level. In regressions (5) and (6) we limit the sample to those with income ratios ranging from +3 to -3 and +1.5 to -1.5 . In our limited sample regressions we choose the third polynomial form as a result of performing an AIC test for polynomial form. In our regressions on the limited sample, regressions with the third polynomial form produce a lower AIC score. ${ }^{* * *},{ }^{* *},{ }^{*}$ indicate significance at the $1 \%, 5 \%$ and $10 \%$ levels. 
Table 12: Fuzzy regression discontinuity estimates of the impact of WIC participation on the likelihood of breastfeeding. 2SLS estimates. Full sample.

\begin{tabular}{|c|c|c|c|c|c|c|}
\hline & $(1)$ & $(2)$ & (3) & $(4)$ & (5) & (6) \\
\hline \multirow[t]{2}{*}{ WIC Participation } & $-0.319 * * *$ & $-0.520 * * *$ & $-0.522 * * *$ & $-0.510 * * *$ & $-0.447 * * *$ & $-0.363^{* * *}$ \\
\hline & $(0.102)$ & $(0.124)$ & $(0.118)$ & $(0.112)$ & (0.108) & $(0.123)$ \\
\hline Marginal Effects & $-0.089 * * *$ & $-0.137 * * *$ & $-0.137^{* * *}$ & $-0.134 * * *$ & $-0.113 * * *$ & $-0.089 * * *$ \\
\hline Controls & No & Yes & Yes & Yes & Yes & Yes \\
\hline Interaction terms & No & Yes & Yes & Yes & Yes & Yes \\
\hline Polynomial of income ratio & First & First & Second & Third & Third & Third \\
\hline Window & Whole & Whole & Whole & Whole & $-3 /+3$ & $-1.5 /+1.5$ \\
\hline Observations & 152,242 & 152,242 & 152,242 & 152,242 & 128,994 & 104,792 \\
\hline \multirow[t]{2}{*}{ WIC Eligible } & $0.614 * * *$ & $0.652 * * *$ & $0.341 * * *$ & $0.185 * * *$ & $0.215^{* *}$ & $0.184^{*}$ \\
\hline & $(0.039)$ & $(0.042)$ & $(0.064)$ & $(0.071)$ & $(0.109)$ & $(0.108)$ \\
\hline$R$-squared & 0.022 & 0.077 & 0.078 & 0.078 & 0.066 & 0.056 \\
\hline \multicolumn{7}{|l|}{ First-stage $F$-statistics } \\
\hline$p$ value & 0.002 & 0.000 & 0.000 & 0.009 & 0.047 & 0.090 \\
\hline
\end{tabular}

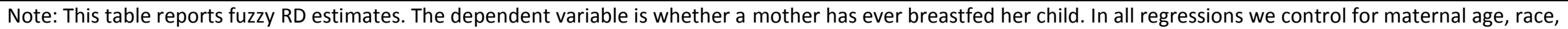

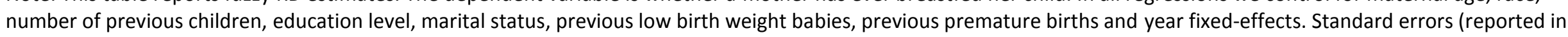

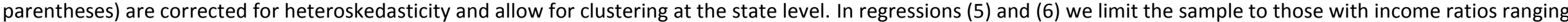

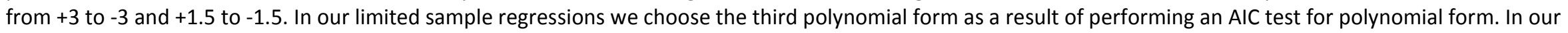

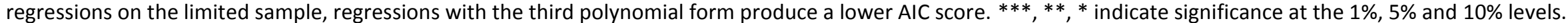


Table 13: Fuzzy regression discontinuity estimates of the impact of WIC participation on the maternal weight gain during pregnancy. 2SLS estimates. Full sample.

\begin{tabular}{|c|c|c|c|c|c|c|}
\hline & $(1)$ & $(2)$ & (3) & $(4)$ & $(5)$ & (6) \\
\hline \multirow[t]{2}{*}{ WIC Participation } & $-1.755 * * *$ & $-1.393 * * *$ & $-0.991 * * *$ & $-1.034 * * *$ & $-1.449 * * *$ & $-1.574 * * *$ \\
\hline & $(0.471)$ & $(0.367)$ & $(0.352)$ & $(0.343)$ & $(0.408)$ & $(0.564)$ \\
\hline Controls & No & Yes & Yes & Yes & Yes & Yes \\
\hline Interaction terms & No & Yes & Yes & Yes & Yes & Yes \\
\hline Polynomial of income ratio & First & First & Second & Third & Third & Third \\
\hline Window & Whole & Whole & Whole & Whole & $-3 /+3$ & $-1.5 /+1.5$ \\
\hline \multirow[t]{2}{*}{ WIC Eligible } & $0.615^{* * *}$ & $0.660 * * *$ & $0.340 * * *$ & $0.182^{* * *}$ & $0.215^{* *}$ & $0.183^{*}$ \\
\hline & $(0.039)$ & $(0.042)$ & $(0.062)$ & $(0.069)$ & $(0.106)$ & $(0.105)$ \\
\hline$R$-squared & 0.003 & 0.032 & 0.033 & 0.033 & 0.030 & 0.026 \\
\hline \multicolumn{7}{|l|}{ First-stage $F$-statistics } \\
\hline$p$ value & 0.000 & 0.000 & 0.000 & 0.008 & 0.042 & 0.082 \\
\hline
\end{tabular}

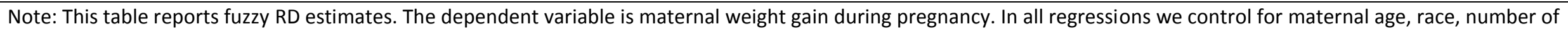
previous children, education level, marital status, previous low birth weight babies, previous premature births and year fixed-effects. Standard errors (reported in

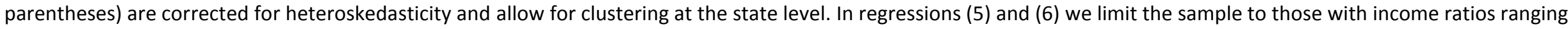

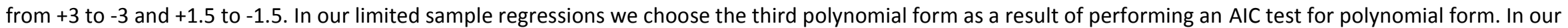

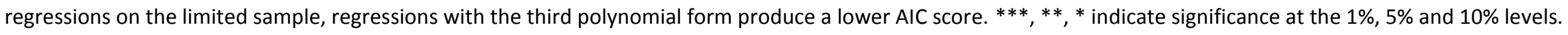


Table 14: Fuzzy regression discontinuity estimates. 2 Stage estimates. Full sample

\begin{tabular}{|c|c|c|c|c|c|c|}
\hline & P(Low Birth) & $\mathbf{P}($ Premature $)$ & P(Breast Fed) & Birth Weight & $\begin{array}{c}\text { Pregnancy Weight } \\
\text { Gain }\end{array}$ & $\begin{array}{c}\text { Breast Feeding } \\
\text { Duration }\end{array}$ \\
\hline WIC Participation & $-0.024(0.061)$ & $-0.143(0.046)^{* * *}$ & $-0.522(0.118)^{* * *}$ & $-19.359(21.222)$ & $-0.991(0.352)^{* * *}$ & $-0.958(1.494)$ \\
\hline Income Ratio & $0.125(0.162)$ & $-0.132(0.211)$ & $0.378(0.461)$ & $-19.689(80.349)$ & $-6.331(2.595)^{* *}$ & $22.322(6.493)^{* * *}$ \\
\hline $\begin{array}{l}\text { Income Ratio*WIC } \\
\text { Eligible }\end{array}$ & $-0.120(0.158)$ & $0.153(0.213)$ & $-0.208(0.468)$ & $23.052(80.610)$ & $5.795(2.672)^{* *}$ & $-23.176(6.743)^{* * *}$ \\
\hline Income Ratio Squared & $-0.002(0.316)$ & $-0.429(0.465)$ & $-0.455(0.821)$ & $22.215(156.475)$ & $-17.390(5.004)^{* * *}$ & $47.531(14.662)^{* * *}$ \\
\hline $\begin{array}{l}\text { Income Ratio } \\
\text { Squared*WIC Eligible }\end{array}$ & $0.003(0.317)$ & $0.426(0.465)$ & $0.421(0.820)$ & $-23.810(156.594)$ & $17.510(4.993) * * *$ & $-47.188(14.636) * * *$ \\
\hline Mom Age 20-34 & $-0.008(0.031)$ & $0.006(0.035)$ & $0.066(0.046)$ & $19.587(10.090)^{*}$ & $-1.108(0.341)^{* * *}$ & $3.715(1.167)^{* * *}$ \\
\hline Mom Age 35+ & $0.159(0.025)^{* * *}$ & $0.103(0.031)^{* * *}$ & $0.034(0.060)$ & $0.584(12.594)$ & $-2.435(0.405)^{* * *}$ & $5.754(1.297)^{* * *}$ \\
\hline Black & $0.340(0.018)^{* * *}$ & $0.249(0.021)^{* * *}$ & $-0.023(0.070)$ & $-190.378(7.612)^{* * *}$ & $-2.687(0.372)^{* * *}$ & $-0.264(0.691)$ \\
\hline Hispanic & $-0.020(0.023)$ & $-0.010(0.031)$ & $0.670(0.047)^{* * *}$ & $-20.718(9.010) * *$ & $-1.858(0.304)^{* * *}$ & $-5.553(0.932) * * *$ \\
\hline Other Race & $0.095(0.023)^{* * *}$ & $0.027(0.030)$ & $0.315(0.100) * * *$ & $-121.671(4.981)^{* * *}$ & $-1.984(0.246)^{* * *}$ & $0.542(0.923)$ \\
\hline Kids (1) & $-0.253(0.013)^{* * *}$ & $-0.184(0.019)^{* * *}$ & $-0.230(0.013)^{* * *}$ & $113.826(6.352)^{* * *}$ & $-3.024(0.192)^{* * *}$ & $3.017(0.447)^{* * *}$ \\
\hline Kids ( 2 or more) & $-0.254(0.14)^{* * *}$ & $-0.123(0.016)^{* * *}$ & $-0.220(0.028)^{* * *}$ & $129.427(4.981)^{* * *}$ & $-3.708(0.247)^{* * *}$ & $8.080(0.632)^{* * *}$ \\
\hline High School & $-0.030(0.023)$ & $0.013(0.023)$ & $0.061(0.025)^{* *}$ & $8.172(8.710)$ & $1.265(0.324)^{* * *}$ & $-3.913(1.051)^{* * *}$ \\
\hline Some College & $-0.104(0.024) * * *$ & $-0.016(0.024)$ & $0.312(0.027) * * *$ & $34.741(6.859) * * *$ & $1.675(0.322)^{* * *}$ & $-4.153(1.219) * * *$ \\
\hline College Degree & $-0.147(0.023) * * *$ & $-0.062(0.026)$ & $0.555(0.042) * * *$ & $56.525(12.193)^{* * *}$ & $1.778(0.311)^{* * *}$ & $2.531(1.300)^{*}$ \\
\hline Not Married & $0.066(0.016)^{* * *}$ & $0.043(0.018)^{* *}$ & $-0.248(0.020)^{* * *}$ & $-33.955(7.546)^{* * *}$ & $1.428(0.162)^{* * *}$ & $-3.329(0.588) * * *$ \\
\hline Previous LBW & $0.470(0.024)^{* * *}$ & $0.254(0.021)^{* * *}$ & $-0.075(0.035)^{* *}$ & $-259.763(12.647)^{* * *}$ & $-1.092(0.253)^{* * *}$ & $-1.010(0.808)$ \\
\hline Previous preemie & $0.439(0.014)^{* * *}$ & $0.652(0.025)^{* * *}$ & $0.015(0.038)$ & $-217.163(10.852)^{* * *}$ & $-0.616(0.203)^{* * *}$ & $-3.046(0.440) * * *$ \\
\hline
\end{tabular}

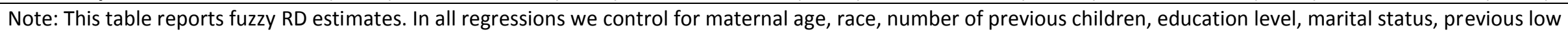

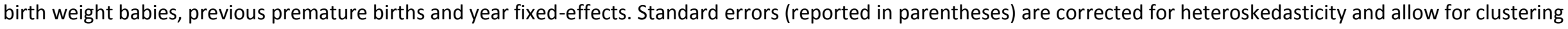
at the state level. $* * *, * *, *$ indicate significance at the $1 \%, 5 \%$ and $10 \%$ levels. All regressions were run using a second degree polynomial form for our income ratio. 
Table 15: Fuzzy regression discontinuity marginal effects. 2 Stage estimates. Full sample.

\begin{tabular}{|c|c|c|c|}
\hline & $\mathbf{P}$ (Low Birth) & $\mathbf{P}$ (Premature) & P(Breast Fed) \\
\hline WIC Participation & $-0.003(0.008)$ & $-0.022(0.007)^{* * *}$ & $-0.137(0.031)^{* * *}$ \\
\hline Income Ratio & $0.015(0.020)$ & $-0.021(0.033)$ & $0.100(0.120)$ \\
\hline Income Ratio*WIC Eligible & $-0.015(0.020)$ & $0.024(0.033)$ & $-0.055(0.123)$ \\
\hline Income Ratio Squared & $-0.0003(0.039)$ & $-0.067(0.073)$ & $-0.120(0.217)$ \\
\hline Income Ratio Squared*WIC Eligible & $0.0004(0.039)$ & $0.067(0.073)$ & $0.111(0.207)$ \\
\hline Mom Age 20-34 & $-0.001(0.004)$ & $0.001(0.005)$ & $0.018(0.012)$ \\
\hline Mom Age 35+ & $0.022(0.003)^{* * *}$ & $0.017(0.005)^{* * *}$ & $0.009(0.016)$ \\
\hline Black & $0.051(0.003)^{* * *}$ & $0.044(0.004)^{* * *}$ & $-0.007(0.020)$ \\
\hline Hispanic & $-0.002(0.003)$ & $-0.001(0.005)$ & $0.148(0.013)^{* * *}$ \\
\hline Other Race & $0.012(0.003)^{* * *}$ & $0.004(0.005)$ & $0.081(0.024)^{* * *}$ \\
\hline Kids (1) & $-0.033(0.002)^{* * *}$ & $-0.029(0.003)^{* * *}$ & $-0.060(0.004)^{* * *}$ \\
\hline Kids ( 2 or more) & $-0.033(0.002)^{* * *}$ & $-0.020(0.003)^{* * *}$ & $-0.057(0.008)^{* * *}$ \\
\hline High School & $-0.004(0.003)$ & $0.002(0.004)$ & $0.020(0.008)^{* *}$ \\
\hline Some College & $-0.014(0.003)^{* * *}$ & $-0.003(0.004)$ & $0.093(0.009)^{* * *}$ \\
\hline College Degree & $-0.019(0.003)^{* * *}$ & $-0.010(0.004)^{* *}$ & $0.151(0.012)^{* * *}$ \\
\hline Not Married & $0.008(0.002)^{* * *}$ & $0.007(0.003)^{* *}$ & $-0.065(0.005)^{* * *}$ \\
\hline Previous LBW & $0.058(0.003)^{* * *}$ & $0.040(0.003)^{* * *}$ & $-0.020(0.009)^{* *}$ \\
\hline Previous preemie & $0.055(0.002)^{* * *}$ & $0.102(0.004)^{* * *}$ & $0.004(0.010)$ \\
\hline
\end{tabular}

Note: This table reports fuzzy RD marginal effects. In all regressions we control for maternal age, race, number of previous children, education level, marital status, previous low birth weight babies, previous premature births and year fixed-effects. Standard errors (reported in parentheses) are corrected for heteroskedasticity and allow for clustering at the state level. ${ }^{* * *}, * *, *$ indicate significance at the $1 \%, 5 \%$ and $10 \%$ levels. All regressions were run using a second degree polynomial form for our income ratio. 


\section{Falsification Tests}

Table 16: Fuzzy regression discontinuity estimates of the impact of WIC participation on the likelihood of a mother having a ruptured membrane during pregnancy. 2SLS estimates. Full sample.

\begin{tabular}{|c|c|c|c|}
\hline & $(1)$ & $(2)$ & (3) \\
\hline \multicolumn{4}{|c|}{ Panel A: two-stage least squares estimates } \\
\hline \multirow[t]{2}{*}{ WIC Participation } & 0.099 & 0.123 & 0.045 \\
\hline & $(0.135)$ & $(0.129)$ & $(0.122)$ \\
\hline Marginal Effects & 0.005 & 0.007 & 0.002 \\
\hline Controls & Yes & Yes & Yes \\
\hline Interaction terms & Yes & Yes & Yes \\
\hline Polynomial of income ratio & First & Second & Third \\
\hline Window & Whole & Whole & Whole \\
\hline Observations & 152,242 & 152,242 & 152,242 \\
\hline \multicolumn{4}{|l|}{ Panel B: first stage } \\
\hline \multirow[t]{2}{*}{ WIC Eligible } & $0.657^{* * *}$ & $0.338 * * *$ & $0.181 * * *$ \\
\hline & $(0.042)$ & $(0.063)$ & $(0.069)$ \\
\hline$R$-squared & 0.029 & 0.029 & 0.030 \\
\hline \multicolumn{4}{|l|}{ First-stage F-statistics } \\
\hline$p$ value & 0.000 & 0.000 & 0.009 \\
\hline
\end{tabular}

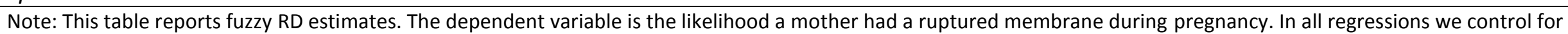

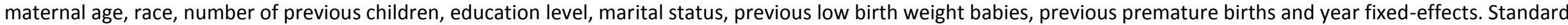

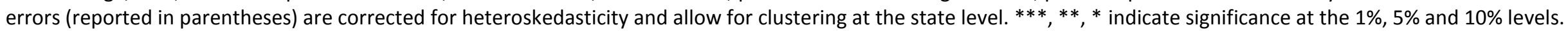


Table 17: Fuzzy regression discontinuity estimates of the impact of WIC participation on the likelihood of having a male child. 2SLS estimates. Full sample.

$$
\text { (1) }
$$

(3)

\begin{tabular}{lccc}
\hline Panel A: two-stage least squares estimates & & -0.104 \\
WIC Participation & -0.022 & $(0.099)$ & -0.063 \\
& $(0.107)$ & -0.041 & $-0.088)$ \\
Marginal Effects & -0.009 & Yes & Yes \\
Controls & Yes & Yes & Yes \\
Interaction terms & Yes & Second & Third \\
Polynomial of income ratio & First & Whole & Whole \\
Window & Whole & 152,242 & 152,242 \\
Observations & 152,242 & & $0.182^{* * *}$ \\
Panel B: first stage & & $0.338^{* * *}$ & $(0.069)$ \\
WIC Eligible & $0.659^{* * *}$ & $(0.063)$ & 0.0003 \\
$R$-squared & $(0.042)$ & 0.0003 & 0.009 \\
First-stage F-statistics & 0.0002 & & 0.000 \\
$p$ value & & 0.000 &
\end{tabular}

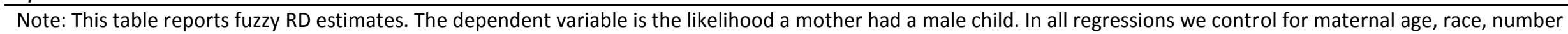
of previous children, education level, marital status, previous low birth weight babies, previous premature births and year fixed-effects. Standard errors (reported in parentheses) are corrected for heteroskedasticity and allow for clustering at the state level. ***,**,* indicate significance at the $1 \%, 5 \%$ and $10 \%$ levels. 


\section{4. “How Does Insurance Contribute to an Individual's Decision to Use Preventive Care?"}

\subsection{Introduction}

According to the Centers for Disease Control (CDC), tens of thousands of lives could be saved annually through increased usage of preventive services ${ }^{28}$. One of the goals of the recently passed Affordable Care Act $(A C A)$ is to increase usage of preventive care services and one of the mandates of the ACA is that most insurance plans cover the preventive health services that are recommended by the U.S. Preventive Services Task Force ${ }^{2930}$. Although likely, it is currently unclear to what extent this increased access to insurance coverage will lead to an increase in the usage of preventive care services. In this paper I seek to examine how insurance coverage contributes to an individual's decision to utilize preventive care services.

By analyzing the estimated costs of adopting 20 proven preventive care services across the U.S. and comparing the costs against the estimated savings that could be generated, Maciosek et al. (2010) state that increased use of preventive services could prevent the loss of more than 2 million quality-adjusted life years ${ }^{31}$ and could result in the savings of several billion dollars. The authors suggest that both insurance payers and policy makers should support the increased use of evidence-based preventive services which could lead to improvements in health for all Americans and help make better use of scarce medical resources.

\footnotetext{
${ }^{28}$ http://health.usnews.com/health-news/news/articles/2012/06/14/many-lacked-preventive-care-before-health reform-law-us-report

${ }^{29}$ http://www.uspreventiveservicestaskforce.org/BrowseRec/Index/browse-recommendations

${ }^{30}$ https://www.healthcare.gov/what-are-my-preventive-care-benefits/

${ }^{31} \mathrm{~A}$ quality-adjusted life year (QALY) is a measure of disease burden which includes both the quality and the quantity of life lived. It is used in assessing the value for money of a medical intervention. The QALY is based on the number of years of life that would be added by the intervention.
} 
Previous studies have examined how various groups utilize preventive care services under different constraints and in different scenarios. For instance, some research has examined differences across gender. Zhang et al. (1994) examine disparities in the use of preventive services between urban and rural women and find that urban women are more likely to use preventive services, while Vaidya et al. (2012) find that women are more likely to use preventive care services more than men. Others examine the role that income and ethnicity play when using preventive care. Ross et al. (2007) show that the working poor are less likely to receive certain preventive care screenings. Ahluwalia et al. (2009) show that working age Hispanics and Blacks lack insurance coverage more than white Americans. Zhang et al. Also, studies have also examine the role of insurance coverage in the decision to use preventive services in different countries. In a Mexican study, Pagán et al. (2007) analyze the relationship between insurance coverage and the use of preventive care services.

The role insurance coverage plays in choosing to use preventive care has been overlooked using U.S. data. I seek to examine the role of insurance coverage and income levels in an individual's decision to use preventive health coverage in an analysis similar to the work by Pagán et al. (2007). To accomplish this goal this I use a large sample of individual-level data across the United States from the Behavioral Risk Factor Surveillance System (BRFSS) over the time period 1996-2000 and 2005-2012. To my knowledge, I am the first to utilize the BRFSS data in an analysis of preventive care usage over a period of more than two years and the first to examine the effects of insurance coverage on an individual's decision to utilize preventive care services using data from the United States. In particular, I examine the utilization of nine preventative measures: influenza vaccinations, colonoscopies, blood cholesterol screenings, 
mammograms, Papanicolaou screening tests (pap smears), breast physical exams, prostate checks, and HPV vaccinations. Results of this paper show that insurance coverage increases the likelihood of using preventive care services. This research contributes to the existing preventive care literature by allowing us to more rigorously form an expectation as to how increased health insurance coverage as a result of the ACA will likely affect preventative care.

Results indicate that, relative to a privately purchased insurance plan, individuals with coverage through their employer or spouse's employer or coverage through the military are more likely to utilize preventive services. When I approach this question more generally and examine the effects of any type of insurance coverage on the likelihood of using preventive services I find that those with coverage were in all cases more likely to use preventive care services than those with no coverage at all. There also appears to be an income bias in the use of preventive services. In almost all cases individuals from the highest income group are more likely to use preventive services than those with lower incomes.

\subsection{Background}

Several papers have examined the factors that may contribute to an individual's decision to use preventive care services. Here I present a summary of the major findings. I separate the papers into two categories: research that examines how various factors affect an individual's decision to engage in preventive care; and - most closely related to this research research that examines the effects of insurance coverage on preventative care utilization. 
Demographics and Usage of Preventive Care

Papers in the preventive care literature have examined how a wide variety of characteristics affect the usage of preventive care services. Zhang et al. (1994) find that urban women were more likely to use preventive care services than their rural counterparts. They note that improving socioeconomic status and providing better access to insurance coverage may help to reduce this disparity. Ross et al (2007) examines how the working poor use preventive care services. Without controlling for insurance and education, they find that the working poor are much less likely to use preventive care services. However when they control for insurance and education the working poor remained less likely to receive more medicalcapital intensive screenings, but were not less likely to receive less medical-capital intensive screenings such as flu shots.

Other papers have examined how self-reported health status affects the use of preventive care services. Wu (2003) uses data from the Health and Retirement Study and the Medical Expenditure Panel Survey to examine the relationship between health status and the likelihood of engaging in medical screenings and other preventive medical behaviors. He examines the utilization of flu shots, cholesterol checks, mammograms, Pap smears, selfadministered breast examinations and prostate examinations. To account for the presence of "high utilization" patients, patients who are more prone to seek medical care, he includes controls for the number of doctor's office visits and hospital stays in the past year. Using one cross section from each of the two panel data sets and a Probit regression methodology, Wu's findings indicate that people with more education, higher incomes and insurance coverage are more likely to receive all types of medical treatment. His findings show the individuals with 
relatively poorer health are more likely to get flu shots and cholesterol checks. However, they are less likely to have mammograms, Pap smears, and prostate checks.

Ahluwalia et al. (2009) examine disparities in insurance coverage among racial and ethnic groups in state and metropolitan areas in the U.S. They utilize data from the 2006 BRFSS system and analyze working adults between the ages of 18 and 64 . They divide their sample into four age groups and examine coverage disparities by group. They sort their sample by Metropolitan Statistical Areas (MSAs) and produce cross-tabulations detailing coverage by age and racial group. According to their study, the median level of un-insurance for the states and DC was 17.01 percent. Nationwide 18.6 percent of working-age adults were without health insurance coverage. Among states the levels varied from 9.7 to 29.0 percent. Overall black and Hispanic population had higher rates of lack of coverage than working age white Americans.

In a more recent paper, Carrieri and Wuebker (2013) examine inequalities in breast cancer and blood test screenings across 13 European countries. Across the countries in their sample, they find evidence that higher income individuals utilize both preventive care services they examine more widely.

Other works have examined how the utilization of preventive care is affected by gender. Vaidya et al. (2012) examine differences in the utilization of preventive care services in the United States between women and men. Using data from the 2008 Medical Expenditure Panel Survey, they examine preventive care services that are common to both women and men. Using a logistic regression strategy and controlling for age, race and ethnicity, they find that in general, the utilization of preventive care is higher for women. 
Insurance Coverage and Usage of Preventive Care

Previous work has examined how insurance coverage affects an individual's decision to use preventive care. Here I discuss a few of the literature's findings on the relationship between insurance coverage and the use of preventive care services. Pagán et al. (2007) implement data from the 2001 Mexican Health and Aging Study to analyze the relationship between insurance coverage and the use of preventive health-care services in Mexico. Their sample consisted of 12,100 adults aged 50 and older. The authors note that Mexico is a case of special interest. Health care access can be a challenge since there are multiple health-care providers with different mandates and objectives. Certain types of workers and citizens are eligible for different types of coverage and most adults are not covered by health insurance plans which provide access to preventive care services. There is also a gap in utilization of preventive services between insured and uninsured adults. They implement a logistic regression strategy to examine how an individual's health insurance status is related to the use of preventive health care services. They find that uninsured adults were less likely to use preventive screenings for hypertension, high cholesterol, diabetes, and several types of cancer than insured adults. Similar results hold for those earning below 200 percent of the poverty level. Their results suggest that insured adults are in a better position to detect several chronic diseases.

Tian et al. (2010) examine the demand for preventive care services in Taiwan. Specifically, they examine the relationship between the utilization of preventive health care services and inpatient services and they also examine the factors affecting the utilization of such services among the middle-aged and the elderly. In Taiwan, the National Health Insurance 
(NHI) program was implemented by health authorities in 1995 and offered comprehensive health care coverage for all citizens. Beginning in 1996, in addition to the comprehensive coverage, citizens have access to free adult preventive care services once every three years for adults aged 40 or more, and on an annual basis for those aged 65 or more.

Tian et al. (2010) construct a recursive simultaneous probit model to estimate whether the utilization of preventive care services reduces later inpatient care utilization. They find that the usage of preventive care services reduces the probability that one will need to use inpatient care services. They also note that with increased preventive services utilization medical resources could be managed more efficiently leading to a reduction in the financial burden faced by government provided health insurance coverage by reducing the probability of the need for future inpatient services.

Decker et al. (2012) use Medicare claims data, the National Health Interview Survey, and the Health and Retirement Study to examine the relationship between insurance status before age 65 and the use of Medicare-covered services available to individuals once the turn 65 . They examine how people who previously did not have insurance before becoming eligible for Medicare use the health care system compared to those who had insurance before qualifying for Medicare. They find that those who were uninsured before age 65 use the healthcare system differently than those who were previously insured. Specifically those without previous coverage made 16 percent fewer visits to physicians' offices, but make 18 and 43 percent more visits to hospital emergency rooms and outpatient departments respectively. Other findings include that there is no statistically significant difference in Medicare expenditures after turning 
65 years old according to insurance status before 65 years old. They present evidence that for at least a few years, individuals who were uninsured before age 65 rely less on outpatient care for the medical care.

\subsection{Data}

The main data source is the Behavioral Risk Factor Surveillance System (BRFSS). The BRFSS consists of repeated cross-sections from years 1995-2012. The survey is collected monthly by telephone interview surveys of persons aged 18 years and older and is a nationally representative survey of the United States and has been conducted by state health departments in conjunction with the Centers for Disease Control (CDC). The BRFSS collects data on several individual-level behavioral health risk factors associated with the leading causes of premature mortality and morbidity among adults, chronic health conditions, and use of preventive services. Fifteen states took part in the initial study in 1984 and by 1994, all 50 states and the District of Columbia became involved. Currently the BRFSS conducts more than 400,000 adult surveys annually.

Of particular interest is the system's information on usage of preventive care screenings and insurance coverage. The dataset contains information on the usage of preventive health care services and doctor visits. For example, the dataset includes information on whether an individual last visited a doctor for a general check-up, blood cholesterol screenings, 
mammogram testing, breast physical examinations, Pap smear testing, flu shot and Human Papillomavirus (HPV) vaccinations, and colonoscopy and prostate cancer screenings. ${ }^{32}$

Certain preventive care screenings are recommended by the CDC only once an individual reaches a certain age. For example, colonoscopy screenings to detect colorectal cancer are recommended once an individual reaches age 50. Mammograms for women and prostate cancer screenings for men are also only recommended for adults once they reach age 50. In cases where the preventive service in question is only recommended for people above or below a certain age, the sample is restricted to reflect the age recommendation.

From 1996-2000, the dataset also contains information on several types of insurance coverage. Specifically the BRFSS asks respondents if they have coverage from their employer, their spouse's employer, Medicare, Medicaid, the military, the Indian Health Service, coverage purchased privately by the respondent, or no coverage at all. The data also contain demographic information such as income and education levels, gender, age, height, weight, and number of children.

The data also have information on several types of demographic characteristics such as age, race, gender, education level and employment status. I also utilize the BRFSS information on whether an individual had a checkup at a doctor's office in the previous year and a rating of their self-reported health status. Self-reported health status is ranked 1-5 with lower numbers corresponding to better self-reported health. An individual rating themselves a " 1 " believes

\footnotetext{
32 The CDC has information on who should partake in a certain preventive care screening and at what point in their life they should. I consult the CDC website for each particular screening and limit the samples respectively based on recommended age and gender for each type of screening. http://www.cdc.gov .
} 
that they are in "Excellent" health, while a rating of " 5 " indicates their belief that they are in "Poor" health.

\subsection{Methodology}

In the first section of this paper I utilize data from the BRFSS from 2005-2012 and estimate a series of regression models to better understand how insurance coverage and income affects the use of preventive care. During these years, information on the specific type of insurance cover is unavailable. Respondents where only asked whether they had any type of insurance coverage with no additional detail as to the specific type of coverage. Because of this I also examine how people in different income groups use preventive care services. I examine respondent's usage of flu shot vaccinations, colonoscopies, blood cholesterol screenings, and HIV tests. I then limit the sample to women and examine several female-specific preventive care screenings such as mammograms, Pap smears, breast physical examinations and HPV Vaccinations. These preventive services were chosen because of their inclusion in the BRFSS survey data and because of their inclusion in U.S. Preventive Services Task Force list of recommended preventive services ${ }^{33}$.

In the second section of this Paper I analyze the effects of various types of insurance coverage on the usage of several preventive care services. I use data from the BRFSS from 1996-2000 because information on the specific type of a respondent's insurance is only available during these years. I analyze six types of insurance coverage and seven preventive

\footnotetext{
${ }^{33}$ http://www.uspreventiveservicestaskforce.org/uspstf/uspsabrecs.htm
} 
care outcomes. The preventive care outcomes are the same as above with the exception of HPV vaccinations ${ }^{34}$.

\section{Regressions with General Insurance Coverage}

In the first section of the analysis, I utilize several cross-sections from later years of the BRFSS survey. During the years 2005-2012, the BRFSS no longer asked respondents about which type of insurance coverage they have. Respondents were only asked if they had any sort of health plan. Data from these years were also used to examine the differences in utilization of preventive care services among from different income groups. Five income groups were considered (with category names in parentheses): \$0-\$14,999 (low), \$15,000-\$24,999 (medium-low), \$25,000-\$49,999 (medium), \$50,000-\$74,999 (medium-high), and \$75,000 and above (high) ${ }^{35}$. I examine the usage flu shots, colonoscopies, blood cholesterol tests, HIV tests, mammograms, pap smears, breast physical exams, prostate cancer screenings and HPV vaccinations. Regressions examining the usage of HPV vaccinations are limited to those age 49 and below since there were no individuals above that age in the sample who had partaken in the vaccine. I control for whether respondents have visited a doctor for a general check-up in the last year and individual respondents' self-reported measures of their general health similar to Wu (2003). I also control for demographic characteristics such as income and education levels, gender, and age. I estimate regressions of the following form:

$$
\operatorname{PREVENT}_{i}=\beta_{0}+\beta_{1} \text { HEALTHPLAN } i+\beta_{2} X_{i}+\tau_{t}+\gamma_{i}+\varepsilon_{i}
$$

\footnotetext{
${ }^{34}$ Information on respondent's use of HPV vaccinations is not available from 1996-2000.

35 These income categories are included in the BRFSS data. When using the income categories in regressions, the highest income category is omitted.
} 
The variable PREVENT represents each type of preventive care screening. HEALTHPLAN is a dummy variable which is equal to 1 if the respondent had any sort of health plan in the previous year. $X$ is a matrix of individual specific characteristics including an individual's age, education and income level, employment status, $\mathrm{BMI}^{36}$, smoker status ${ }^{37}$, gender, race, marital status, self-assessed general level of health ${ }^{38}$, whether or not they have visited a doctor for a general check-up in the previous year, and the income categories mentioned above. Again, $\tau$ and $\gamma$ represent controls for year and the state in which the respondent resides, respectively, and $\varepsilon$ is an error term.

Summary statistics for regressions with men and women are shown in Table 18 and summary statistics for regressions with limited sample sizes are shown in Table 19. The full sample consists of 3,205,179 observations. Roughly 25 percent of the sample falls into the medium income category and another 25 percent in the medium-high income category. The majority of the sample has at least a high school diploma and roughly 34 percent are college graduates. Eighty-nine percent of the sample had some sort of health coverage and roughly 72 percent visited a doctor's office in the previous year.

\footnotetext{
${ }^{36}$ Body Mass Index (BMI) is a number calculated from a person's weight and height. BMI can be considered an alternative for direct measures of body fat. A BMI in the range of $18.5-25$ is considered normal, a BMI of $25-29.9$ is considered overweight, and a BMI of greater than 30 is considered obese.

${ }^{37}$ Smoker status indicates whether or not the respondent is a current cigarette smoker at the time of the BRFSS survey interview.

${ }^{38}$ Respondents report whether they believe they are in good or poor health on a scale of 1-5 with one being good health and 5 being poor health.
} 


\section{Regressions with specific insurance coverage type}

In the second section of this paper I use only data from 1996-2000, which contains information on specific insurance coverage type. In particular, the BRFSS questions asks respondents whether they have insurance coverage from their employer, their spouse's employer, Medicare, Medicaid, the Military, the Indian Health Service, private insurance, or some other form of coverage. I examine all the preventive care services as above with the exception of prostate cancer screenings and HPV vaccinations ${ }^{39}$. I also implement the same controls as above. I control for an individual's self-reported health status, whether they have visited a doctor for a checkup in the last year and several demographic characteristics. I estimate regressions of the following form:

$$
\operatorname{PREVENT}_{i}=\beta_{0}+\beta_{1} \operatorname{INSURANCE}_{i}+\beta_{2} X_{i}+\tau_{t}+\gamma_{i}+\varepsilon_{i}
$$

The variable INSURANCE represents the different categories of insurance mentioned above. The variables PREVENT, $x, \tau, r$, and $\epsilon$ represent the same as above. Summary statistics for these regressions are shown in Table 22. The full sample consists of 606,937 observations spanning the years 1996-2000. Roughly 65 percent of the sample have insurance coverage through their employer and 16 percent have no coverage at all.

\subsection{Results}

\section{Regressions with General Insurance Coverage}

In this section results from regressions with a general insurance coverage variable and different income category variables are presented. I examine the effect of insurance coverage

\footnotetext{
${ }^{39}$ Data for these two preventive care services were not available during the time period 1996-2000.
} 
and individual's income level on the utilization of nine preventive care outcomes. This subsection is further broken down into three parts: results from the full sample including both men and women, results from male-specific preventive care services, and results from femalespecific preventive care services.

I present the results from the series of regression models of preventive services utilized by both men and women in Table 20. Individuals with any type of health insurance coverage were more likely to receive preventive services similar to Pagán et al. (2007). It is clear that income is a factor in the utilization of all preventive services. Those in the lowest income group are consistently less likely to use these select preventive care services than those in the highest income group. As income rises, individuals become more likely to utilize these services. This is similar to findings by Wu (2003), Ross et al. (2007), and Carrieri and Wuebker (2013).

Having health insurance increases the likelihood that an individual will use preventive care services. When I examine flu shots I estimate a marginal effect of 0.134 . This implies that individuals with any type of insurance coverage are 13.4 percentage points more likely to receive a flu shot than those with no coverage. This trend is also apparent when examining colonoscopy screenings and blood cholesterol tests. I estimate marginal effects of 0.085 and 0.058 respectively. This suggests that individuals with insurance coverage are 8.5 percentage points more likely to have a colonoscopy screening and 5.8 percentage points more likely to have a blood cholesterol test than those with no insurance coverage.

In this section I also examine how individuals in different income groups use preventive care. I find that those in the lowest income group are consistently less-likely to use preventive 
services than those with the highest incomes. When examining flu shots, colonoscopy

screenings and blood cholesterol checks I estimate marginal effects of $-0.032,-0.045$ and -0.042

respectively. This implies that those in the lowest income group are roughly 4 percentage

points less likely to use the preventive services mentioned above. This trend is consistent in the rest of the income groups. As income increases individuals are more likely to use these preventive services.

Similar to Wu (2003), I also control for whether an individual has had a checkup at a doctor's office in the past year and their self-reported measures of their general health. Individuals with a checkup in the previous year were 6.0, 9.0, and 8.7 percentage points more likely to have a flu shot, colonoscopy and blood test relative to people who had not visited a doctor's office in the previous year ${ }^{40}$. The lower individuals rated their self-reported health, the more likely they were to receive preventive care services as well, although only slightly so.

The control variables were significant at the 99 percent level in almost all cases and in most cases do not change signs. In all cases men were less likely to receive the preceding preventive care services than women, similar to Vaidya et al. (2012). Older individuals were more likely to seek out preventive care. Those with higher BMI levels were more likely to seek out these services. In all cases smokers were less likely to receive the services. Employed individuals were more likely to receive blood cholesterol checks, but less likely to receive a flu shot or a colonoscopy.

\footnotetext{
${ }^{40}$ Regressions were also run without controlling for a check-up in the previous year due to a concern that the check-up last year variable might be picking up some of the effects of insurance coverage. As a result the marginal effect of the health plan variable increased slightly by a range of 0.1 to 1 percentage point which indicates that the health plan variable was accounting for some of the effect of visiting a doctor in the previous year.
} 
I now proceed with an examination of utilization of prostate checks for prostate cancer. This sections uses the same BRFSS sample from 2005-2012, but limits the sample to men only since there is no prostate check for women. Summary statistics for this section can be found in Table 19 and the results for this section are presented in Table 20.

Similar to Wu (2003) and Pagán et al. (2007), individuals with a health plan and a checkup last year were both more likely to receive a prostate check in the previous year with marginal effects of 0.045 and 0.097 respectively. Similar to most of the regressions in the previous section, the results from prostate check regressions show an income bias. Relative to the highest income earners in the sample, the lowest income earners are 5 percentage points less likely to receive a prostate check. A person's self-reported general health status seems to have a very small and insignificant effect on prostate check utilization. Older individuals and those with higher levels of education are more likely to receive a prostate check. Blacks were more likely to have their prostates checked than whites.

I now move on to regressions of women-specific preventive care services. In this section I examine the usage of mammograms, Pap smears, breast physical exams, and HPV vaccinations. The results from these regressions are presented in Table 21.

Similar to the findings from the full sample, women with health insurance were more likely to use preventive care services. I estimate marginal effects of $0.049,0.009$ and 0.027 for mammograms, pap smears and breast physical examinations respectively. This implies that women with insurance coverage are 4.9, 0.9 and 2.7 percentage points more likely to receive the preceding preventive services than women without coverage. Women with insurance 
coverage were also much more likely to have an HPV vaccination. I estimate a marginal effect of 0.093 for HPV vaccinations, which implies that women with insurance coverage are 9.3 percentage points more likely to have the series of HPV vaccination injections than those without coverage.

Similar to the full sample I also examine how income can affect a woman's decision to use preventive services. Women in the lowest income category were 2.1 percentage points less likely to have a mammogram. However, I find that women in the medium and medium-high income groups were more likely to have a mammogram than those in the highest income group. These results were very small though. Pap smears examinations also follow a similar trend with women in the lowest income group being the least likely to have pap smear while women in the middle income groups were slightly more likely than women in the highest income group to have a pap smear.

Women who had a checkup in the previous year were more likely to have use the preceding preventive services. I estimate marginal effects of $0.055,0.014,0.035$, and 0.100 for mammograms, pap smears, breast physical examinations and HPV vaccinations. For HPV vaccinations, women with a check-up in the previous year were 10 percentage points more likely to have the series of vaccinations. This highlights how visiting a doctor can be a significant driver in the usage of relatively new preventive care services. There was not a large difference in the likelihood of using preventive care services between women who rated themselves as being in poor health and women who rated themselves as being in good health. 
Identical control variables were used in all four women-specific regressions. In all regressions, as women age they are less likely to seek out these services, but only slightly so. In all cases higher levels of education lead to higher utilization of these preventive care services similar to Wu (2003). Smokers were less likely to receive mammograms and HPV vaccinations, but more likely to have a Pap smear or breast physical examination. Those with higher BMI levels were more likely to have mammograms, Pap smears, and breast physical examinations, but less likely to have the series of HPV vaccinations. Single women were more likely than married women to have an HPV vaccination, but less likely than married women to have a mammogram, Pap smear, or breast physical examination. Black women were more likely than white women to have mammograms, Pap smears, and the series of HPV vaccinations, but only slightly so.

\section{Different Types of Insurance Coverage}

In this section I present results from the series of models that explain the utilization of various preventive care services as a function of different types insurance coverage. BRFSS data from 1996-2000 are used since these are the only years the survey asked about respondent's specific type of insurance coverage. I analyze six types of insurance coverage and 7 preventive care outcomes. Summary statistics for this section are shown in Table 22 and results are shown in Table 23 and Table 24. This sub-section is also broken down into two sub-sections: results from the full sample including men and women and results from the limited sample of female specific preventive care outcomes.

Shown in column 1 of Table 23, flu shot utilization varied greatly among respondents with different types of insurance coverage. With the exception of military coverage, all other 
respondents with different types of insurance coverage were less likely to receive a flu shot than those with private coverage. Relative to those with a private insurance plan, those with insurance coverage through the military were much more likely to receive a flu shot vaccination. The sample mean for those receiving flu shot was 0.23 . The marginal effects for those with military coverage was 0.213 , meaning that the average person with military coverage had 21.3 percentage points higher likelihood of receiving a flu shot than those with private coverage. The marginal effects for flu shot utilization for employer, Medicaid, other, and no coverage are $0.000,-0.039,-0.010$, and -0.069 respectively. Those with no insurance coverage were the least likely to receive a flu shot in the previous year. Those visiting a doctor's office for a check-up in the previous year were 9.3 percentage points more likely to receive a flu shot than the sample mean. Also, individuals who rated themselves in poorer health were 1.7 percentage points more likely to receive a flu shot.

The results for colonoscopy screenings are presented in column 2 of Table 23. Those with employer military coverage were more likely to receive a colonoscopy screening than those with private insurance coverage, however the resulting marginal effects were not significant. Those with no coverage were 2.3 percentage points less likely to receive a colonoscopy than those with private insurance coverage. This result was significant at the 99 percent level. Those with Medicaid and other coverage were only slightly less likely to have a colonoscopy than those with private insurance, however these results came in as insignificant. Again if an individual visited a doctor's office for a check-up within the previous year they were 4.3 percentage points more likely to receive a colonoscopy than the average individual in the 
sample. Those who rated themselves as having poor health were 1.1 percentage points more likely to have a colon screening than the sample mean.

Presented in column 3 of Table 23 are results on the utilization of blood cholesterol tests. Similar to the colonoscopy results, those with employer and military coverage were more likely to receive a blood cholesterol test. Those with military coverage were 8.8 percentage points more likely to receive a blood cholesterol test than those with private coverage. The marginal effects for employer, military, Medicaid, other, and no coverage were $0.003,0.088$, $0.009,-0.001$, and -0.082 respectively. The marginal effects for military and no coverage are significant at the 99 percent level. Those who received a check-up within the past year were 17.1 percentage points more likely to receive a blood cholesterol test than the sample mean and those with poorer ratings of self-assessed health status were 0.9 percentage points more likely than the sample mean. Both of these results are significant at the 99 percent level.

The above results are similar to those found by Pagán et al. (2007). Insured individuals are more likely to use preventive screenings than uninsured individuals. The control variables included in the preceding regressions had similar magnitudes and generally retained their significance across regressions. Similar to Wu (2003), individuals with higher levels of education are more likely to seek out these preventive health care services. All marginal effects for education were positive and significant at the 99 percent level. With the exception of HIV testing, as individuals age they were more likely to seek out preventive services. Also, with the exception of HIV testing, smokers were less likely to seek out preventive services. With the exception of blood cholesterol tests, men were more likely than women to participate in preventive screenings similar to Vaidya et al. (2012). 
The following paragraphs present results of regressions for female-specific preventive health care measures. These results are presented in Table 24, beginning with mammogram screenings which are presented in column 1. The marginal effects for employer, military, Medicaid, other, and no coverage are $0.008,0.014,-0.021,0.009,-0.052$ respectively. Those with employer coverage were 0.7 percentage points more likely to receive a mammogram than those with privately-sourced insurance. This result is significant at the 95 percent level. Those with Medicaid coverage were 2.1 percentage points and those with no coverage were 5.2 percentage points less likely to receive a mammogram than those with private coverage. Women who visited a doctor's office in the previous year were 15 percentage points more likely to have a mammogram and those who rated themselves in poorer health were 0.4 percentage points more likely to have a mammogram in the past year. Both of these marginal effects are significant at the 99 percent level.

Most women in the sample seemed to have had a Pap smear screen. The sample mean for a Pap smear screening was 0.98. However all types of insurance coverage point to an increased likelihood of receiving a Pap smear. The marginal effects for employer, military, Medicaid, other, and no coverage were $0.005,0.007,0.012,0.002$, and 0.000 respectively. The marginal effects for employer, military, and Medicaid coverage were significant at the 99 percent level. Women having a check-up within the past year were 2.0 percentage points more likely to have a Pap smear. Also those with poorer ratings of self-reported health were less likely to have a Pap smear by 0.1 percentage points. The marginal effects for these two variables are significant at the 99 percent level. 
In regressions examining the utilization of breast physical examinations, the marginal effects for employer, military, Medicaid, other, and no coverage are 0.011, 0.020, 0.015, 0.001, -0.011 respectively. The marginal effects for employer, military, and Medicaid are significant at the 99 percent level. Those having a check-up within the past year were 5 percentage points more likely to have a breast-physical examination and this marginal effect is significant at the 99 percent level. Those who rate their health poorer were less likely to receive a breast physical examination by 0.3 percentage points. This marginal effect is also significant at the 99 percent level.

Since mammograms are recommended for those above 50 years of age, it is not surprising that the marginal effect for the age variable is negative. Even with the mammogram sample restricted to women over 50 , younger women were less likely to have a mammogram. However, this marginal effect is very small and not significant. Education and income level have a positive relationship with the utilization or preventive services among women, similar to $\mathrm{Wu}$ (2003). In all cases the marginal effects for education and income are significant at the 99 percent level. Single women are less likely to seek out these preventive services than married women and this marginal effect is significant at the 99 percent level. Women who smoked are more likely to have Pap smears and breast physical examinations but less like to have a mammogram. The marginal effect for women who smoke is also significant at the 99 percent level. Women with higher income levels were $0.5-1.0$ percentage points more likely to receive preventive services similar to Carrieri and Wuebker (2013). 


\subsection{Discussion and Conclusion}

This Paper has examined the utilization of several different preventive care services by looking at differences in the specific type of insurance coverage held by an individual and differences in income among individuals. Results show that there are indeed differences in the usage of preventive services.

In the first section of this paper I find that there is a significant pro-high income bias in the usage of preventive services similar to Carrieri and Wuebker (2013). In the first section of this paper, individuals were divided into 5 income groups. With the exception of HIV testing and HPV vaccinations, individuals become more likely to utilize preventive services as they climb through the different income groups. That is, individuals in higher income groups are more likely to use preventive services than those in the middle income groups who are more likely to use preventive services than those in low income groups.

In this section I was also able to take a look at two preventive services that were not asked about in earlier years of the sample. Prostate cancer checks followed similar trends as other preventive services, namely as individuals age and have higher levels of education and if they have had a check-up in the last year, they are more likely to have a prostate cancer screening. Questions about HPV vaccinations were asked in the latest years of the survey. However, the number of observations, roughly 5,284 , is much smaller relative to the other samples analyzed in this paper. HPV vaccination data is only available in the later years of the BRFSS survey and the sample is limited to those between ages 18 and 26 per the recommended age limit for receiving the HPV vaccination. Perhaps the sample size is responsible for the unique results. Individuals in the lowest and highest income groups were very similar in there 
usage of preventive services. However, those in the middle income groups were much more likely to receive a vaccination. More observations would help increase the understanding of this result. It could be that this is a relatively cheap vaccination that can prevent the spread of several strains sexually transmitted diseases as well as cervical cancer and because of the cost, individuals from all income groups are equally likely to make use of it.

A significant driver in the majority of these preventive care screenings appears to be whether or not an individual has visited a doctor's office in the previous year. Perhaps a yearly chat with one's doctor can lead to a significant increase in the take-up of preventive care services. In all cases the effect of a check-up in the last year carries the same sign as the insurance coverage variable which leads me to believe that it too is an important driver in the decision to use many preventive care screenings ${ }^{41}$.

To conclude, the paper has shown that individuals with certain types of insurance coverage or no coverage are less likely to receive preventive services. Also there is a pro-rich bias in the utilization of most of the preventive services considered in this paper. In the future with more individuals gaining insurance coverage through the newly passed Affordable Care Act, I expect that we will continue to see an increase in the utilization of preventive services throughout the country.

In the second section of this Paper I examined how individuals with insurance coverage from an employer or their spouse's employer, the military, Medicaid, some sort of other coverage, and those with no coverage use preventive care services relative to those who have

\footnotetext{
${ }^{41}$ Regressions were also run without controlling for a check-up in the previous year. As a result the marginal effect of the health plan variable increased slightly by a range of 0.1 to 1 percentage point which shows that the health plan variable was accounting for some of the effect of visiting a doctor in the previous year.
} 
purchased their own insurance coverage on the private market. Individuals with insurance coverage through a branch of the military seem to have higher rates of utilization of services relative to private coverage, than any other type of coverage. This could be a result of the military's preference to ensure that its personnel are in good health and to make sure they are fit for service. With the exception of flu shots and HIV tests, individuals with employer coverage were more likely than those with private insurance plans use the preventive services covered in this paper. However, these results were very small, which indicates that there is not a significant difference in utilization of preventive services between employer sponsored and privately purchased insurance plans.

Individuals with coverage through Medicaid were less to have a mammogram, flu shot, and blood cholesterol test than those with private coverage. However, Medicare coverage holders were 12 percentage points more likely to have an HIV test than individuals with private insurance coverage. Initially I believed that this could be because poorer individuals are more likely to contract HIV. However, Gillespe et al. (2007) state that "whereas it is true poor individuals and households are more likely to be hit harder by the downstream impacts of AIDS, their chances of being exposed to HIV in the first place are not necessarily greater than wealthier individuals or households." Medicare providers could possible realize the potential difficulties for poorer individuals with AIDS and thus make a greater effort for recommending testing for poor individuals.

Similar to Pagán et al. (2007), individuals with no coverage were much less likely than those with private coverage to receive any type of preventive care covered in this paper. Individuals with no coverage were 6.9 percentage points less likely to receive a flu shot, 2.3 
percentage points less likely to receive a colonoscopy, 8.2 percentage points less likely to receive a blood cholesterol check, 1.8 percentage points less likely to receive an HIV screening, 5.2 percentage points less likely to receive a mammogram, and 1.1 percentage points less likely to receive a breast physical exam. It seems that once an individual becomes covered by any type of insurance, they are more likely to receive preventive services. 


\subsection{Tables}

Table 18: 2005-2012 Full Sample Summary Statistics

\begin{tabular}{|c|c|}
\hline Flu Shot & $0.423(0.0004)$ \\
\hline Colonoscopy & $0.019(0.0001)$ \\
\hline Blood Cholesterol Test & $0.872(0.0002)$ \\
\hline \multicolumn{2}{|l|}{ Income Categories } \\
\hline$\$ 0-\$ 14,999$ & $0.104(0.0002)$ \\
\hline$\$ 15,000-\$ 24,999$ & $0.156(0.0002)$ \\
\hline$\$ 25,000-\$ 49,999$ & $0.251(0.0002)$ \\
\hline$\$ 50,000-\$ 74,999$ & $0.246(0.0002)$ \\
\hline$\$ 75,000+$ & $0.216(0.0002)$ \\
\hline Health Plan (1=yes) & $0.886(0.0002)$ \\
\hline Doctor Visit Last Year & $0.715(0.0003)$ \\
\hline Sex (Male=1) & $0.395(0.0003)$ \\
\hline Age & $54.47(0.010)$ \\
\hline Less Than High School & $0.031(0.0001)$ \\
\hline Some High School & $0.063(0.0001)$ \\
\hline High School Grad & $0.300(0.0003)$ \\
\hline Some College & $0.267(0.0002)$ \\
\hline College Grad & $0.339(0.0003)$ \\
\hline Employed & $0.519(0.0003)$ \\
\hline Unemployed & $0.049(0.0001)$ \\
\hline Not In Labor Force & $0.430(0.0003)$ \\
\hline Smoker & $0.174(0.0002)$ \\
\hline $\mathrm{BMI}$ & $27.47(0.003)$ \\
\hline White & $0.786(0.0002)$ \\
\hline Black & $0.079(0.0002)$ \\
\hline Hispanic & $0.068(0.0001)$ \\
\hline Asian/Pacific Islander & $0.040(0.0001)$ \\
\hline Other Race & $0.086(0.0002)$ \\
\hline Single & $0.126(0.0002)$ \\
\hline Married & $0.550(0.0003)$ \\
\hline Divorced & $0.141(0.0002)$ \\
\hline Unmarried Couple & $0.023(0.0000)$ \\
\hline Self-Reported General Health Status & $2.56(0.0006)$ \\
\hline
\end{tabular}

Note: Means and standard errors presented here. Standard errors are in parentheses. 
Table 19: 2005-2012 Limited Sample Summary Statistics

\begin{tabular}{|c|c|c|c|}
\hline & Males Only & $\begin{array}{l}\text { Females Only (HPV } \\
\text { Vaccinations } \\
\text { Excluded) }\end{array}$ & $\begin{array}{l}\text { Females Only (HPV } \\
\text { Vaccinations Included) }\end{array}$ \\
\hline Prostate Check & $0.26(0.00039)$ & -- & -- \\
\hline Mammogram & -- & $0.79(0.00040)$ & -- \\
\hline Pap Smear & -- & $0.96(0.00020)$ & -- \\
\hline Breast Physical Exam & -- & $0.92(0.00027)$ & -- \\
\hline HPV Vaccination & -- & -- & $0.074(0.0014)$ \\
\hline \multicolumn{4}{|l|}{ Income Categories } \\
\hline$\$ 0-\$ 14,999$ & 0.079 (0.00024) & $0.12(0.00032)$ & $0.092(0.0015)$ \\
\hline$\$ 15,000-\$ 24,999$ & $0.14(0.00031)$ & $0.17(0.00037)$ & $0.13(0.0017)$ \\
\hline$\$ 25,000-\$ 49,999$ & $0.25(0.00039)$ & $0.24(0.00042)$ & $0.21(0.0021)$ \\
\hline$\$ 50,000-\$ 74,999$ & $0.16(0.00033)$ & $0.14(0.00034)$ & $0.16(0.0019)$ \\
\hline$\$ 75,000+$ & $0.28(0.00040)$ & $0.20(0.00040)$ & $0.32(0.0024)$ \\
\hline Health Plan (1=yes) & $0.88(0.00029)$ & $0.90(0.00030)$ & $0.87(0.0018)$ \\
\hline Doctor Visit Last Year & $0.66(0.00042)$ & $0.75(0.00043)$ & $0.72(0.0023)$ \\
\hline Age & $53.68(0.015)$ & $55.10(0.017)$ & $37.00(0.047)$ \\
\hline Less Than High School & $0.032(0.0002)$ & $0.038(0.0002)$ & $0.006(0.001)$ \\
\hline Some High School & $0.060(0.0002)$ & $0.071(0.0002)$ & $0.057(0.004)$ \\
\hline High School Grad & $0.292(0.0004)$ & $0.337(0.0005)$ & $0.257(0.008)$ \\
\hline Some College & $0.247(0.0004)$ & $0.271(0.0004)$ & $0.343(0.009)$ \\
\hline College Grad & $0.366(0.0004)$ & $0.281(0.0004)$ & $0.336(0.009)$ \\
\hline Employed & $0.59(0.00044)$ & $0.47(0.00049)$ & $0.68(0.0024)$ \\
\hline Unemployed & $0.053(0.00020)$ & $0.046(0.00021)$ & $0.072(0.0013)$ \\
\hline Not In Labor Force & $0.36(0.00043)$ & $0.48(0.00049)$ & $0.25(0.0022)$ \\
\hline Smoker & $0.19(0.00035)$ & $0.16(0.00037)$ & $0.20(0.00021)$ \\
\hline BMI & $27.92(0.0045)$ & $27.21(0.060)$ & $26.95(0.033)$ \\
\hline White & $0.80(0.00036)$ & $0.78(0.00041)$ & $0.74(0.0023)$ \\
\hline Black & $0.065(0.00022)$ & $0.090(0.00028)$ & $0.089(0.0015)$ \\
\hline Hispanic & $0.066(0.00022)$ & $0.067(0.00025)$ & $0.11(0.0016)$ \\
\hline Asian/Pacific Islander & $0.043(0.00018)$ & $0.037(0.00019)$ & $0.041(0.0010)$ \\
\hline Other Race & $0.084(0.00025)$ & $0.086(0.00028)$ & $0.13(0.0017)$ \\
\hline Single & $0.15(0.00032)$ & $0.11(0.00031)$ & $0.21(0.0021)$ \\
\hline Married & $0.62(0.00043)$ & $0.51(0.00049)$ & $0.57(0.0026)$ \\
\hline Divorced & $0.13(0.00030)$ & $0.15(0.00036)$ & $0.12(0.0017)$ \\
\hline Unmarried Couple & $0.025(0.00014)$ & $0.022(0.00014)$ & $0.041(0.0010$ \\
\hline $\begin{array}{l}\text { Self-Reported General Health } \\
\text { Status }\end{array}$ & $2.55(0.00098)$ & $2.57(0.0011)$ & $2.29(0.0053)$ \\
\hline Observations & $1,216,047$ & $1,388,030$ & 5,284 \\
\hline
\end{tabular}

Note: Means and standard errors presented here. Standard errors are in parentheses. The HPV sample is limited to women under 50 because there were no women in the sample receiving this vaccination. 
Table 20: Utilization of Select Preventive Care Services by Income Level among Males and Females 20052012: Results from Logit Regressions.

\begin{tabular}{|c|c|c|c|}
\hline & $\begin{array}{c}\text { Flu Shot: } \\
P(F S)=0.336\end{array}$ & $\begin{array}{c}\text { Colonoscopy } \\
\mathrm{P}(\text { Colon })=0.160\end{array}$ & $\begin{array}{c}\text { Blood Cholesterol Test } \\
\qquad P(B C)=0.918\end{array}$ \\
\hline Health Plan & $0.134(0.002)^{* *}$ & $0.085(0.001)^{* *}$ & $0.058(0.001)^{* *}$ \\
\hline Low Income & $-0.032(0.003)^{* *}$ & $-0.045(0.001)^{* *}$ & $-0.042(0.001)^{* *}$ \\
\hline Med-Low Income & $-0.004(0.002)$ & $-0.033(0.001)^{* *}$ & $-0.037(0.001)^{* *}$ \\
\hline Medium Income & $-0.007(0.002)^{* *}$ & $-0.007(0.001)^{* *}$ & $-0.021(0.001)^{* *}$ \\
\hline Medium-High Income & $-0.012(0.002)^{* *}$ & $0.009(0.001)^{* *}$ & $-0.006(0.001)^{* *}$ \\
\hline Check-Up Last Year & $0.060(0.004)^{* *}$ & $0.092(0.001)^{* *}$ & $0.087(0.001)^{* *}$ \\
\hline Gender (Male=1) & $-0.011(0.002)^{* *}$ & $-0.005(0.001)^{* *}$ & $-0.010(0.000)^{* *}$ \\
\hline Age & $0.010(0.000)^{* *}$ & $0.002(0.000)^{* *}$ & $0.004(0.000)^{* *}$ \\
\hline Less Than High School & $-0.097(0.003)^{*}$ & $-0.097(0.001)^{* *}$ & $-0.159(0.002)^{* *}$ \\
\hline Some High School & $-0.064(0.002)^{* *}$ & $-0.081(0.001)^{* *}$ & $-0.105\left(0.0071^{* *}\right.$ \\
\hline High School Grad & $-0.050(0.002)^{*}$ & $-0.060(0.001)^{* *}$ & $-0.059(0.001)$ \\
\hline Some College & $-0.026(0.002)^{* *}$ & $-0.032(0.001)^{* *}$ & $-0.027(0.001)^{* *}$ \\
\hline Employed & $-0.057(0.002)^{* *}$ & $-0.041(0.001)^{* *}$ & $0.008(0.000)^{* *}$ \\
\hline Unemployed & $-0.076(0.004)^{* *}$ & $-0.027(0.001)^{* *}$ & $0.005(0.001)^{* *}$ \\
\hline BMI & $0.001(0.000)^{* *}$ & $0.002(0.000)^{* *}$ & $0.003(0.000)^{* *}$ \\
\hline Smoker & $-0.062(0.002)^{* *}$ & $-0.050(0.001)^{* *}$ & $-0.016(0.000)^{* *}$ \\
\hline Black & $-0.047(0.004)^{* *}$ & $-0.020(0.001)^{* *}$ & $-0.012(0.001)^{* *}$ \\
\hline Hispanic & $-0.002(0.004)$ & $-0.029(0.002)^{* *}$ & $-0.016(0.002)^{* *}$ \\
\hline Asian/PI & $0.024(0.005)^{* *}$ & $-0.049(0.001)^{* *}$ & $-0.024(0.001)^{* *}$ \\
\hline Other Race & $-0.016(0.005)^{* *}$ & $-0.014(0.001)^{* *}$ & $-0.012(0.001)$ \\
\hline Single & $0.054(0.003)^{* *}$ & $-0.037(0.002)^{* *}$ & $-0.026(0.001)^{* *}$ \\
\hline Divorced & $-0.022(0.002)^{* *}$ & $-0.008(0.001)^{* *}$ & $0.004(0.001)^{* *}$ \\
\hline Un-Married Couple & $0.009(0.002)$ & $-0.013(0.002)^{* *}$ & $-0.020(0.001)^{* *}$ \\
\hline General Health & $0.029(0.001)^{* *}$ & $0.008(0.000)^{* *}$ & $0.005(0.000)^{* *}$ \\
\hline Observations & 487,974 & $1,982,153$ & $1,938,110$ \\
\hline
\end{tabular}

Note: Standard errors in parentheses. These marginal effects are calculated with a standard Logit model with state and year fixed effects and state-clustered standard errors. ** results are significant at the $1 \%$ level and * are significant at the $5 \%$ level. State and year controls employed in all regressions. Colonoscopy regressions are limited to those age 50 and above. 
Table 20: Utilization of Prostate Checks by Income Level among Males 2005-2012

\begin{tabular}{|c|c|}
\hline & $\begin{array}{c}\text { Prostate Check } \\
\mathrm{P}(\text { Prostate })=0.138\end{array}$ \\
\hline Health Plan & $0.045(0.001)^{* *}$ \\
\hline Low Income & $-0.050(0.001)^{* *}$ \\
\hline Med-Low Income & $-0.039(0.001)^{* *}$ \\
\hline Medium Income & $-0.012(0.001)^{* *}$ \\
\hline Medium-High Income & $-0.004(0.001)^{* *}$ \\
\hline Check-Up Last Year & $0.097(0.001)^{* *}$ \\
\hline Age & $0.007(0.000)^{* *}$ \\
\hline Less Than High School & $-0.085(0.001)^{* *}$ \\
\hline Some High School & $-0.075(0.001)$ \\
\hline High School Grad & $0.051(0.001)^{* *}$ \\
\hline Some College & $0.024(0.001)^{* *}$ \\
\hline Employed & $0.013(0.000)^{* *}$ \\
\hline Unemployed & $0.006(0.002)^{* *}$ \\
\hline Smoker & $-0.023(0.001)^{* *}$ \\
\hline Black & $0.034(0.001)^{* *}$ \\
\hline Hispanic & $0.005(0.001)$ \\
\hline Asian/Pacific Islander & $-0.050(0.001)^{* *}$ \\
\hline Other Race & $-0.010(0.003)^{* *}$ \\
\hline Single & $-0.031(0.001)^{* *}$ \\
\hline Divorced & $-0.006(0.001)^{* *}$ \\
\hline Unmarried Couple & $-0.007(0.003)^{* *}$ \\
\hline General Health & $-0.002(0.000)^{* *}$ \\
\hline Observations & $1,216,047$ \\
\hline
\end{tabular}

Note: Standard errors in parentheses. These marginal effects are calculated with a standard Logit model with state and year fixed effects and state-clustered standard errors. ${ }^{* *}$ results are significant at the $1 \%$ level and ${ }^{*}$ are significant at the $5 \%$ level. State and year controls employed in all regressions. Males only included in regressions. Only with age 40 and above included in regressions. 
Table 21: Utilization of Select Preventive Care Services by Income Level among Females 20052012: Results from Logit Regressions

\begin{tabular}{|c|c|c|c|c|}
\hline & $\begin{array}{c}\text { Mammogram } \\
P(\text { Mam })=0.963\end{array}$ & $\begin{array}{c}\text { Pap Smear } \\
P(\text { Pap })=0.970\end{array}$ & $\begin{array}{l}\text { Breast Physical Exam } \\
\qquad P(B F E)=0.0937\end{array}$ & $\begin{array}{l}\text { HPV Vaccination } \\
\mathrm{P}(\mathrm{HPV})=0.0302\end{array}$ \\
\hline Health Plan & $0.049(0.001)^{* *}$ & $0.009(0.001)^{* *}$ & $0.027(0.001)^{* *}$ & $0.093(0.017)^{* *}$ \\
\hline Low Income & $-0.021(0.001)^{* *}$ & $-0.001(0.000)^{*}$ & $-0.020(0.001)^{* *}$ & $-0.043(0.020)^{*}$ \\
\hline Med-Low Income & $-0.010(0.001)^{* *}$ & $0.001(0.000)$ & $-0.014(0.001)^{* *}$ & $-0.053(0.018)^{* *}$ \\
\hline Medium Income & $0.001(0.001)$ & $0.008(0.000)^{* *}$ & $0.005(0.001)^{* *}$ & $-0.040(0.018)^{*}$ \\
\hline Medium-High Income & $0.005(0.001)^{* *}$ & $0.014(0.000)^{* *}$ & $0.024(0.001)^{* *}$ & $-0.024(0.021)$ \\
\hline Check-Up Last Year & $0.055(0.001)^{* *}$ & $0.014(0.000)^{* *}$ & $0.035(0.001)^{* *}$ & $0.100(0.014)^{* *}$ \\
\hline Age & $-0.001(0.000)^{* *}$ & $0.000(0.000)^{* *}$ & $0.000(0.000)^{* *}$ & $0.012(0.001)^{* *}$ \\
\hline Less Than High & $-0.053(0.004)$ & $-0.063(0.002)^{* *}$ & $-0.128(0.002)^{* *}$ & $-0.163(0.053)^{* *}$ \\
\hline Some High School & $-0.041(0.001)$ & $-0.051(0.001)^{* *}$ & $-0.108(0.002)^{* *}$ & $0.008(0.032)$ \\
\hline High School Grad & $-0.021(0.001)^{* *}$ & $-0.027(0.001)^{* *}$ & $-0.059(0.001)^{* *}$ & $0.024(0.019)$ \\
\hline Some College & $-0.010(0.001)^{* *}$ & $-0.015(0.001)^{* *}$ & $-0.026(0.001)^{* *}$ & $0.045(0.017)^{* *}$ \\
\hline Employed & $-0.005(0.001)^{* *}$ & $0.021(0.000)^{* *}$ & $0.027(0.001)^{* *}$ & $-0.012(0.015)$ \\
\hline Unemployed & $-0.002(0.001)$ & $0.012(0.000)^{* *}$ & $0.014(0.001)^{* *}$ & $-0.015(0.024)$ \\
\hline BMI & $0.001(0.000)^{* *}$ & $0.001(0.000)^{* *}$ & $0.001(0.000)^{* *}$ & $-0.001(0.001)$ \\
\hline Smoker & $-0.026(0.001)^{* *}$ & $0.012(0.000)^{* *}$ & $0.007(0.001)^{* *}$ & $-0.033(0.017)$ \\
\hline Black & $0.005(0.001)^{* *}$ & $0.003(0.001)^{* *}$ & $-0.014(0.001)^{* *}$ & $-0.090(0.019)^{* *}$ \\
\hline Hispanic & $0.011(0.001)^{* *}$ & $-0.004(0.001)^{* *}$ & $-0.037(0.003)^{* *}$ & $0.043(0.048)$ \\
\hline Asian/PI & $-0.010(0.001)^{* *}$ & $-0.044(0.001)^{* *}$ & $-0.086(0.002)^{* *}$ & $-0.037(0.030)$ \\
\hline Other Race & $-0.006(0.002)^{* *}$ & $-0.003(0.001)^{* *}$ & $-0.007(0.002)^{* *}$ & $-0.043(0.039)$ \\
\hline Single & $-0.031(0.001)^{* *}$ & $-0.093(0.001)^{* *}$ & $-0.083(0.001)^{* *}$ & $0.254(0.015)^{* *}$ \\
\hline Divorced & $-0.001(0.001)$ & $0.003(0.000)^{* *}$ & $0.006(0.001)^{* *}$ & $0.015(0.052)$ \\
\hline Un-Married Couple & $-0.010(0.002)^{* *}$ & $-0.007(0.001)^{* *}$ & $-0.014(0.002)^{* *}$ & $0.222(0.034)^{* *}$ \\
\hline General Health & $0.003(0.000)^{* *}$ & $-0.001(0.000)^{* *}$ & $-0.003(0.003)^{* *}$ & $-0.019(0.008)^{*}$ \\
\hline Observations & 828,730 & $1,388,030$ & $1,387,980$ & 5,284 \\
\hline \multicolumn{5}{|c|}{$\begin{array}{l}\text { Note: Standard errors in parentheses. These marginal effects are calculated with a standard Logit model with state } \\
\text { and year controls and state-clustered standard errors. }{ }^{* *} \text { results are significant at the } 1 \% \text { level and }{ }^{*} \text { are significant } \\
\text { at the } 5 \% \text { level. State and year controls employed in all regressions. HPV Vaccinations are limited to women below } \\
\text { the age of } 26 . \text { Mammogram regressions are limited to those over } 50 .\end{array}$} \\
\hline
\end{tabular}


Table 22: 1996-2000 Sample Summary Statistics

\begin{tabular}{|c|c|c|}
\hline & Males and Females & Females Only \\
\hline Flu Shot & $0.23(0.0019)$ & - \\
\hline Colonoscopy & $0.11(0.0014)$ & -- \\
\hline Blood Cholesterol Test & $0.72(0.0020)$ & -- \\
\hline HIV Test & $0.45(0.0022)$ & -- \\
\hline Mammogram & -- & $0.55(0.0010)$ \\
\hline Pap Smear & -- & $0.97(0.00038)$ \\
\hline Breast Physical Exam & -- & $0.92(0.00058)$ \\
\hline Employer Coverage & $0.65(0.0021)$ & $0.67(0.00099)$ \\
\hline Private Coverage & $0.062(0.0011)$ & $0.067(0.00052)$ \\
\hline Military Coverage & $0.012(0.00048)$ & $0.014(0.00025)$ \\
\hline Medicaid Coverage & $0.050(0.00096)$ & $0.046(0.00044)$ \\
\hline Other Coverage & $0.014(0.00051)$ & $0.013(0.00024)$ \\
\hline No Coverage & $0.16(0.0016)$ & $0.14(0.00074)$ \\
\hline Doctor Visit Last Year & $0.75(0.0019)$ & $0.75(0.00091)$ \\
\hline Sex (Male=1) & $0.42(0.00058)$ & -- \\
\hline Age & $40.91(0.053)$ & $40.04(0.025)$ \\
\hline Less Than High School & $0.027(0.0002)$ & $0.026(0.0003)$ \\
\hline Some High School & $0.068(0.003)$ & $0.069(0.0004)$ \\
\hline High School Grad & $0.32(0.006)$ & $0.321(0.008)$ \\
\hline Some College & $0.29(0.006)$ & $0.300(0.0008)$ \\
\hline College Grad & $0.30(0.006)$ & $0.283(0.0008)$ \\
\hline Income & $5.08(0.0090)$ & $5.12(0.0043)$ \\
\hline Employed & $0.69(0.0020)$ & $0.71(0.00095)$ \\
\hline Unemployed & $0.043(0.00090)$ & $0.042(0.00042)$ \\
\hline Not In Labor Force & $0.25(0.0019)$ & $0.24(0.00090)$ \\
\hline Smoker & $0.26(0.0019)$ & $0.25(0.00091)$ \\
\hline White & $0.82(0.0017)$ & $0.83(0.00079)$ \\
\hline Black & $0.11(0.0014)$ & $0.10(0.00064)$ \\
\hline Hispanic & $0.085(0.0012)$ & $0.082(0.00057)$ \\
\hline Asian/Pacific Islander & $0.020(0.00060)$ & $0.021(0.00030)$ \\
\hline Other Race & $0.042(0.00088)$ & $0.040(0.00041)$ \\
\hline Single & $0.16(0.0016)$ & $0.17(0.00079)$ \\
\hline Married & $0.56(0.0022)$ & $0.56(0.0010)$ \\
\hline Divorced & $0.17(0.0017)$ & $0.16(0.00077)$ \\
\hline Unmarried Couple & $0.024(0.00067)$ & $0.026(0.00033)$ \\
\hline $\begin{array}{l}\text { Self-Reported General Health Status } \\
\text { (Ranked 1-5 with } 5 \text { being poor health) }\end{array}$ & $2.35(0.0047)$ & $2.27(0.0022)$ \\
\hline Observations & 606,937 & 349,712 \\
\hline
\end{tabular}

Note: Means and standard errors presented here. Standard errors are in parentheses. 
Table 23: Utilization of Select Preventive Care Services by Type of Health Care Coverage among Males and Females 1996-2000: Marginal Effects of Logit Regressions Presented

\begin{tabular}{|c|c|c|c|c|}
\hline & Flu Shot: $P(F S)=0.23$ & $\begin{array}{c}\text { Colonoscopy: } \\
\mathrm{P}(\text { Colon })=0.11\end{array}$ & $\begin{array}{l}\text { Blood Cholesterol Test: } \\
\qquad P(B C)=0.72\end{array}$ & $\begin{array}{c}\text { HIV Test: } \mathrm{P}(\mathrm{HIV})= \\
0.45\end{array}$ \\
\hline Employer Coverage & $0.000(0.002)$ & $0.002(0.002)$ & $0.003(0.003)$ & $-0.051(0.003)^{* *}$ \\
\hline Military Coverage & $0.213(0.009)^{* *}$ & $0.007(0.005)$ & $0.088(0.006)^{* *}$ & $0.242(0.007)^{* *}$ \\
\hline Medicaid Coverage & $-0.039(0.005)^{* *}$ & $-0.003(0.005)$ & $-0.009(0.006)$ & $0.117(0.006)^{* *}$ \\
\hline Other Coverage & $-0.010(0.007)$ & $-0.006(0.006)$ & $-0.001(0.009)$ & $-0.028(0.008)^{* *}$ \\
\hline No Coverage & $-0.069(0.003)^{* *}$ & $-0.023(0.003)^{* *}$ & $-0.082(0.004)^{* *}$ & $-0.017(0.004)^{* *}$ \\
\hline Check-Up Last Year & $0.093(0.002)^{* *}$ & $0.043(0.002)^{* *}$ & $0.171(0.002)^{* *}$ & $0.095(0.002)^{* *}$ \\
\hline Gender (Male=1) & $0.009(0.002)^{* *}$ & $0.019(0.002)^{* *}$ & $-0.021(0.002)^{* *}$ & $0.035(0.002)^{* *}$ \\
\hline Age & $0.006(0.000)^{* *}$ & $0.005(0.000)^{* *}$ & $0.011(0.000)^{* *}$ & $-0.010(0.000)^{* *}$ \\
\hline Less Than High & $-0.054(0.032)$ & $0.031(0.040)$ & $-0.029(0.046)$ & $0.009(0.045)$ \\
\hline Some High School & $-0.046(0.034)$ & $0.033(0.040)$ & $-0.001(0.042)$ & $0.030(0.0045)$ \\
\hline High School Grad & $-0.040(0.037)$ & $0.043(0.036)$ & $0.037(0.040)$ & $0.040(0.045)$ \\
\hline Some College & $-0.022(0.0038)$ & $0.062(0.041)$ & $0.093(0.037)^{*}$ & $0.111(0.0045)^{*}$ \\
\hline College Grad & $-0.005(0.0039)$ & $0.076(0.043)$ & $0.137(0.035)^{* *}$ & $0.149(0.044)^{* *}$ \\
\hline Income & $0.000(0.001)$ & $0.006(0.001)^{* *}$ & $0.021(0.001)^{* *}$ & $0.003(0.001)^{* *}$ \\
\hline Employed & $-0.004(0.002)$ & $-0.022(0.002)^{* *}$ & $-0.009(0.003)^{* *}$ & $0.009(0.003)^{* *}$ \\
\hline Unemployed & $-0.021(0.005)^{* *}$ & $-0.007(0.004)$ & $-0.002(0.005)$ & $0.041(0.005)^{* *}$ \\
\hline BMI & $0.000(0.000)$ & $0.000(0.000)^{* *}$ & $0.001(0.000)^{* *}$ & $0.000(0.000)^{* *}$ \\
\hline Smoker & $-0.033(0.002)^{* *}$ & $-0.014(0.002)^{* *}$ & $-0.046(0.002)^{* *}$ & $0.078(0.002)^{* *}$ \\
\hline Black & $-0.025(0.003)^{* *}$ & $-0.001(0.003)$ & $-0.020(0.004)^{* *}$ & $0.140(0.003)^{* *}$ \\
\hline Hispanic & $-0.020(0.004)^{* *}$ & $-0.009(0.004)^{* *}$ & $0.004(0.004)$ & $0.006(0.004)$ \\
\hline Asian/PI & $0.025(0.007)^{* *}$ & $-0.032(0.005)^{* *}$ & $-0.064(0.008)^{* *}$ & $-0.090(0.006)^{* *}$ \\
\hline Other Race & $0.031(0.005)^{* *}$ & $-0.006(0.004)$ & $-0.027(0.005)^{* *}$ & $0.032(0.005)^{* *}$ \\
\hline Single & $0.049(0.003)^{* *}$ & $-0.002(0.003)$ & $0.000(0.003)$ & $-0.067(0.003)^{* *}$ \\
\hline Divorced & $0.005(0.005)^{*}$ & $0.006(0.002)^{* *}$ & $0.019(0.003)^{* *}$ & $0.102(0.003)^{* *}$ \\
\hline Un-Married Couple & $0.007(0.006)$ & $-0.005(0.008)$ & $-0.014(0.006)^{*}$ & $0.053(0.006)^{* *}$ \\
\hline General Health & $0.017(0.001)^{* *}$ & $0.011(0.001)^{* *}$ & $0.009(0.001)^{* *}$ & $0.013(0.001)^{* *}$ \\
\hline Observations & 257,462 & 96,309 & 237,550 & 324,603 \\
\hline
\end{tabular}

Note: Standard errors in parentheses. These marginal effects are calculated with a standard Logit model with state and year controls. ${ }^{* *}$ results are significant at the $1 \%$ level and * are significant at the $5 \%$ level. State and year controls employed in all regressions. Colonoscopy regressions are limited to those age 50 and above. 
Table 24: Utilization of Select Preventive Care Services by Type of Health Care Coverage among Females 1996-2000: Marginal Effects of Logit Regressions Presented

\begin{tabular}{|c|c|c|c|}
\hline & $\begin{array}{c}\text { Mammogram: } \mathrm{P}(\text { Mam) } \\
\quad=0.55\end{array}$ & Pap Smear: $\mathrm{P}(\mathrm{Pap})=0.97$ & $\begin{array}{c}\text { Breast Physical Exam: P(BPE) } \\
=0.92\end{array}$ \\
\hline Employer Coverage & $0.008(0.003)^{*}$ & $0.005(0.001)^{* *}$ & $0.011(0.002)^{* *}$ \\
\hline Military Coverage & $0.014(0.008)$ & $0.007(0.002)^{* *}$ & $0.020(0.003)^{* *}$ \\
\hline Medicaid Coverage & $-0.021(0.007)^{* *}$ & $0.012(0.001)^{* *}$ & $0.015(0.002)^{* *}$ \\
\hline Other Coverage & $0.009(0.009)$ & $0.002(0.002)$ & $0.001(0.004)$ \\
\hline No Coverage & $-0.052(0.005)^{* *}$ & $0.000(0.001)$ & $-0.011(0.002)^{* *}$ \\
\hline Check-Up Last Year & $0.152(0.004)^{* *}$ & $0.020(0.001)^{* *}$ & $0.050(0.001)^{* *}$ \\
\hline Age & $0.000(0.000)$ & $0.000(0.000)^{* *}$ & $0.001(0.000)^{* *}$ \\
\hline Less Than High School & $-0.059(0.061)$ & $-0.004(0.009)$ & $-0.031(0.025)$ \\
\hline Some High School & $-0.060(0.059)$ & $0.004(0.006)^{* *}$ & $-0.009(0.019)$ \\
\hline High School Grad & $-0.033(0.043)$ & $0.009(0.006)$ & $0.009(0.016)$ \\
\hline Some College & $-0.020(0.042)$ & $0.013(0.006)^{*}$ & $0.030(0.0014)^{*}$ \\
\hline College Grad & $-0.004(0.039)$ & $0.016(0.005)^{* *}$ & $0.040(0.0013)^{* *}$ \\
\hline Income & $0.010(0.001)^{* *}$ & $0.001(0.000)^{* *}$ & $0.007(0.000)^{* *}$ \\
\hline Employed & $-0.005(0.003)$ & $0.013(0.001)^{* *}$ & $0.009(0.001)^{* *}$ \\
\hline Unemployed & $0.009(0.006)$ & $0.008(0.001)^{* *}$ & $0.004(0.002)^{* *}$ \\
\hline BMI & $0.000(0.000)^{* *}$ & $0.000(0.000)$ & $0.000(0.000)$ \\
\hline Smoker & $-0.033(0.003)^{* *}$ & $0.009(0.000)^{* *}$ & $0.006(0.001)^{* *}$ \\
\hline Black & $-0.004(0.004)$ & $0.007(0.001)^{* *}$ & $-0.014(0.002)^{* *}$ \\
\hline Hispanic & $-0.008(0.005)$ & $-0.010(0.001)^{* *}$ & $-0.031(0.002)^{* *}$ \\
\hline Asian/Pacific Islander & $-0.051(0.017)^{* *}$ & $-0.083(0.005)^{* *}$ & $-0.186(0.008)^{* *}$ \\
\hline Other Race & $-0.008(0.007)$ & $-0.004(0.001)^{* *}$ & $-0.017(0.003)^{* *}$ \\
\hline Single & $-0.026(0.006)^{* *}$ & $-0.058(0.002)^{* *}$ & $-0.049(0.002)^{* *}$ \\
\hline Divorced & $0.013(0.003)^{* *}$ & $-0.001(0.001)$ & $0.007(0.001)^{* *}$ \\
\hline Un-Married Couple & $-0.019(0.015)$ & $-0.012(0.002)^{* *}$ & $-0.002(0.003)$ \\
\hline General Health & $0.004(0.001)^{* *}$ & $-0.001(0.000)^{* *}$ & $-0.003(0.000)^{* *}$ \\
\hline Observations & 54,489 & 227,166 & 227,172 \\
\hline
\end{tabular}

Note: Standard Errors in parentheses. These marginal effects are calculated with a standard Logit model with state and year controls. ${ }^{* *}$ results are significant at the $99 \%$ level and ${ }^{*}$ are significant at the $95 \%$ level. State and year controls employed in all regressions. The sample for Mammograms is limited to those aged 50 years and above. 


\section{Works Cited}

"About BMI for Adults." Centers for Disease Control and Prevention. Centers for Disease Control and Prevention, 13 Sept. 2011. Web. 9 Jan. 2014.

<http://www.cdc.gov/healthyweight/assessing/bmi/adult_bmi/index.html>.

Abu-Saad, Kathleen and Drora Fraser. 2010. "Maternal Nutrition and Birth Outcomes."

Epidemiologic Reviews. 32(1): 5-25.

"Adult Obesity Facts." Centers for Disease Control and Prevention. 16 Aug. 2013. Web. 22 Oct. 2013. <http://www.cdc.gov/obesity/data/adult.html>.

Ahluwalia, IB, J Bolen, WS Pearson, M Link, W Garvin, and A Mokdad. "State and metropolitan variation in lack of health insurance among working-age adults, Behavioral Risk Factor Surveillance System, 2006." Public Health Reports 124.1 (2009): 34-41.

Almond, D., H. W. Hoynes, and D. W. Schanzenbach. 2011. "Inside the War on Poverty: The Impact of Food Stamps on Birth Outcomes." Review of Economics and Statistics 93(2): 387-403.

Andrews, Michelle. "Despite Health Law, Uninsured Rely On Prevention Care Patchwork." NPR. NPR, 16 Jan. 2014.

<http://www.npr.org/blogs/health/2013/11/12/244751564/despite-health-lawuninsured-rely-on-prevention-care-patchwork>.

Anger, Silke, Michael Kvasnicka, and Thomas Siedler. "One last puff? Public smoking bans and smoking behavior." Journal of Health Economics 30.3 (2011): 591-601.

Angrist, Joshua D. and Jörn-Steffen Pischke. 2009. "4.4.4 Counting and Characterizing Compliers." Mostly Harmless Econometrics: An Empiricist's Companion. Princeton, NJ: Princeton University Press.

Baum, Charles L. "The Effects of Cigarette Costs on BMI and Obesity." Health Economics 18 (2009): 3-19.

"Behavioral Risk Factor Surveillance System." Centers for Disease Control and Prevention, 24 Dec. 2013. Web. 23 Mar. 2014. <http://www.cdc.gov/brfss/>.

Besharov, D.J., \& Germanis, D. (2001). Rethinking WIC: An evaluation of the Women, Infants and Children program. Washington, DC: AEI Press. 
Besley, Timothy, and Anne Case. "Unnatural Experiments? Estimating the Incidence of Endogenous Policies." National Bureau of Economic Research. Working paper no. 4956 (1994): 23.

Bitler, Marianne P. and Janet Currie. 2005. "Does WIC Work? The Effects of WIC on Pregnancy and Birth Outcomes," Journal of Policy Analysis and Management. 24(1): 73-91.

Bitler, Marianne, Craig Gundersen, and Grace S. Marquis. 2005. "Are WIC Nonrecipients at Less Nutritional Risk Than Recipients? An Application of the Food Security Measure*." Review of Agricultural Economics 27(3): 433-438.

Black, David R. "The Effect of Complete Smoking Bans in Bars and Restaurants on Smoking Prevalence and Intensity." Dissertation 0 (2010): 41-75.

Brien, M.J., Swann, C.A., 2001. Prenatal WIC participation and infant health: selection and maternal fixed effects. Manuscript, SUNY-Stony Brook Department of Economics.

"CDC - Fact Sheet - Economic Facts about U.S. Tobacco Production and Use - Smoking \& Tobacco Use." Smoking \& Tobacco Use. Centers for Disease Control and Prevention, 1 Aug. 2013. Web. 25 Sept. 2013. <http://www.cdc.gov/tobacco/data_statistics/fact_sheets/economics/econ_facts/\#cos ts>.

Caan, B. "Women Gain Weight 1 Year after Smoking Cessation While Dietary Intake Temporarily Increases." Journal of the American Dietetic Association 96.11 (1996): 1150-1155.

Carrieri, Vincenzo, and Ansgar Wuebker. "Assessing inequalities in preventive care use in Europe." Health Policy 113 (2013): 247-257.

Castner, L. and Mabli J. 2010. "Food Expenditures and Diet Quality among Low-Income Households and Individuals." Report submitted to the U.S. Department of Agriculture, Food and Nutrition Service. Washington, DC: Mathematica Policy Research.

Chatterji, P., Bonuck, K., Dhawan, S., Deb, N., 2002. "WIC participation and the initiation and duration of breastfeeding." Institute for Research on Poverty Discussion Paper 1246-02.

Chou, Shin-Yi, Michael Grossman, and Henry Saffer. "An Economic Analysis Of Adult Obesity: Results From The Behavioral Risk Factor Surveillance System." Journal of Health Economics 23.3 (2004): 565-587.

Cole, Nancy and Mary Kay Fox. 2008a. "Diet Quality of Americans by Food Stamp Participation Status: Data from the National Health and Nutrition Examination Survey, 1999-2004." Report submitted to the U.S. Department of Agriculture, Food and Nutrition Service. Cambridge, MA: Abt Associates, Inc. 
Cole, Nancy and Mary Kay Fox. 2008b. "Diet Quality of American Young Children by WIC Participation Status: Data from the National Health and Nutrition Examination Survey, 1999-2004." Report submitted to the U.S. Department of Agriculture, Food and Nutrition Service. Cambridge, MA: Abt Associates, Inc.

Courtemanche, Charles. "Rising cigarette prices and rising obesity: Coincidence or unintended consequence?" Journal of Health Economics 28.4 (2009): 781-798.

Crump, Casey, Kristina Sundquist, Jan Sundquist, and Marilyn A. Winkleby. 2012. "Gestational Age at Birth and Mortality in Young Adulthood." Obstetrical \& Gynecological Survey 67.1: 12-13.

Cunnyngham, Karen E. 2011. "Reaching Those in Need: State Supplemental Nutrition Assistance Program Participation Rates in 2009." Report submitted to the U.S. Department of Agriculture, Food and Nutrition Service. Washington, DC: Mathematica Policy Research.

Currie, Janet, and Rosemary Hyson. 1999. "Is the Impact of Health Shocks Cushioned by Socioeconomic Status? The Case of Low Birthweight." American Economic Review 89.2: 245-250.

Currie, Janet and Enrico Moretti, 2007. "Biology as Destiny? Short- and Long-Run Determinants of Intergenerational Transmission of Birth Weight," Journal of Labor Economics, University of Chicago Press, vol. 25, pages 231-264

Currie, Janet and Enrico Moretti. 2008. "Did the Introduction of Food Stamps Affect Birth Outcomes in California?" In Making Americans Healthier: Social and Economic Policy as Health Policy. R. F. Schoeni, J. S. House, G. A. Kaplan, and H. Pollack, eds., pp. 122-144. New York: Russell Sage Foundation.

Czart, C, RI Pacula, RJ Chaloupka, and H Wechsler. "The Impact of Prices and Control Policies on Cigarette Smoking Among College Students." Contemporary Economic Policy 19.2 (2001): 135-149.

Decker, Sandra L., Jalpa A. Doshi, Amy E. Knaup, and Daniel Polsky. "Health Service Use Among The Previously Uninsured: Is Subsidized Health Insurance Enough?" Health Economics 21 (2011): 1155-1168.

Farrelly, M. C., Evans, W.N., and Montgomery, E. "Do Workplace Smoking Bans Reduce Smoking?" American Economic Review, 89.4 (1999): 728-747.

Farrelly, M. C., W. N Evans, and A. E. Sfekas. "The Impact of Workplace Smoking Bans: Results From a National Survey." Tobacco Control 8.3 (1999): 272-277.

Fichtenberg, Caroline A., and Stanton A. Glantz. "Effect of smoke-free workplaces on smoking 
behaviour: systematic review." British Medical Journal 325.7357 (2002): 188.

Figlio, David, Sarah Hamersma, and Jeffrey Roth. 2009. "Does Prenatal WIC Participation Improve Birth Outcomes? New Evidence from Florida," Journal of Public Economics 93: $235-245$.

Finklestein, Eric, lan Fiebelkorn, and Guijing Wang. "National Medical Spending Attributable To Overweight And Obesity: How Much, And Who's Paying?" Health Affairs (2003).

Fowles, E. R. 2004. "Prenatal Nutrition and Birth Outcomes." Journal of Obstetric, Gynecologic, and Neonatal Nursing 33.6: 809-822.

Fox, M. K., W. Hamilton, and B. Lin. 2004. "Effects of Food Assistance and Nutrition Programs on Nutrition and Health, Volume 3, Literature Review." Food and Nutrition Research Report No. 19-3. Washington, DC: U.S. Department of Agriculture Economic Research Service.

Froom, P, E Kristal-Boneh, S Melamed, D Gofer, J Benbassat, and J Ribak. "Smoking Cessation and Body Mass Index of Occupationally Active Men: The Israeli CORDIS Study." American Journal of Public Health 89.5 (1999): 718-722.

Gillespe, Stewart, Suneetha Kadiyala, and Robert Greener. "Is poverty or wealth driving HIV transmission?" AIDS 21 (2007): s5-s16.

Goldenberg, Robert L., and Jennifer F. Culhane. 2007. "Low Birth Weight in the United States." The American Journal of Clinical Nutrition 85.2: 5845-5905.

Goel, Rajeev K., and Michael A. Nelson. "The Effectiveness of Anti-Smoking Legislation: A Review." Journal of Economic Surveys 20.3 (2006): 325-355.

Gruber, Jonathan, and Michael Frakes. "Does Falling Smoking Lead to Rising Obesity?" Journal of Health Economics 25.2 (2006): 183-197.

Hoynes Hilary, Marianne Page, Ann Huff Stevens. 2011. "Can targeted transfers improve birth outcomes? Evidence from the introduction of the WIC program." Journal of Public Economics 95: 813-827.

John, U, M Hanke, H-J Rumpf, and J R Thyrian. "Smoking Status, Cigarettes per Day, and Their Relationship to Overweight and Obesity among Former and Current Smokers in A National Adult General Population Sample." International Journal of Obesity 29.10 (2005): 1289-1294.

Kenkel, Donald S., and Hua Wang. "Impact of Restaurant Smoking Bans on Demand for Smoking and Restaurant Food." NBER Working Paper. New Zealand Institute for the Study of 
Competition and Regulation. Working Paper (2008): 1-38.

Kramer, M. S., L. Kozlova, E. Fombonne, S. Igumnov, L. Matush, R. W. Platt, I. Vanilovich, E. Mironova, F. Aboud, S. Shapiro, O. Trofimovich, O. Skugarevsky, S. Davidovsky, E. Hodnett, B. Chalmers, J.-P. Collet, T. Ducruet, and N. Bogdanovich. 2008. "Breastfeeding and Child Cognitive Development: New Evidence from a Large Randomized Trial."Archives of General Psychiatry 65.5: 578-584.

Kramer MS, L Seguin, J Lydon, L Goulet. 2000. "Socio-economic disparities in pregnancy outcome: Why do the poor fare so poorly?" Paediatric and Perinatal Epidemiology. 14:194-210.

Kreider, P., Pepper, J., \& Roy, M. 2012. Identifying the Effect of WIC on Very Low Food Security among Infants and Children. University of Kentucky Center for Poverty Research Discussion Paper Series, DP2012-11. Retrieved April 22, 2014 from http://www.ukcpr.org/Publications/DP2012-11.pdf.

Kreider, Brent, John V. Pepper, and Manan Roy. 2014. "Does the Women, Infants, and Children Program (WIC) Improve Infant Health Outcomes?" Working Paper.

Larson, Charles P. 2007. "Poverty during pregnancy: Its effects on child health outcomes." Paediatrics \& Child Health 12(8): 673-677.

Lee, David S, and Thomas Lemieux. 2010. "Regression Discontinuity Designs in Economics." Journal of Economic Literature 48.2: 281-355.

Levy, D. T., and K.B. Friend. "The Effects Of Clean Indoor Air Laws: What Do We Know And What Do We Need To Know?" Health Education Research 18.5 (2003): 592-609.

Liu, Feng, Ning Zhang, Kai-Wen Cheng, and Hua Wang. "Reduced smoking and rising obesity: Does smoking ban in the workplace matter?" Economics Letters: 108.3 (2010): 249-252.

Maciosek, M. V., A. B. Coffield, T. J. Flottemesch, N. M. Edwards, and L. I. Solberg. "Greater Use Of Preventive Services In U.S. Health Care Could Save Lives At Little Or No Cost." Health Affairs29.9 (2010): 1656-1660.

"Many Lacked Preventive Care before Health Reform Law: U.S. Report." US News and World Reports Health. US News and World Reports, 14 June 2012. Web. 16 Jan. 2014. <http://health.usnews.com/health-news/news/articles/2012/06/14/many-lackedpreventive-care-before-health-reform-law-us-report>.

Meyerhoefer, Chad D. and Muzhe Yang. 2011. "The Relationship between Food Assistance and Health: A Review of the Literature and Empirical Strategies for Identifying Program Effects," Applied Economic Perspectives and Policy 33(3): 304-344. 
Mizoue, Tetsuya, Ryoji Ueda, Noritaka Tokui, Yoshiyuki Hino, and Takesumi Yoshimuia. "Body mass decrease after initial gain following smoking cessation." International Journal of Epidemiology 27.6 (1998): 984-988.

"Obesity and Overweight for Professionals: Data and Statistics: Adult Obesity - DNPAO - CDC." Overweight \& Obesity. Centers for Disease Control, 16 Aug. 2013. Web. 25 Sept. 2013. <http://www.cdc.gov/obesity/data/adult.html>.

"Obesity and Overweight for Professionals: Data and Statistics: Adult Obesity - DNPAO - CDC." Centers for Disease Control and Prevention. 16 Aug. 2013. Web. 16 Oct. 2013. <http://www.cdc.gov/obesity/data/adult.html>.

Okoro, C, T Strine, S Young, L Balluz, and A Mokdad. "Access to Health Care among Older Adults and Receipt of Preventive Services. Results From The Behavioral Risk Factor Surveillance System, 2002." Preventive Medicine 40.3 (2005): 337-343.

Orzechowski, W., and Walker, R., 2011. The Tax Burden on Tobacco, vol. 46. Orzechowski and Walker, Arlington, VA.

Pagan, Jose A., Andrea Puig, and Beth J. Soldo. "Health Insurance Coverage and the Use of Preventive Services by Mexican Adults." Health Economics 16 (2007): 1359-1369.

Pinkowish, M. D. (1999). Hand in glove: smoking cessation and weight gain. Patient care, 33(2), 134.

"Premature Rupture of Membranes." University of Maryland Medical Center. 26 Aug. 2014. http://umm.edu/health/medical/pregnancy/labor-and-delivery/premature-rupture-ofmembranes.

Rashad, Inas, and Michael Grossman. "The Economics of Obesity." Public Interest Summer.156 (2004): 104-112.

"Recommendations for Adults." US Preventive Services Task Force, n.d. Web. 27 Mar. 2014. <http://www.uspreventiveservicestaskforce.org/adultrec.htm>

Reynolds, D., E. Hennessy, and E. Polek. 2014. "Is breastfeeding in infancy predictive of child mental well-being and protective against obesity at 9 years of age?" Child: Care, Health and Development. Online Pre-Publication.

Ross, J, S Bernheim, E Bradley, H Teng, and W Gallo. "Use of Preventive Care by the Working Poor in the United States." Preventive Medicine 44.3 (2007): 254-259.

Schanzenbach, Diane W. 2009. “Do School Lunches Contribute to Childhood Obesity?" Journal of Human Resources 44(3): 684-709. 
"The Medical Minute: Make preventive care part of your 2014 health focus." Penn State News. Penn State, 9 Jan. 2014. Web. 16 Jan. 2014.

$<$ http://news.psu.edu/story/299695/2014/01/09/impact/medical-minute-makepreventive-care-part-your-2014-health-focus>.

Tian, Wei-Hua, Chin-Shyan Chen, and Tsai-Ching Liu. "The Demand for Preventive Care Services and Its Relationship with Inpatient Services." Health Policy 94 (2010): 164-174.

United States Department of Agriculture, Food and Nutrition Service, Office of Research and Analysis. 2012. "Building a Health America: A Profile of the Supplemental Nutrition Assistance Program." US Department of Agriculture, Washington, DC.

U.S. Department of Health and Human Services. The Health Benefits of Smoking Cessation. U.S. Department of Health and Human Services, Public Health Service, Centers for Disease Control, Center for Chronic Disease Prevention and Health Promotion. Office on Smoking and Health. DHHS Publication No. (CDC) 90-8416. 1990.

Vaidya, Varun, Gautam Partha, and Monita Karmakar. "Gender Differences in Utilization of Preventive Care Services in the United States." Journal of Women's Health 21.2 (2012): 140-145.

Williamson, David F., Jennifer Madans, Robert F. Anda, Joel C. Kleinman, Gary A. Giovino, and Tim Byers. "Smoking Cessation and Severity of Weight Gain in a National Cohort." New England Journal of Medicine 324.11 (1991): 739-745.

Wu, Stephen. "Sickness and Preventive Medical Behavior." Journal of Health Economics 22.4 (2003): 675-689.

Yen, Steven T., Donald J. Bruce, and Lisa Jahns. 2012. "Supplemental Nutrition Assistance Program Participation and Health: Evidence from Low-Income Individuals in Tennessee," Contemporary Economic Policy 30(1): 1-12.

Zhang, Ping, Guoyu Too, and Kathleen L. Irwin. "Utilization of Preventive Medical Services in the United States: A Comparison between Rural and Urban Populations." The Journal of Rural Health 16.4 (2000): 349-356. 